OPEN ACCESS

Edited by:

Abhay Satoskar,

Ohio State University at Columbus,

USA

Reviewed by:

Abraham Aseffa,

Armauer Hansen Research Institute, Ethiopia

Paul Fisch,

University Medical Center Freiburg,

Germany

*Correspondence:

Anastasia Polycarpou anastpoly@yahoo.gr

Specialty section:

This article was submitted to Microbial Immunology,

a section of the journal

Frontiers in Immunology

Received: 15 November 2016

Accepted: 17 February 2017

Published: 13 March 2017

Citation:

Polycarpou A, Walker SL and Lockwood DNJ (2017) A Systematic Review of Immunological Studies of Erythema Nodosum Leprosum.

Front. Immunol. 8:233.

doi: 10.3389/fimmu.2017.00233

\section{A Systematic Review of Immunological Studies of Erythema Nodosum Leprosum}

\author{
Anastasia Polycarpou*, Stephen L. Walker and Diana N. J. Lockwood \\ Faculty of Infectious and Tropical Diseases, Clinical Research Department, London School of Hygiene and Tropical Medicine, \\ London, UK
}

Erythema nodosum leprosum (ENL) is a painful inflammatory complication of leprosy occurring in $50 \%$ of lepromatous leprosy patients and $5-10 \%$ of borderline lepromatous patients. It is a significant cause of economic hardship, morbidity and mortality in leprosy patients. Our understanding of the causes of ENL is limited. We performed a systematic review of the published literature and critically evaluated the evidence for the role of neutrophils, immune complexes (ICs), T-cells, cytokines, and other immunological factors that could contribute to the development of ENL. Searches of the literature were performed in PubMed. Studies, independent of published date, using samples from patients with ENL were included. The search revealed more than 20,000 articles of which 146 eligible studies were included in this systematic review. The studies demonstrate that ENL may be associated with a neutrophilic infiltrate, but it is not clear whether it is an IC-mediated process or that the presence of ICs is an epiphenomenon. Increased levels of tumor necrosis factor- $\alpha$ and other pro-inflammatory cytokines support the role of this cytokine in the inflammatory phase of ENL but not necessarily the initiation. T-cell subsets appear to be important in ENL since multiple studies report an increased $\mathrm{CD} 4^{+} / \mathrm{CD}^{+}$ratio in both skin and peripheral blood of patients with ENL. Microarray data have identified new molecules and whole pathophysiological pathways associated with ENL and provides new insights into the pathogenesis of ENL. Studies of ENL are often difficult to compare due to a lack of case definitions, treatment status, and timing of sampling as well as the use of different laboratory techniques. A standardized approach to some of these issues would be useful. ENL appears to be a complex interaction of various aspects of the immune system. Rigorous clinical descriptions of well-defined cohorts of patients and a systems biology approach using available technologies such as genomics, epigenomics, transcriptomics, and proteomics could yield greater understanding of the condition.

Keywords: erythema nodosum leprosum, leprosy, type 2 reaction, immunology, systematic review, TNF- $\alpha$, neutrophils, immune complexes

\section{INTRODUCTION}

Leprosy is an infectious disease predominantly of skin and peripheral nerves, caused by the obligate, intracellular, acid-fast bacillus Mycobacterium leprae. The organism shows tropism for macrophages and Schwann cells (1). The pathology and clinical phenotype of leprosy is determined by the host immune response to $M$. leprae (2). Patients develop leprosy on a clinical spectrum ranging from 
tuberculoid leprosy through borderline forms to lepromatous leprosy (LL) of the Ridley-Jopling classification (2). Patients with tuberculoid leprosy have a strong cell-mediated immune response to $M$. leprae limiting the disease to a few well-defined skin lesions and/or peripheral nerves (3). Patients with LL have absent cellular immunity and high titers of antibodies against $M$. leprae, which are not effective in controlling the bacilli (4).

Multi-drug therapy (MDT) is highly effective for treating the infection (1). However, despite this, $30-40 \%$ of patients with leprosy undergo immune-mediated inflammatory episodes such as Type 1 reactions (T1R) and erythema nodosum leprosum (ENL or Type 2 reactions) (5).

ENL is a painful inflammatory complication occurring in $50 \%$ of LL patients and $5-10 \%$ of borderline lepromatous leprosy (BL) patients particularly those with a bacterial index above 4 (6), whereas T1R predominantly affect those with borderline tuberculoid leprosy (BT), mid-borderline, and BL leprosy. Individuals with ENL present crops of painful, erythematous skin nodules with systemic symptoms of fever and malaise (6). ENL is a multisystem disorder and other organ involvement includes iritis, arthritis, lymphadenitis, orchitis, and neuritis (6). The histology of ENL skin lesions often shows an intense perivascular infiltrate of neutrophils throughout the dermis and subcutis (7) and vasculitis with edema of the endothelium together with granulocyte infiltration of vessels walls (8-10). However, not all ENL skin biopsies show evidence of vasculitis $(10-13)$.

ENL is usually treated with high-dose oral corticosteroids or thalidomide if it is available and affordable. High doses of clofazimine are also commonly used (6). Treatment often lasts for many months or years. Few patients experience a single episode of acute ENL with the majority experiencing recurrent or chronic disease $(6,14)$. Prolonged use of oral corticosteroids is associated with multiple adverse effects (6). Our group has demonstrated that ENL results in significant economic hardship, morbidity, and mortality in patients $(15,16)$.

ENL is often described as a neutrophilic immune-complexmediated condition, while there is evidence that T-cells further complicate the immunopathology. Elevated levels of certain cytokines such as tumor necrosis factor (TNF)- $\alpha$ and other immunological factors have been associated with episodes of ENL.

We performed a systematic review of the published literature and critically evaluated the current evidence for the role of immunological factors that have been associated with the ENL. We created a flowchart showing our search strategy by identifying the studies to be included in this systematic review (Figure 1). We divided the systematic review into sections according to the immune parameter under investigation including neutrophils, immune complexes/complement, T-cells, and cytokines. Furthermore, we sought to identify possible methodological issues that might account for discrepancies between studies and to make recommendations for future immunological studies of ENL. The studies that we considered to have the most important findings are discussed in detail, while all the studies included in the review are summarized in the comprehensive tables.

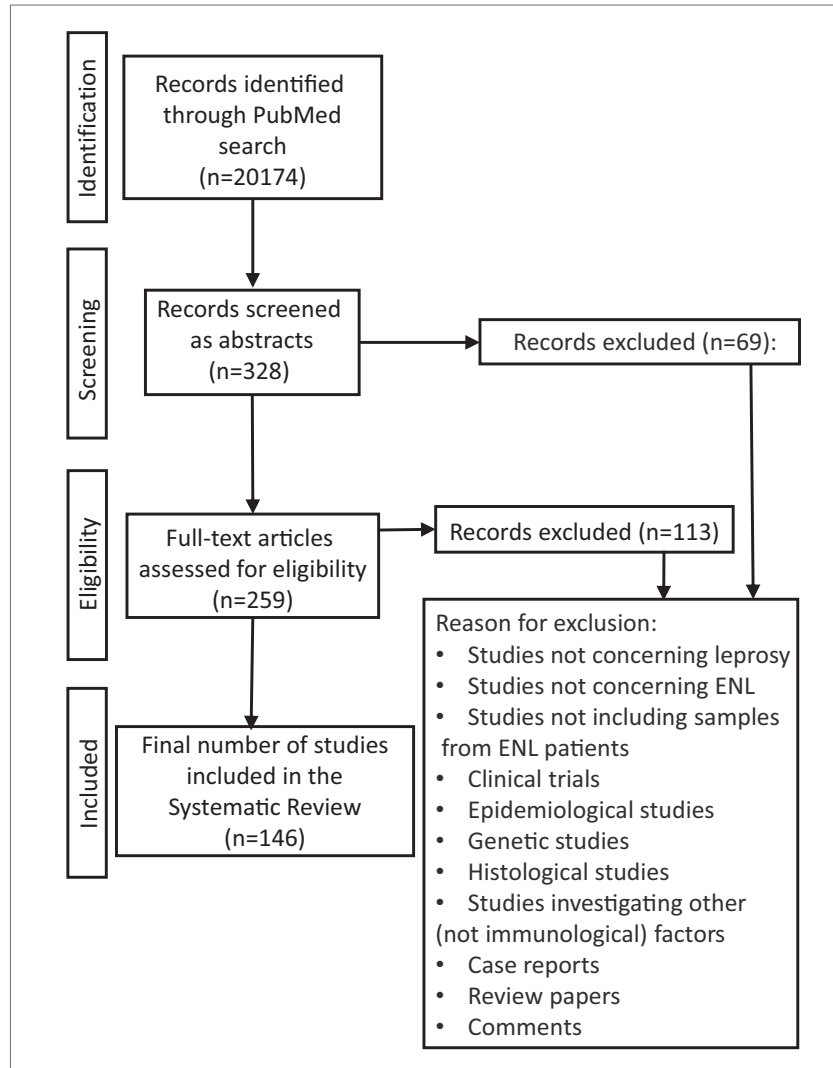

FIGURE 1 | Flowchart. Flowchart of included studies.

\section{METHODOLOGY}

The Preferred Reporting Items for Systematic review and MetaAnalysis Protocols (PRISMA-P) 2015 guideline was used to prepare this systematic review (17).

\section{Searching}

Searches of the literature were performed up to 31st October 2016 in PubMed by the first author. Keywords used were: Hansen* OR Type 2 OR Type II OR leprosy OR lepra*, AND reaction OR erythema nodosum leprosum OR ENL. The references included in each study were also checked for potentially relevant publications.

\section{Inclusion Criteria}

Immunological studies in PubMed, independent of published date, using samples from patients with ENL were included. Human samples including sera, peripheral blood mononuclear cells (PBMC), skin biopsies, or any other tissue were eligible for inclusion. Publications in languages other than English were translated.

An immunological study was defined as any study of the molecular and cellular components that comprise the immune system, including their function and interaction.

\section{Results of Search}

The search in PubMed revealed 95,771 records, which were narrowed down by using restrictions, species (humans), and search 
fields (title/abstracts), leading to 20,174 records (Figure 1). A total of 19,846 studies were excluded by title because they did not address leprosy or ENL. Others were excluded because they did not include samples from ENL patients or they were clinical trials, epidemiological studies, case reports, review papers, commentaries, histological studies, genetic studies, and investigations of non-immunological factors. The abstracts of the remaining 328 titles were reviewed and a further 69 studies were excluded due to the same considerations.

The 259 papers were obtained full text of which 113 were excluded for the reasons described above. When there was doubt about studies, the first and second author agreed on whether they should be included in the systematic review. Data were extracted from the 146 eligible studies. Of these 146 eligible studies, 5 studies investigated the role of neutrophils in ENL, 28 studies investigated the role of immune complexes and complement in ENL, 44 studies investigated the role of T-cells in ENL, and 49 studies investigated the role of cytokines in ENL, of which 30 investigated the role of TNF- $\alpha$ in ENL. Sixty-four studies investigated the role of other immunological factors in ENL.

\section{Data Synthesis and Analysis}

Data extraction from each study was conducted by the first author. Structured forms were designed for each of the five main sections of the systematic review: neutrophils, immune complexes and complement, T-cellular immunity, cytokines, and other immunological molecules or factors involved in the pathophysiology of ENL. Data were collected on the setting (study location and country of affiliation of the authors), study design and characteristics of the subjects (ENL case definition, study population included, number of patients with ENL, control subjects, timing of sampling, treatment for ENL and leprosy treatment), study measures and main findings reported by the study authors. A study could include multiple measures and therefore be part of more than one section of the systematic review.

\section{WHAT IS THE ROLE OF NEUTROPHILS IN ENL?}

Neutrophils are the predominant immune cell population in human blood and provide protection through phagocytosis, generation of neutrophil extracellular traps (NETs), and secretion of antimicrobial peptides (18). Recent evidence supports a role for neutrophils in the orchestration of adaptive immunity, engaged with lymphocytes and antigen-presenting cells (APCs) (19).

Neutrophils are considered to be the histological hallmark of ENL $(7,13)$. The histology of ENL skin lesions shows an intense perivascular infiltrate of neutrophils throughout the dermis and subcutis $(7,13)$. However, not all ENL lesions are characterized by the presence of neutrophils $(12,20-22)$ and the timing of biopsies appears crucial in detecting neutrophil infiltration $(7,23)$. A study of skin biopsies of ENL lesions within $72 \mathrm{~h}$ of onset showed a predominance of neutrophils in $30.4 \%$ of biopsies. Skin biopsies performed between 9 and 12 days showed neutrophils in $1.6 \%$ of specimens and increasing numbers of lymphocytes, plasma cells, and histiocytes (7). Neutrophils may precede the chemotaxis of lymphocytes into ENL lesions, but it is unclear why neutrophils are not always present in the initial stage of ENL.

The study by Lee et al. used DNA microarray and bioinformatic pathway analysis of gene expression profiles in skin biopsies obtained from six patients with ENL compared to seven LL controls (24). They identified 57 functional groups and 17 canonical pathways characteristic of ENL. Their striking finding was the "cell movement" functional pathway composed of 188 genes. From the list of genes of the "cell movement" pathway, 25 were identified to be involved specifically in neutrophil recruitment including the genes for P-selectin, E-selectin, and its ligands (24). Using immunohistochemistry, they showed that E-selectin was expressed in a vascular pattern and at higher levels in ENL skin lesions than in LL, although this was not quantified (24). They described an integrated pathway of TLR2/Fc Receptor activation triggering induction of interleukin (IL)-1 $\beta$, which together with interferon (IFN)- $\gamma$, induced E-selectin expression on endothelial cells and neutrophil migration and adhesion to endothelial cells (24). Interestingly, thalidomide inhibited this neutrophil recruitment pathway (24).

A recent Brazilian study reported that surface CD64 (Fc $\gamma \mathrm{RI})$ expression on circulating neutrophils increased significantly during ENL, while BL/LL patients without ENL had lower levels of CD64 (25). In addition, CD64 expression on neutrophils decreased after thalidomide treatment (25). Moreover, the higher levels of CD64 on circulating neutrophils were correlated with disease severity (25). This study demonstrated the potential of CD64 as an early biomarker for ENL and as a marker of severity (25). CD64 (FcyRI) is the high-affinity receptor for monomeric IgG1 and IgG3 (26). While resting neutrophils express low levels of CD64 (26), an increase of neutrophil CD64 surface expression is observed in certain Gram negative bacterial infections (27) and has been associated with the prognosis of disseminated intravascular coagulation during sepsis (28). The authors suggested that CD64 upregulation during ENL could be due to the presence of inflammatory cytokines such as IFN- $\gamma$ and GM-CSF (29) or certain intracellular components of fragmented $M$. leprae bacilli following treatment with MDT (25). This was further supported by clinical studies showing that although ENL may also occur before initiation of treatment with MDT, the incidence of ENL is higher during treatment with $\operatorname{MDT}(5,30)$.

Studies in the 70s tried to assess the polymorphonuclear leukocyte (PMN) functions in different forms of leprosy and ENL, investigating whether ENL is associated with PMN activation (31, 32). The nitro blue tetrazolium (NBT) test that measures PMN activation was increased in six patients described as LL with leprosy reactions compared with non-reactional leprosy patients (from across the leprosy spectrum) and healthy controls (31). In addition, LL patients with reactions had lower PMN activation when treated with steroids or thalidomide, although this was not significant (31). Another study found the resting NBT levels in different leprosy groups (tuberculoid, lepromatous, and patients with ENL) to be within normal limits (32). However, the sera from patients with ENL produced significantly increased levels of PMN activation as measured by the NBT test when incubated with PMN cells from healthy controls and patients with ENL 
(32). This finding suggested that sera from ENL patients may lead to activation of neutrophils. However, when cell motility was studied as a marker of PMN activation using random migration, chemotaxis, and chemokinesis, all three were defective in lepromatous patients with or without complicating ENL (32).

Oliveira et al. reported the apoptotic rate of neutrophils to be greatly accelerated in ENL patients compared to BL/LL patients and healthy volunteers (33). Neutrophils isolated from leprosy patients (ENL and BL/LL) released TNF- $\alpha$ and IL-8, after stimulation with lipopolysaccharide (LPS) or M. leprae (33). Interestingly, in vitro TNF- $\alpha$ production by neutrophils was inhibited by thalidomide at both 3 and $6 \mathrm{~h}$ post-stimulation with LPS (33). This supports the role of neutrophils as effector cells actively producing pro-inflammatory cytokines and not only as migratory cells following chemoattractants.

There is little direct evidence of the actual role of neutrophils in ENL, despite the cell being the histological hallmark of ENL. There are multiple histological studies showing the presence of neutrophils in ENL lesions; however, only five studies investigated whether neutrophils actively take part in ENL as effector cells (Table 1). It remains unclear whether the neutrophil initiates ENL or is recruited to the site of the affected skin lesion under the action of chemokines such as IL- 8 secreted by other cell types.

\section{WHAT IS THE ROLE OF IMMUNE COMPLEXES IN ENL?}

An IC or antigen-antibody complex is the result of binding of one or more antibody molecules with one or more antigen molecules (34). The ability of ICs to activate the complement system and to interact with a number of cells determines their biological properties (35). ICs activate complement pathways that opsonize or coat antigen-antibody complexes with large numbers of C3 molecules (36). Opsonization facilitates the clearance of ICs by the macrophage system (36). By maintaining complexes in solution, the complement allows clearance of ICs from their site of formation, minimizing local inflammatory consequences (36).

It was hypothesized that ENL is an IC-mediated disorder because it has some clinical features in common with the Arthus reaction, a type III hypersensitivity reaction that involves the deposition of ICs mainly in the vascular walls, serosa, and glomeruli and is characterized histologically by vasculitis with a polymorphonuclear cell infiltrate (37). The multisystem involvement of ENL resembling autoimmune diseases associated with ICs such as systemic lupus erythematosus (SLE), also lends credence to this theory.

\section{TABLE 1 | Studies of neutrophils in ENL.}

\begin{tabular}{|c|c|c|c|c|c|c|c|}
\hline $\begin{array}{l}\text { Reference; } \\
\text { study site(s) }\end{array}$ & $\begin{array}{l}\text { Study } \\
\text { population }\end{array}$ & $\begin{array}{l}\text { Timing of } \\
\text { screening }\end{array}$ & $\begin{array}{l}\text { MDT } \\
\text { status }\end{array}$ & $\begin{array}{l}\text { ENL } \\
\text { treatment }\end{array}$ & $\begin{array}{l}\text { Type of } \\
\text { samples }\end{array}$ & Measures & Findings \\
\hline $\begin{array}{l}\text { Goihman-Yahr } \\
\text { et al. (31); } \\
\text { Venezuela }\end{array}$ & $\begin{array}{l}6 \text { ENL, } 32 \\
\text { BL/LL, } 6 \\
\text { treated ENL, } 9 \\
\text { indeterminate, } \\
11 \text { tuberculoid, } \\
14 \mathrm{HC}\end{array}$ & ND & ND & $\begin{array}{l}\text { Excluded } \\
\text { patients on } \\
\text { steroids except } \\
\text { treated ENL }\end{array}$ & $\begin{array}{l}\text { Peripheral } \\
\text { blood } \\
\text { neutrophils } \\
\text { Serum } \\
\text { Plasma }\end{array}$ & $\begin{array}{l}\text { Reduction of nitro blue } \\
\text { tetrazolium (NBT) } \\
\text { Neutrophil response to } \\
\text { endotoxin } \\
\text { Effect of adding sera } \\
\text { and plasma from ENL to } \\
\text { neutrophils of HC }\end{array}$ & $\begin{array}{l}\text { Lower neutrophil activation after ENL treatment } \\
\text { Sera from ENL did not activate neutrophils } \\
\text { from } \mathrm{HC}\end{array}$ \\
\hline $\begin{array}{l}\text { Sher et al. } \\
\text { (32); South } \\
\text { Africa }\end{array}$ & $\begin{array}{l}8 \mathrm{ENL}, 17 \mathrm{BT}, 11 \\
\text { lepromatous, HC }\end{array}$ & ND & ND & $\begin{array}{l}\text { ENL not } \\
\text { receiving } \\
\text { steroids or } \\
\text { other anti- } \\
\text { inflammatory } \\
\text { drugs }\end{array}$ & $\begin{array}{l}\text { Peripheral } \\
\text { blood } \\
\text { neutrophils } \\
\text { Serum }\end{array}$ & $\begin{array}{l}\text { PMN leukocyte motility } \\
\text { Reduction of nitro blue } \\
\text { tetrazolium (NBT) }\end{array}$ & $\begin{array}{l}\text { Defect in random migration, chomotaxis, and } \\
\text { chemokinesis in both ENL and lepromatous } \\
\text { patients } \\
\text { Reconstitution of PMN leukocytes from HC } \\
\text { and ENL with sera from ENL led to increased } \\
\text { neutrophil activation }\end{array}$ \\
\hline $\begin{array}{l}\text { Oliveira et al. } \\
\text { (33); Brazil } \delta\end{array}$ & $\begin{array}{l}10 \mathrm{BL} / \mathrm{LL}: 6 \mathrm{ENL} \text {, } \\
10 \mathrm{HC}\end{array}$ & ND & On MDT & ND & $\begin{array}{l}\text { Peripheral } \\
\text { blood } \\
\text { neutrophils }\end{array}$ & $\begin{array}{l}\text { Apoptosis } \\
\text { DNA fragmentation } \\
\text { extracted from } \\
\text { neutrophils } \\
\text { TNF- } \alpha \text { and IL-8 }\end{array}$ & $\begin{array}{l}\text { Increased apoptosis in ENL } \\
\text { Stimulated neutrophils secrete IL-8 and tumor } \\
\text { necrosis factor (TNF)- } \alpha\end{array}$ \\
\hline $\begin{array}{l}\text { Lee et al. (24); } \\
\text { USA } \varepsilon\end{array}$ & 6 ENL, 7 LL & ND & ND & ND & Skin & $\begin{array}{l}\text { Microarrays and gene } \\
\text { expression analysis } \\
\text { Ability of HUVEC to bind } \\
\text { neutrophils from HC }\end{array}$ & $\begin{array}{l}\text { Genes involved in neutrophil recruitment } \\
\text { identified } \\
\text { Thalidomide diminished neutrophil binding to } \\
\text { HUVECs stimulated with cytokines }\end{array}$ \\
\hline $\begin{array}{l}\text { Schmitz et al. } \\
\text { (25); Brazil } \varepsilon\end{array}$ & $\begin{array}{l}62 \text { leprosy: } 22 \\
\text { ENL, } 16 \text { HC }\end{array}$ & $\begin{array}{l}\text { ENL: } \\
\text { before and } \\
7 \text { days after } \\
\text { thalidomide }\end{array}$ & $\begin{array}{l}\text { Patients } \\
\text { before } \\
\text { and after } \\
\text { MDT }\end{array}$ & $\begin{array}{l}\text { ENL: before } \\
\text { and after } \\
\text { thalidomide }\end{array}$ & $\begin{array}{l}\text { Peripheral } \\
\text { blood } \\
\text { neutrophils }\end{array}$ & CD64 expression & $\begin{array}{l}\text { CD64 upregulated on neutrophils during ENL } \\
\text { Higher CD64 on neutrophils from severe ENL } \\
\text { CD64 decreased after thalidomide }\end{array}$ \\
\hline
\end{tabular}

$\beta$, also in Table 2; $\gamma$, also in Table 3; $\delta$, also in Table 4; $\varepsilon$, also in Table 5.

BB, mid-borderline leprosy; BL, borderline lepromatous leprosy; BT, borderline tuberculoid leprosy; ENL, erythema nodosum leprosum; HC, healthy controls; HUVEC, human umbilical vein endothelial cells; ICs, immune complexes; LL, lepromatous leprosy polar; ND, not described; PMN, polymorphonuclear; SLE, systemic lupus erythematosus; TB, tuberculosis; TT, tuberculoid leprosy polar. 
Multiple studies have been performed investigating ICs in ENL. The widely cited study of Wemambu et al included 17 patients with ENL and six uncomplicated LL controls (37). Direct immunofluorescence demonstrated granular deposits of immunoglobulin and complement in a perivascular distribution in association with a polymorph infiltrate in the dermis of 10 out of 17 ENL lesions but not in any lesions of uncomplicated LL (37). However, such deposition is not conclusive evidence of ICs. The presence of soluble mycobacterial antigen was seen in ICs in only 3 out of 17 ENL lesions (37). The authors hypothesized that ENL results from the deposition of ICs in and around venules of the connective tissue septa of subcutaneous fat (37). The study was repeated using 38 patients with ENL and 13 LL controls and demonstrated the presence of immunoglobulin, complement, and mycobacterial antigen in less than half of the skin biopsies from patients with ENL and none of the LL control biopsies (22). Non-specific granular deposits of IgG were demonstrated along the collagen and elastic fibers in the dermis of all 25 patients with ENL in another study, not in any of the 10 LL patient controls (38). However, the deposits were not consistently seen in and around the blood vessels (38). Later studies in ENL suggest that these ICs are extravascular and hence ENL differs from the Arthus reaction $(39,40)$. These studies taken together provide evidence of an association of ICs and ENL but they do not necessarily support that ICs are the trigger leading to ENL.

Circulating ICs have been demonstrated in patients across the leprosy spectrum (41). The level of circulating ICs in the sera of leprosy patients have been measured in many studies using different immunological techniques (42-54) of which the most commonly used are C1q immunoassays $(42,43,51)$. This highlights the fact that the use of different immunoassays to detect circulating ICs in studies may explain the contradictory results. The first study measuring ICs in sera of leprosy patients performed $\mathrm{Clq}$ immunoassays in samples from LL patients, tuberculoid leprosy patients, and healthy volunteers and showed that more than $70 \%$ of LL patients had demonstrable ICs (43). A subsequent study demonstrated increased occurrence of ICs in both the sera of ENL patients (80\%) and uncomplicated LL patients $(82 \%)$, indicating that the presence of circulating ICs is not a characteristic feature of ENL per se (46). Wager et al. analyzed sera from 135 leprosy patients using the platelet aggregation test (PAT) which had been previously suggested to be a sensitive detector of IgG complexes in other immunological and infectious diseases $(55,56)$ and concluded that PAT is a sensitive detector of IgG complexes peculiar to LL (44). No ICs were detected in the sera of leprosy patients using the C1q immunoassay (44).

Specific mycobacterial antigens (41) or antibodies against $M$. leprae antigens $(50,57)$ have been identified in the ICs derived from sera of lepromatous patients with or without ENL. Rojas et al. precipitated ICs from sera and detected antibodies against phenolic glycolipid-1 (PGL-1) (50) and major cytosolic protein of M. leprae (MCP-I). The finding that ICs are composed of antiPGL-I and anti-MCP-I antibodies supports the concept that ENL is an IC-mediated disorder (50). However, the composition of circulating ICs of leprosy controls (combined BT and BL/LL) also showed high levels of anti-PGL-I antibodies (50) again suggesting that ICs are not specific to ENL.
Dupnik et al. used DNA microarrays to examine gene expression in PBMC isolated from patients with ENL and matched leprosy controls (58). Several components of the classical complement pathway showed increased expression in PBMC from patients with ENL: C1qA, B, and C and the complement receptors C3AR1 and C5AR1 (58). Increased intensity of fluorescent staining for $\mathrm{C} 1 \mathrm{q}$ in skin lesions of ENL compared to BT and BL/ LL controls was demonstrated (58). The finding of increased C1q deposition in the skin of ENL does not necessarily mean IC deposition has occurred (35). However, these data do support activation of the classical complement pathway in ENL, which may result from antigen-antibody formation.

Earlier studies in leprosy looked at the role of free complement in the sera of lepromatous patients (59). The serum C3 levels were decreased in patients with ENL, whereas they were elevated in LL controls (60). The low levels of C3 supported the concept that ENL is mediated by an antigen-antibody reaction and may be due to its utilization during the course of such antigen-antibody reactions. Similar decreased serum complement levels have been reported in other IC disorders such as acute glomerulonephritis (61-63) and acute systemic lupus erythematosus (SLE) $(64,65)$. It has been suggested that ENL is characterized by complement hypercatabolism because the level of the $\mathrm{C} 3$ breakdown product C3d in the sera was increased in 70\% of the patients with ENL but in only $18 \%$ of patients with uncomplicated LL (46).

In other IC-associated diseases such as SLE, systemic vasculitides, and nephritis, defective complement-mediated solubilization of immune precipitates have been observed (48, $49,66)$. Similarly, leprosy patients with ENL were shown to have markedly reduced solubilization levels that remained low for 3 months, whereas the $\mathrm{C} 3 \mathrm{~d}$ and circulating IC levels returned to baseline levels (48). Circulating ICs isolated from sera across the leprosy spectrum as PEG precipitates were shown to be efficient activators of the alternative complement pathway. In addition, PEG precipitates from BL/LL leprosy patients including those with ENL were shown to activate the classical complement pathway as well (52).

A Brazilian study of 46 patients with ENL investigated the association between the MHC class III complement proteins C2, BF, C4A, and C4B and leprosy (67). All patients who were homozygous for the silent $\mathrm{C} 4 \mathrm{~B}$ allele $\left(\mathrm{C}_{4} \mathrm{~B}^{\star} \mathrm{Q} 0\right)$ and thus $\mathrm{C} 4 \mathrm{~B}$ deficient had ENL (67). Increased frequency of ENL was also associated with those who were hemizygous for the $C 4 \mathrm{~B}^{\star} \mathrm{Q} 0$ allele. The relative risk of patients suffering from ENL carrying the $\mathrm{C}_{4} \mathrm{~B}^{\star} \mathrm{Q} 0$ allele was 5.3 compared with LL patients without $\mathrm{C}_{4} \mathrm{~B}^{\star} \mathrm{Q} 0$ (67). Interestingly, their findings suggested that $\mathrm{C} 4 \mathrm{~B}$ deficiency could play an important role in the abnormal immune response to $M$. leprae and to the lack of IC clearance, leading to ENL reactions (67). Hemizygous C4 deficiencies are associated with immune complex diseases such as SLE (68).

There is lack of evidence to support a causative role of ICs in ENL, which requires the deposition of ICs in tissues, the presence of bacterial antigens in these ICs, and the interaction of the ICs with the complement cascade and with phagocytic cells (35). Although there are 28 studies investigating the presence of ICs in the skin or circulating ICs in the sera of patients with ENL (Table 2), their role remains uncertain. It is unclear 


\begin{tabular}{|c|c|c|c|c|c|c|c|}
\hline $\begin{array}{l}\text { Reference; } \\
\text { study site(s) }\end{array}$ & Study population & $\begin{array}{l}\text { Timing of } \\
\text { screening }\end{array}$ & MDT status & ENL treatment & $\begin{array}{l}\text { Type of } \\
\text { samples }\end{array}$ & Measures & Findings \\
\hline $\begin{array}{l}\text { de Azevedo and } \\
\text { de Melo (59); } \\
\text { Brazil }\end{array}$ & $\begin{array}{l}37 \text { lepromatous, } \\
33 \text { tuberculoid, } 18 \\
\text { "lepra reaction" }\end{array}$ & ND & ND & ND & Serum & $\begin{array}{l}\text { Complement unit }(K) \\
\text { Angular inclination }(1 / n)\end{array}$ & Reduced complement activity in the reactional group \\
\hline $\begin{array}{l}\text { Wemambu et al. } \\
\text { (37); United } \\
\text { Kingdom and } \\
\text { Malaysia }\end{array}$ & $\begin{array}{l}17 \text { ENL, } 6 \\
\text { lepromatous }\end{array}$ & ND & ND & ND & $\begin{array}{l}\text { Skin } \\
\text { Serum }\end{array}$ & $\begin{array}{l}\text { Immunoglobulin } \\
\text { Complement }\end{array}$ & $\begin{array}{l}\text { Perivascular deposits of immunoglobulin and complement } \\
\text { Mycobacterial antigen in some ENL skin lesions }\end{array}$ \\
\hline $\begin{array}{l}\text { Waters et al. } \\
\text { (22); United } \\
\text { Kingdom and } \\
\text { Malaysia } \varepsilon\end{array}$ & $\begin{array}{l}38 \text { lepromatous } \\
\text { with ENL, } 13 \\
\text { lepromatous }\end{array}$ & ND & ND & ND & $\begin{array}{l}\text { Skin } \\
\text { Serum }\end{array}$ & $\begin{array}{l}\text { Immunoglobulin and } \\
\text { complement } \\
\text { Detection of mycobacterial } \\
\text { antigen in the ICs }\end{array}$ & $\begin{array}{l}\text { Immunoglobulin and complement perivascular in some ENL skin } \\
\text { lesions } \\
\text { Mycobacterial antigen present in ICs }\end{array}$ \\
\hline $\begin{array}{l}\text { Gelber et al. } \\
\text { (69); Taiwan and } \\
\text { USA }\end{array}$ & $\begin{array}{l}15 \mathrm{LL} \text { with ENL, } 47 \\
\text { BT-LL }\end{array}$ & $\begin{array}{l}3 \text { or more } \\
\text { specimens } \\
\text { time-span up to } \\
4 \text { months in BT } \\
\text { and LL/ENL and } \\
\text { up to } 6 \text { months to } \\
\text { LL without ENL }\end{array}$ & ND & ND & Serum & $\begin{array}{l}\text { C1q precipitin activity } \\
\text { Complement levels C3 } \\
\text { Cryoglobulins }\end{array}$ & Association of C1a precipitin activity with ENL \\
\hline $\begin{array}{l}\text { Bjorvatn et al. } \\
\text { (46); Ethiopia } \\
\text { and Switzerland }\end{array}$ & $\begin{array}{l}13 \text { ENL, } 7 \mathrm{LL} \text {, } \\
6 \text { tuberculoid, } \\
\text { pulmonary TB, } 30 \\
\text { HC }\end{array}$ & ND & $\begin{array}{l}\text { All on dapsone } \\
\text { or clofazimine }\end{array}$ & $\begin{array}{l}\text { ENL patients } \\
\text { received treatment } \\
\text { for ENL }\end{array}$ & Serum & $\begin{array}{l}\text { ICs with }{ }^{125} \text {-C1q binding } \\
\text { assay } \\
\text { Complement }\end{array}$ & $\begin{array}{l}\text { ICs increased in ENL and LL but also in tuberculoid leprosy } \\
\text { Increased C3d level in most patients with ENL }\end{array}$ \\
\hline $\begin{array}{l}\text { Tung et al. (51); } \\
\text { Ethiopia }\end{array}$ & $\begin{array}{l}22 \text { BL/LL with ENL, } \\
\text { 23TT-LL, } 17 \text { SLE }\end{array}$ & ND & $\begin{array}{l}\text { 19/23 non-ENL } \\
\text { on dapsone }\end{array}$ & Untreated ENL & Serum & $\begin{array}{l}\text { C1q ICs } \\
\text { Raji test ICs }\end{array}$ & $\begin{array}{l}\text { Circulating ICs in } 67 \% \text { of leprosy by C1q test } \\
\text { Only } 7 \% \text { of this } 67 \% \text { showed ICs by the Raji test }\end{array}$ \\
\hline $\begin{array}{l}\text { Anthony et al. } \\
\text { (60); India } \varepsilon\end{array}$ & $\begin{array}{l}25 \text { LL with ENL, } 10 \\
\text { LL without ENL }\end{array}$ & $\begin{array}{l}\text { Active ENL } \\
\text { lesions at the time } \\
\text { of the biopsy }\end{array}$ & ND & ND & $\begin{array}{l}\text { Skin } \\
\text { Serum }\end{array}$ & $\begin{array}{l}\text { Immunoglobulin deposits } \\
\text { in skin } \\
\text { Complement in sera }\end{array}$ & $\begin{array}{l}\text { Immunoglobulin deposits in ENL skin but not in LL } \\
\text { Decreased serum complement in ENL } \\
\text { Elevated levels in LL }\end{array}$ \\
\hline $\begin{array}{l}\text { Wager et al. } \\
\text { (44); Finland, } \\
\text { Brazil, and } \\
\text { Ethiopia }\end{array}$ & $\begin{array}{l}11 \mathrm{ENL}, 112 \\
\text { leprosy, } 61 \mathrm{LL}, 7 \\
\text { tuberculoid, } 28 \text { SLE, } \\
42 \mathrm{RA}, 374 \mathrm{HC}\end{array}$ & ND & ND & ND & Serum & $\begin{array}{l}\text { ICs with Platelet aggregation } \\
\text { test (PAT) } \\
\text { Other sero-immunological } \\
\text { parameters }\end{array}$ & $\begin{array}{l}\text { Higher PAT titers toward the lepromatous end of the spectrum } \\
\text { No significant differences for ENL patients }\end{array}$ \\
\hline $\begin{array}{l}\text { Izumi et al. (70); } \\
\text { Japan } \gamma\end{array}$ & $\begin{array}{l}12 \mathrm{ENL}, 49 \text { active } \\
\text { lepromatous, } \\
24 \text { inactive } \\
\text { lepromatous, } \\
7 \text { borderline, } 6 \\
\text { tuberculoid, } 9 \mathrm{HC}\end{array}$ & ND & ND & ND & Serum & C4, C3c, C3 activator & $\begin{array}{l}\text { C3 activator and } \mathrm{C} 3 \mathrm{c} \text { concentrations higher in ENL compared with } \\
\text { active lepromatous }\end{array}$ \\
\hline
\end{tabular}


TABLE 2 | Continued

\begin{tabular}{|c|c|c|c|c|c|c|c|}
\hline $\begin{array}{l}\text { Reference; } \\
\text { study site(s) }\end{array}$ & Study population & $\begin{array}{l}\text { Timing of } \\
\text { screening }\end{array}$ & MDT status & ENL treatment & $\begin{array}{l}\text { Type of } \\
\text { samples }\end{array}$ & Measures & Findings \\
\hline $\begin{array}{l}\text { Harikrishan et al. } \\
\text { (71); India } \varepsilon\end{array}$ & $\begin{array}{l}20 \text { active } \mathrm{LL}, 15 \mathrm{ENL} \\
\text { active and subsided, } \\
20 \mathrm{HC}\end{array}$ & $\begin{array}{l}\text { ENL: during the } \\
\text { active and the } \\
\text { subsided phase }\end{array}$ & ND & ND & Serum & Complement factor $\mathrm{C} 3$ & $\begin{array}{l}\text { Increased levels of } \mathrm{C} 3 \text { in } \mathrm{LL} \text { and } \mathrm{ENL} \\
\text { Decrease in } \mathrm{C} 3 \text { during the "subsided phase" of reaction }\end{array}$ \\
\hline $\begin{array}{l}\text { Saha et al. (72); } \\
\text { India }\end{array}$ & $20 \mathrm{ENL}, 15 \mathrm{HC}$ & $\begin{array}{l}\text { Initial sample first } \\
\text { visit, subsequent } \\
\text { on ENL clinical } \\
\text { remission } \\
4 \text { weeks later }\end{array}$ & ND & $\begin{array}{l}\text { Second sample: } \\
\text { on antireactional } \\
\text { treatment }\end{array}$ & Serum & Complement C1q, C3, C4 & $\begin{array}{l}\text { C3 level decreased during ENL, while increased after remission } \\
\text { C3d increased during ENL, and remained elevated after clinical } \\
\text { remission in most patients } \\
\text { No significant difference in C1q or C4 during ENL }\end{array}$ \\
\hline $\begin{array}{l}\text { Valentijn } \\
\text { et al. (54); } \\
\text { Netherlands and } \\
\text { Surinam }\end{array}$ & $\begin{array}{l}70 \text { leprosy } \\
\text { throughout the } \\
\text { whole spectrum, } \\
11 \mathrm{HC}\end{array}$ & ND & ND & $\begin{array}{l}\text { ENL patients } \\
\text { possibly on } \\
\text { thalidomide } \\
\text { treatment? }\end{array}$ & Serum & $\begin{array}{l}\text { ICs } \\
\text { Complement C1q, C3, C4 }\end{array}$ & Elevated C3d significantly associated with ENL \\
\hline $\begin{array}{l}\text { Mshana et al. } \\
\text { (73); Ethiopia }\end{array}$ & 26 ENL, 20 BL/LL & $\begin{array}{l}\text { Skin biopsies of } \\
\text { ENL less than } \\
12 \mathrm{~h} \text { old }\end{array}$ & ND & ND & Skin & $\begin{array}{l}\text { Immunoglobulin deposits } \\
\text { Complement deposits } \\
\text { Mycobacterial antigens }\end{array}$ & $\begin{array}{l}\text { No ICs around blood vessels in ENL lesions IC formation common } \\
\text { feature in LL } \\
\text { Absence of immunoglobulin or C3 deposits in early ENL } \\
\text { Extracellular antigens not seen }\end{array}$ \\
\hline $\begin{array}{l}\text { Ridley and } \\
\text { Ridley (39); } \\
\text { Malaysia, PNG, } \\
\text { Ethiopia, and } \\
\text { UK }\end{array}$ & $\begin{array}{l}20 \mathrm{ENL}, 10 \text { non- } \\
\text { reactional leprosy }\end{array}$ & ND & ND & ND & Skin & $\begin{array}{l}\text { Immunoglobulins IgG, IgM, } \\
\text { IgA, IgE } \\
\text { Complement C3, C4, C1q, } \\
\text { C3d }\end{array}$ & $\begin{array}{l}\text { ENL lesions had disintegration of macrophages and release of } \\
\text { bacterial antigen combined first with IgM, later with IgG, present } \\
\text { together with complement components of the classical pathway } \\
\text { ICs were both extracellular and in neutrophils and macrophages } \\
\text { ICs were extravascular }\end{array}$ \\
\hline $\begin{array}{l}\text { Ramanathan } \\
\text { et al. (74); India }\end{array}$ & $\begin{array}{l}10 \mathrm{BT}, 10 \mathrm{LL}, 10 \\
\text { BT reactional, } 30 \mathrm{LL} \\
\text { reactional }\end{array}$ & ND & $\begin{array}{l}\text { All patients on } \\
\text { dapsone }\end{array}$ & $\begin{array}{l}\text { Sampling before } \\
\text { antireactional } \\
\text { treatment }\end{array}$ & Serum & $\begin{array}{l}\text { C3 and C4 } \\
\text { ICs } \\
\text { Isolated ICs for IgG, IgA, IgM, } \\
\text { C3, C4 and antimycobacterial } \\
\text { antibody }\end{array}$ & $\begin{array}{l}\text { Increased C3d in both BT reactional (T1R) and LL reactional } \\
\text { Circulating ICs in all reactional patients No antimycobacterial } \\
\text { antibody in ICs from LL reactional patients }\end{array}$ \\
\hline $\begin{array}{l}\text { Saha et al. (75); } \\
\text { India }\end{array}$ & $20 \mathrm{ENL}, 15 \mathrm{HC}$ & $\begin{array}{l}\text { Before and } \\
4 \text { weeks after } \\
\text { starting treatment } \\
\text { for ENL }\end{array}$ & ND & $\begin{array}{l}\text { Second sample: } \\
\text { on antireactional } \\
\text { treatment }\end{array}$ & Serum & $\begin{array}{l}\text { Quantitative analysis } \\
\text { of composition of } \\
\text { PEG precipitates } \\
\text { (immunoglobulins, } \\
\text { complement components, } \\
\text { autoantibodies and acute } \\
\text { phase proteins) and } \\
\text { anticomplementary activity of } \\
\text { PEG precipitates }\end{array}$ & $\begin{array}{l}\text { Anticomplementary activity of PEG precipitates more in the } \\
\text { lepromatous than in normal sera, independent of the presence of } \\
\text { ENL }\end{array}$ \\
\hline
\end{tabular}


TABLE 2 | Continued

\begin{tabular}{|c|c|c|c|c|c|c|c|}
\hline $\begin{array}{l}\text { Reference; } \\
\text { study site(s) }\end{array}$ & Study population & $\begin{array}{l}\text { Timing of } \\
\text { screening }\end{array}$ & MDT status & ENL treatment & $\begin{array}{l}\text { Type of } \\
\text { samples }\end{array}$ & Measures & Findings \\
\hline $\begin{array}{l}\text { Ramanathan } \\
\text { et al. (48); India }\end{array}$ & $\begin{array}{l}32 \mathrm{LL} \text { in reaction, } \\
10 \mathrm{BT}, 10 \mathrm{BT} \text { in } \\
\text { reaction, } 10 \mathrm{LL} \\
\text { uncomplicated, } \\
15 \mathrm{HC}\end{array}$ & ND & $\begin{array}{l}\mathrm{BT} \text { and } \mathrm{LL} \\
\text { without reaction } \\
\text { treatment for at } \\
\text { least } 2 \text { years; all } \\
\text { patients were on } \\
\text { dapsone }\end{array}$ & ND & Serum & $\begin{array}{l}\text { ICs by fluid phase }{ }^{125} \text {-labeled } \\
\text { conglutinin binding assay; } \\
\text { serum C3d } \\
\text { Complement-mediated } \\
\text { solubilization of immune } \\
\text { precipitates }\end{array}$ & $\begin{array}{l}\text { Reduced solubilization of in vitro formed immune precipitates by } \\
\text { the sera of ENL patients } \\
\text { C3d, ICs, and solubilization levels correlated with the clinical course } \\
\text { of reaction } \\
\text { ICs and C3d decline after clinical subsidence of ENL }\end{array}$ \\
\hline $\begin{array}{l}\text { Sehgal et al. } \\
\text { (76); India } \varepsilon\end{array}$ & $21 \mathrm{T1R}$ or ENL & ND & ND & ND & Serum & Complement C3 & Lower level of C3 during ENL \\
\hline $\begin{array}{l}\text { Chakrabarty } \\
\text { et al. (77); India }\end{array}$ & $\begin{array}{l}27 \text { BB-BL-LL: } 7 \\
\text { ENL, } 4 \text { T1R }\end{array}$ & $\begin{array}{l}\text { Initial blood } \\
\text { collected at the } \\
\text { onset of reaction } \\
\text { and subsequent } \\
4 \text { weeks after ENL } \\
\text { remission }\end{array}$ & Patients on MDT & $\begin{array}{l}\text { Second blood } \\
\text { sample on } \\
\text { antireactional } \\
\text { treatment }\end{array}$ & Serum & $\begin{array}{l}\text { Solubilization of preformed } \\
\text { ICs (125|-BSA-anti-BSA } \\
\text { complexes) }\end{array}$ & $\begin{array}{l}\text { The mean solubilizing capacity of the reaction patients' sera during } \\
\text { the reaction was not significantly different from } L L \text { without } E N L \\
\text { After clinical remission of the reaction, most patients showed no } \\
\text { increase in the ICs solubilization }\end{array}$ \\
\hline $\begin{array}{l}\text { Rao and Rao } \\
\text { (78); India } \varepsilon\end{array}$ & $\begin{array}{l}44 \text { ENL, } 39 \text { BL/LL, } \\
22 \text { post-ENL }\end{array}$ & $\begin{array}{l}\text { ENL: before } \\
\text { starting treatment } \\
\text { with anti- } \\
\text { inflammatory } \\
\text { drugs/steroids } \\
\text { Post-ENL: } \\
\text { ensuring that } \\
\text { the patient had } \\
\text { not taken anti- } \\
\text { inflammatory } \\
\text { drugs/steroids } \\
\text { for at least } 3 \text { or } \\
7 \text { days }\end{array}$ & $\begin{array}{l}20 \text { BL/LL } \\
\text { untreated and } \\
19 \text { BL/LL treated } \\
\text { with dapsone } \\
\text { less than a year }\end{array}$ & $\begin{array}{l}\text { Untreated first } \\
\text { sample and } \\
\text { second post-ENL } \\
\text { sample after } \\
\text { discontinuation } \\
\text { of antireactional } \\
\text { treatment }\end{array}$ & Serum & $\begin{array}{l}\text { C3 and C4 levels } \\
\text { IgG, IgA, IgM, C3, and C4 } \\
\text { levels in the ICs } \\
\text { ICs by PEG method }\end{array}$ & $\begin{array}{l}\mathrm{C} 3 \text { and } C 4 \text { levels were not significantly different in ENL compared } \\
\text { to BL/LL and post-ENL } \\
C 3 \text { and } C 4 \text { levels in the ICs reduced insignificantly in ENL than BL/ } \\
\mathrm{LL} \text { and post-ENL } \\
\text { IgG, IgA, and IgM in ICs showed no significant differences from LL } \\
\text { to ENL and post-ENL }\end{array}$ \\
\hline $\begin{array}{l}\text { Sehgal et al. } \\
\text { (79); India }\end{array}$ & $17 \mathrm{ENL}$ & $\begin{array}{l}\text { Before } \\
\text { antireactional } \\
\text { treatment and } \\
1 \text { week after } \\
\text { the clinical } \\
\text { subsidence of } \\
\text { ENL }\end{array}$ & On MDT & $\begin{array}{l}\text { First sample } \\
\text { untreated and } \\
\text { second sample on } \\
\text { prednisolone in } 10 \\
\text { patients }\end{array}$ & Serum & $\begin{array}{l}\text { Complement components: } \\
\text { classic pathway: C1q and C4 } \\
\text { Alternative pathway: C3, } \\
\text { C3d, Factor B }\end{array}$ & $\begin{array}{l}\text { No significant change in classical pathway in ENL reaction C3 } \\
\text { elevated, C3d decreased and increase of Factor B after ENL }\end{array}$ \\
\hline $\begin{array}{l}\text { Jayapal } 1989 \\
\text { (47); India }\end{array}$ & $\begin{array}{l}37 \text { leprosy: } 9 \\
\text { ENL, } 6 \text { bacterial } \\
\text { endocarditis, } \\
\text { syphilis, SLE, HC }\end{array}$ & ND & $\begin{array}{l}\text { All leprosy } \\
\text { patients on } \\
\text { dapsone }\end{array}$ & $\begin{array}{l}\text { ENL patients } \\
\text { on clofazimine, } \\
\text { prednisolone, } \\
\text { antihistamine and } \\
\text { chloroquine }\end{array}$ & Serum & ICs with PEG method & ICs higher in ENL than in LL \\
\hline
\end{tabular}


TABLE 2 | Continued

\begin{tabular}{|c|c|c|c|c|c|c|c|}
\hline $\begin{array}{l}\text { Reference; } \\
\text { study site(s) }\end{array}$ & Study population & $\begin{array}{l}\text { Timing of } \\
\text { screening }\end{array}$ & MDT status & ENL treatment & $\begin{array}{l}\text { Type of } \\
\text { samples }\end{array}$ & Measures & Findings \\
\hline $\begin{array}{l}\text { Sehgal et al. } \\
\text { (81); India }\end{array}$ & $\begin{array}{l}18 \mathrm{~T} 1 \mathrm{R}, 17 \mathrm{ENL}, \\
\text { non-reactional } \\
\text { controls }\end{array}$ & $\begin{array}{l}\text { During and after } \\
\text { reaction }\end{array}$ & On MDT & ND & Serum & $\begin{array}{l}\text { Complement components: } \\
\text { classic pathway: C1q and C4 } \\
\text { Alternative pathway: C3, } \\
\text { C3d, Factor B }\end{array}$ & $\begin{array}{l}\text { Classic pathway: no significant change in } \mathrm{C} 1 \mathrm{q} \text { and } \mathrm{C} 4 \text { during } \mathrm{ENL} \\
\text { Alternative pathway: increase in } \mathrm{C} 3 \mathrm{~d} \text { during } \mathrm{ENL} \text {; decrease of } \mathrm{C} 3 \\
\text { during ENL; reduction of Factor B during ENL; elevation of } \mathrm{C} 3 \text { and } \\
\text { Factor B after ENL }\end{array}$ \\
\hline $\begin{array}{l}\text { Tyagi et al. (52); } \\
\text { India }\end{array}$ & $\begin{array}{l}20 \mathrm{BL} / \mathrm{LL} \text { with ENL, } \\
20 \mathrm{TT} / \mathrm{BT}, 20 \mathrm{BT} \\
\text { with reaction, } 20 \\
\mathrm{BL} / \mathrm{LL} ; 15 \mathrm{HC}\end{array}$ & ND & ND & ND & Serum & $\begin{array}{l}\text { ICs by PEG precipitation } \\
\text { Mycobacterial ICs in PEG } \\
\text { precipitates; } \mathrm{CH} 50 \text { assay and } \\
\text { AH50 assay (complement } \\
\text { consumption) }\end{array}$ & $\begin{array}{l}\text { PEG ICs from BL/LL and ENL higher IgG and IgM antimycobacterial } \\
\text { antibodies than TT/BT, BT reactional (T1R) and HC } \\
\text { No significant functional differences between the PEG ICs from } \\
\text { reactional and non-reactional leprosy }\end{array}$ \\
\hline $\begin{array}{l}\text { Ramanathan } \\
\text { et al. (49); } \\
\text { India } \varepsilon\end{array}$ & $\begin{array}{l}26 \text { BL/LL: } 11 \text { ENL, } \\
24 \mathrm{HC}\end{array}$ & $\begin{array}{l}\text { Before initiation } \\
\text { of treatment } \\
\text { and } 2 \text {-monthly } \\
\text { intervals }\end{array}$ & $\begin{array}{l}\text { Untreated and } \\
\text { then on MDT }\end{array}$ & $\begin{array}{l}\text { Treated but after } \\
\text { sampling }\end{array}$ & Serum & $\begin{array}{l}\text { ICs by PEG method } \\
\text { C3d } \\
\text { Complement-induced IC } \\
\text { solubilization }\end{array}$ & $\begin{array}{l}\text { High levels of ICs in both LL and ENL } \\
\text { Lower levels of complement-induced IC solubilization in ENL } \\
\text { Highest levels of ICs and C3d at the time of ENL }\end{array}$ \\
\hline $\begin{array}{l}\text { Scollard et al. } \\
\text { (82); Thailand } \varepsilon\end{array}$ & $\begin{array}{l}4 \text { cured leprosy, } \\
10 \text { non-reactional } \\
\text { leprosy } \mathrm{BT} / \mathrm{BL} / \mathrm{LL}, 8 \\
\text { ENL patients }(5 \mathrm{LL} / 3 \\
\text { BL), } 3 \mathrm{~T} 1 \mathrm{R}, 4 \mathrm{HC}\end{array}$ & ND & ND & ND & $\begin{array}{l}\text { Blisters } \\
\text { induced over } \\
\text { representative } \\
\text { skin lesion } \\
\text { Serum }\end{array}$ & ICs & $\begin{array}{l}\text { ICs in ENL similar to that of active leprosy (either lepromatous or } \\
\text { tuberculoid) } \\
\text { Higher ICs in blisters than in matching sera }\end{array}$ \\
\hline $\begin{array}{l}\text { Rojas et al (50); } \\
\text { Brazil } \varepsilon\end{array}$ & $\begin{array}{l}19 \mathrm{ENL}, 10 \mathrm{BL} / \\
\mathrm{LL}, 13 \text { family } \\
\text { contacts; } 15 \text { healthy } \\
\text { non-contacts }\end{array}$ & ND & $\begin{array}{l}\text { Both untreated } \\
\text { and patients } \\
\text { on MDT for } \\
1-72 \text { months }\end{array}$ & ND & Serum & $\begin{array}{l}\text { ICs; anti-PGL-I IgM in IC } \\
\text { precipitated from sera; } \\
\text { anti-10-kDa hsp IgG in IC } \\
\text { precipitated from sera }\end{array}$ & $\begin{array}{l}\text { ENL highest levels of ICs compared with all other groups IgM } \\
\text { anti-PGL-I and lgG anti-MCP-1 heat shock protein antibodies } \\
\text { constituents of ICs in ENL }\end{array}$ \\
\hline $\begin{array}{l}\text { Dupnik et al. } \\
\text { (58); Brazil } \delta, \varepsilon\end{array}$ & $\begin{array}{l}11 \mathrm{ENL}, 11 \mathrm{~T} 1 \mathrm{R}, \\
19 \text { non-reactional } \\
\text { leprosy, additional } 6 \\
\text { ENL, } 11 \mathrm{~T} 1 \mathrm{R}, 11 \mathrm{HC}\end{array}$ & ND & $\begin{array}{l}3 \text { ENL pre- } \\
\text { treatment, } 2 \text { ENL } \\
\text { on treatment } \\
\text { and } 6 \text { ENL } \\
\text { post-treatment; } \\
\text { Leprosy controls } \\
\text { matched } \\
\text { for stage of } \\
\text { treatment }\end{array}$ & $\begin{array}{l}\text { Excluded patients } \\
\text { who had received } \\
\text { corticosteroids } \\
\text { within } 7 \text { days } \\
\text { or thalidomide } \\
\text { within } 28 \text { days of } \\
\text { enrollment }\end{array}$ & $\begin{array}{l}\text { PBMC } \\
\text { Skin }\end{array}$ & $\begin{array}{l}\text { Microarray and qPCR for } \\
\text { transcriptional profile of } \\
\text { PBMC; IHC for C1q in skin } \\
\text { lesions }\end{array}$ & $\begin{array}{l}\text { Complement and coagulation pathway common in ENL and T1R } \\
\text { Transcripts uniquely increased in ENL included complement } \\
\text { receptors C3AR1 and C5AR1 } \\
\text { C1q staining higher in both ENL and T1R compared with non- } \\
\text { reactional leprosy }\end{array}$ \\
\hline
\end{tabular}

$\alpha$, also in Table 1; $\gamma$, also in Table 3; $\delta$, also in Table 4; $\varepsilon$, also in Table 5.

$B B$, mid-borderline leprosy; BL, borderline lepromatous leprosy; BT, borderline tuberculoid leprosy; ENL, erythema nodosum leprosum; HC, healthy controls; ICs, immune complexes; LL, lepromatous leprosy polar; ND, not described; PEG, polyethylene glycol; PNG, Papua New Guinea; RA, rheumatoid arthritis; SLE, systemic lupus erythematosus; TB, tuberculosis; TT, tuberculoid leprosy polar; WHO, World Health Organization. 
whether they are involved in the pathogenesis of ENL or simply an epiphenomenon.

\section{WHAT IS THE ROLE OF T-CELLS IN ENL?}

T-lymphocytes are part of the adaptive immune response which help to eliminate bacterial, viral, parasitic infections or malignant cells. The antigen specificity of the $\mathrm{T}$-cell is based on recognition through the T-cell receptor (TCR) of unique antigenic peptides presented by major histocompatibility complex (MHC)-molecules on APCs: B cells, macrophages, and dendritic cells. There are two major T-cell lineages, defined by the presence of two surface coreceptor molecules, namely, $\mathrm{CD} 4$ and $\mathrm{CD} 8 . \mathrm{CD} 4^{+}$cells when they are activated produce cytokines as effector T helper cells, whereas $\mathrm{CD}^{+}$lymphocytes form effector cytotoxic $\mathrm{T}$ lymphocytes (CTL). Furthermore, activated $\mathrm{CD} 4^{+} \mathrm{T}$ helper cells can be subdivided into Th 1 , Th2, Th17, and T regulatory (Treg) subsets based on the production of signature cytokines (83).

Early studies investigating T-cell biology in the pathophysiology of ENL reported that ENL patients had higher T-cell numbers in peripheral blood than uncomplicated LL patients, although both LL and ENL patients had a significantly lower percentage and absolute number of T-cells compared to healthy controls (84). In addition, the high numbers of T-cells observed during ENL remained high post-ENL treatment compared to the LL controls (85).

Patients with ENL had increased $\mathrm{CD} 4^{+} \mathrm{T}$ cell numbers and a simultaneous decrease in $\mathrm{CD} 8^{+} \mathrm{T}$ cell numbers and an increased $\mathrm{CD}^{+} / \mathrm{CD}^{+}$ratio in the blood compared to LL controls $(86,87)$, while ENL patients had decreased $\mathrm{CD}^{+} / \mathrm{CD}^{+}$ratio after successful treatment. This ratio increased in those patients who had an ENL recurrence (87). An increased $\mathrm{CD}^{+} / \mathrm{CD}^{+}$ratio in $\mathrm{ENL}$ patients was reported by several subsequent studies (87-92). In acute SLE, it has been suggested that the failure of $\mathrm{CD}^{+} \mathrm{T}$-cell activity could lead to increased IgG production and to the subsequent formation of ICs (93). However, there are studies in ENL reporting a decreased $\mathrm{CD} 4^{+} / \mathrm{CD} 8^{+}$ratio compared to nonreactional LL controls $(94)$ or a similar ratio $(95,96)$.

The first immunohistological studies of T-cell subsets in skin lesions included small numbers of ENL patients and assessed the percentage and ratio of $\mathrm{CD} 4^{+}$and $\mathrm{CD} 8^{+} \mathrm{T}$ cells by comparing them to non-ENL lepromatous specimens $(89,91,97-103)$. ENL skin lesions, like peripheral blood, were characterized by an increased $\mathrm{CD} 4^{+} / \mathrm{CD} 8^{+}$ratio in all but one of these studies $(89,91$, 97-100, 102, 103).

$\mathrm{CD} 4^{+} \mathrm{T}$ cells differentiate according to the microenvironment into Th1, Th2 cells, or subsets of Th17 and Treg (104). Recent studies have reported the frequency of the newly described Th17 and Treg subsets in leprosy $(105,106)$. Using flow cytometry in ENL, the absolute numbers and proportion of Tregs were shown to be significantly lower during ENL although FoxP3 expression, a marker they used to define Tregs, was higher (107). Tregs suppress or downregulate induction and proliferation of effector T cells (108). Therefore, the observation of lower numbers of Tregs in ENL could account for the relatively higher proportion of $\mathrm{T}$ cells previously described in multiple ENL studies. Two more publications from the same group addressed the frequency of Tregs in ENL, defined as $\mathrm{CD} 4^{+} \mathrm{CD} 25^{\text {high }}$ FoxP3 ${ }^{+}$ cells and reported the ratio of Treg/Teffector cells to be low in ENL $(109,110)$. These results should be interpreted with caution since dichotomizing cells into CD25 high and CD25 $5^{\text {low }}$ to identify Tregs is highly subjective. There is no consensus on the thresholds of CD25 expression to delineate Tregs within the CD2 $5^{\text {high }}$ population (111). Variations in FoxP3 expression within the CD25 high population have been observed even in healthy individuals (112).

A recent study that used flow cytometry described a significant reduction in percentage of $\mathrm{CD} 4^{+} \mathrm{CD} 25^{+} \mathrm{FoxP}^{+}$Treg cells and mean fluorescence intensity of FoxP3 in PBMC in patients with ENL compared to LL controls (113). The observed reduction of Tregs in ENL patients could lower the inhibitory effects on effector $\mathrm{T}$ cells and therefore lead to enhanced Th17 activity, tipping the balance toward inflammation, as previously described in other conditions such as tuberculous pleural effusion (114). Interestingly, an increase of FoxP3 mRNA expression by PBMC in ENL patients compared to LL controls has also been reported (113). The conflicting results for FoxP3 could be due to variation in the flow cytometry gating or the fact that FoxP3 mRNA may not be translated to functional FoxP3. A previous study measured the expression of Foxp3 by qPCR in skin biopsies and PBMC of five patients with ENL and detected Foxp3 in all skin and PBMC samples. An upward trend of Foxp3 in PBMC was described during the first 21 days of thalidomide treatment (115). The authors suggested that thalidomide may boost Tregs by T-cell costimulation via $\mathrm{CD} 28$ and therefore augment the IL-2-dependent number and/or function of Tregs (115). However, the changes in Foxp3 expression did not reach statistical significance, while no IL-2 mRNA was detected in any samples (115). Another study addressed FoxP3 expression by immunohistochemistry in skin but there was no difference in patients with ENL compared to non-reactional leprosy controls across the spectrum (116). Recent research suggests that Tregs constitute a stable cell lineage whose committed state in a changing environment is ensured by DNA demethylation of the Foxp3 locus irrespective of ongoing Foxp3 expression (117). Further investigation is needed to better define the role of Tregs in the pathogenesis of ENL.

Patients with ENL do not exhibit the phenomenon of "anergy" of cell-mediated immune response observed in untreated LL patients (118). Patients with ENL had elevated mean proliferative responses to several mitogens compared to uncomplicated LL patients $(86,87)$, while an enhancement in T-cell-related functions during the acute phase of an ENL reaction has also been described (94).

The interpretation of the role of $\mathrm{T}$ cell subsets in ENL is hampered by small sample sizes and methodological issues. $63.6 \%$ of the 44 studies investigating the role of T-cells in ENL (Table 3) are cross-sectional and lack serial sampling before and after treatment for ENL. However, it appears that T cell subsets do play an important role in ENL because multiple studies report an increased $\mathrm{CD} 4^{+} / \mathrm{CD}^{+}$ratio in ENL patients in both skin and peripheral blood. 
TABLE 3 | Human studies on ENL investigating T-cell biology.

\begin{tabular}{|c|c|c|c|c|c|c|c|}
\hline $\begin{array}{l}\text { Reference; } \\
\text { study site(s) }\end{array}$ & Study population & $\begin{array}{l}\text { Timing of } \\
\text { sampling }\end{array}$ & MDT status & ENL treatment status & $\begin{array}{l}\text { Type of } \\
\text { samples }\end{array}$ & Measures & Findings \\
\hline $\begin{array}{l}\text { Lim et al. (84); } \\
\text { USA and Korea } \\
\text { (mixed ethnic } \\
\text { background) }\end{array}$ & $\begin{array}{l}7 \mathrm{LL} \mathrm{ENL,} 20 \text { active } \mathrm{LL} \text {, } \\
9 \text { inactive } \mathrm{LL}, 4 \mathrm{BB}, 3 \\
\text { indeterminate leprosy }\end{array}$ & ND & $\begin{array}{l}\text { All patients } \\
\text { treated with } \\
\text { Dapsone or } \\
\text { Clofazimine } \\
\text { or Rifampicin } \\
\text { for varying } \\
\text { durations }\end{array}$ & $\begin{array}{l}5 \text { had received various } \\
\text { doses of steroids and } \\
3 \text { were treated with } \\
\text { steroids at the time of } \\
\text { the study }\end{array}$ & Blood & $\begin{array}{l}\text { T lymphocyte numbers by } \\
\text { the rosette assay }\end{array}$ & $\begin{array}{l}\text { ENL showed T-lymphocyte numbers significantly higher than } \\
\text { LL } \\
\text { LL had lower T-lymphocyte numbers than HC }\end{array}$ \\
\hline $\begin{array}{l}\text { Anders et al. } \\
\text { (119); Papua } \\
\text { New Guinea }\end{array}$ & $\begin{array}{l}31 \text { leprosy: } 13 \text { BL/LL } \\
\text { with amyloidosis (11/13 } \\
\text { frequent ENL), } 9 \text { BL/LL } \\
\text { ENL without amyloidosis, } \\
9 \text { BL/LL with few or no } \\
\text { ENL episodes }\end{array}$ & ND & $\begin{array}{l}\text { Approximately } \\
\text { half patients on } \\
\text { clofazimine and } \\
\text { other half on } \\
\text { dapsone }\end{array}$ & $\begin{array}{l}2 \text { ENL at testing: } \\
1 \text { steroids and } 1 \\
\text { stibophen }\end{array}$ & Blood & $\begin{array}{l}\text { Lympohocyte } \\
\text { transformation tests }\end{array}$ & $\begin{array}{l}\text { Patients with a history of frequent ENL had greater cell- } \\
\text { mediated responses to PHA than patients without ENL }\end{array}$ \\
\hline $\begin{array}{l}\text { Izumi et al. (70); } \\
\text { Japan } \beta\end{array}$ & $\begin{array}{l}12 \mathrm{ENL}, 49 \text { active } \\
\text { lepromatous, } 24 \text { inactive } \\
\text { lepromatous, } 7 \text { borderline, } \\
6 \text { tuberculoid, } 9 \mathrm{HC}\end{array}$ & ND & ND & ND & PBMC & $\begin{array}{l}\text { Percentage and number } \\
\text { of } T \mu \text { ( }(T \text { cells with } F c \\
\text { receptor for IgG) and } T \gamma \\
\text { (T cells with } F c \text { receptor } \\
\text { for IgM) }\end{array}$ & No significant differences between different clinical groups \\
\hline $\begin{array}{l}\text { Bach et al. (86); } \\
\text { France (multiple } \\
\text { ethnic groups) }\end{array}$ & $\begin{array}{l}9 \text { BL/LL with no recent } \\
\text { history of ENL, } 9 \text { BL/LL } \\
\text { suffered from ENL less } \\
\text { than } 2 \text { months prior to } \\
\text { the investigation, } 13 \mathrm{BT} / \\
\pi, \mathrm{HC}\end{array}$ & ND & $\begin{array}{l}\text { Some untreated } \\
\text { and others on } \\
\text { MDT }\end{array}$ & $\begin{array}{l}\text { Certain ENL on } \\
\text { antireactional treatment }\end{array}$ & Blood & $\begin{array}{l}\text { T cell subsets; Proliferative } \\
\text { responses to mitogens } \\
\text { Con A-induced } \\
\text { suppressive activity }\end{array}$ & $\begin{array}{l}\text { Increased \%age of helper T cells in ENL } \\
\text { Decreased \%age of suppressor T cells in ENL } \\
\text { Elevated proliferative responses to mitogens in ENL } \\
\text { Most ENL decrease of suppressive index, whereas none of } \\
\text { the LL or TT patients had a diminished suppressive activity }\end{array}$ \\
\hline $\begin{array}{l}\text { Dubey et al. } \\
\text { (120); India }\end{array}$ & $\begin{array}{l}41 \text { untreated cases } \\
\text { of leprosy, } 64 \pi \text { and } \\
\text { LL taking antileprosy } \\
\text { treatment, reactional ( } 8 \\
\text { ENL and } 10 T 1 R s), 11 / 41 \\
\text { follow-up from untreated } \\
\text { leprosy patients }\end{array}$ & ND & $\begin{array}{l}64 \text { cases on } \\
\text { antileprosy } \\
\text { treatment }\end{array}$ & $\begin{array}{l}\text { Untreated cases of } \\
\text { ENL? }\end{array}$ & Blood & $\begin{array}{l}\text { Lymphocytic culture: } \\
\text { percentage of Blast } \\
\text { transformation }\end{array}$ & Blast percentage in ENL slightly higher than T1R \\
\hline $\begin{array}{l}\text { Mshana et al. } \\
\text { (90); Ethiopia }\end{array}$ & $21 \mathrm{BL} / \mathrm{LL}, 10 \mathrm{BT}, 5 \mathrm{ENL}$ & ND & $\begin{array}{l}\text { All patients } \\
\text { received MDT } \\
\text { but unclear } \\
\text { whether } \\
\text { sampled prior to } \\
\text { MDT }\end{array}$ & $\begin{array}{l}\text { No patient on } \\
\text { thalidomide }\end{array}$ & Blood & $\begin{array}{l}\text { Lymphoproliferative } \\
\text { responses to PPD or PHA } \\
\text { T-cell subsets }\end{array}$ & $\begin{array}{l}\text { Higher responses to PPD or PHA in ENL Decreased number } \\
\text { of suppressor cells prior to ENL, which increased with clinical } \\
\text { recovery from ENL }\end{array}$ \\
\hline $\begin{array}{l}\text { Mshana et al. } \\
\text { (88); Ethiopia }\end{array}$ & $\begin{array}{l}69 \text { leprosy patients: } 26 \\
\text { ENL, } 13 \text { HC }\end{array}$ & $\begin{array}{l}\text { Untreated } \\
\text { samples }\end{array}$ & $\begin{array}{l}\text { Untreated } \\
\text { samples }\end{array}$ & Untreated samples & Blood & $\begin{array}{l}\text { T lymphocyte } \\
\text { subpopulations; } \\
\text { lymphoproliferation using } \\
\text { M. leprae, PHA and PPD }\end{array}$ & $\begin{array}{l}\text { ENL patients had decrease in suppressor cells and an } \\
\text { increase of } C D 4^{+} / C D 8^{+} \text {ratio compared to } L L E N L \text { had higher } \\
\text { responses to both PHA and PPD BL/LL patients with or } \\
\text { without ENL lower proliferative responses to } M \text {. leprae than } \\
\text { BT patients and HC }\end{array}$ \\
\hline
\end{tabular}


TABLE 3 | Continued

\begin{tabular}{|c|c|c|c|c|c|c|c|}
\hline $\begin{array}{l}\text { Reference; } \\
\text { study site(s) }\end{array}$ & Study population & $\begin{array}{l}\text { Timing of } \\
\text { sampling }\end{array}$ & MDT status & ENL treatment status & $\begin{array}{l}\text { Type of } \\
\text { samples }\end{array}$ & Measures & Findings \\
\hline $\begin{array}{l}\text { Wallach et al. } \\
\text { (87); France } \\
\text { (samples from } \\
\text { multiple ethnic } \\
\text { groups) }\end{array}$ & $\begin{array}{l}9 \text { recent ENL, } 6 \\
\text { bacteriologically positive } \\
\text { patients of which } 1 \mathrm{ENL} \\
\text { more than } 5 \text { years ago, } 9 \\
\text { treated leprosy patients of } \\
\text { which } 3 \text { had ENL }\end{array}$ & $\begin{array}{l}\text { Described in } \\
\text { detail each } \\
\text { patient duration } \\
\text { of disease }\end{array}$ & $\begin{array}{l}\text { All treatment } \\
\text { described in } \\
\text { detail }\end{array}$ & $\begin{array}{l}\text { Some on antireactional } \\
\text { treatment }\end{array}$ & Blood & $\begin{array}{l}\text { T cell subsets; } \\
\text { Lymphocyte } \\
\text { transformation tests: } \\
\text { proliferative responses to } \\
\text { mitogens }\end{array}$ & $\begin{array}{l}\text { ENL patients have elevated Helper/Suppressor ratio } \\
\text { Mean proliferative responses elevated in ENL }\end{array}$ \\
\hline $\begin{array}{l}\text { Bach et al. } \\
\text { (121); France }\end{array}$ & $\begin{array}{l}8 \text { treated lepromatous } \\
\text { without recent ENL with } \\
\mathrm{BI}<1+, 6 \text { lepromatous } \\
\text { with } \mathrm{BI}>2+\text { (untreated } \\
\text { or suffering a relapse, } \\
\text { without recent ENL } \\
\text { reaction), } 12 \text { lepromatous } \\
\text { who underwent at least } \\
\text { one ENL episode, } 13 \\
\text { tuberculoid, } 41 \mathrm{HC}\end{array}$ & ND & ND & ND & PBMC & $\begin{array}{l}\text { T-cell subsets; Proliferative } \\
\text { response to } M \text {. leprae } \\
\text { and PPD of isolated T-cell } \\
\text { subsets }\end{array}$ & $\begin{array}{l}\text { ENL decreased CD8 }{ }^{+} T \text { cell percentages and increased } \\
C D 4^{+} / C D 8^{+} \text {ratios } T \text {-cell subset percentages returned to } \\
\text { normal either when the bacterial load was reduced by } \\
\text { treatment or when the ENL reaction resolved ENL episodes } \\
\text { associated with improvement of T-cell unresponsiveness to } \\
\text { various antigens or mitogens }\end{array}$ \\
\hline $\begin{array}{l}\text { Modlin et al. } \\
\text { (97); USA }\end{array}$ & $\begin{array}{l}15 \text { non-reactional } \\
\text { leprosy BT/BB/BL/LL, } 17 \\
\text { reactional (6 T1R, } 9 \text { ENL, } \\
2 \text { Lucio's reaction) }\end{array}$ & ND & $\begin{array}{l}\text { Results did not } \\
\text { differ between } \\
\text { treated and } \\
\text { untreated } \\
\text { subjects }\end{array}$ & 3 ENL had no therapy & Skin & T lymphocyte subsets & $\begin{array}{l}\text { The helper/suppressor ratio in ENL was significantly higher } \\
\text { than in non-reactional lepromatous disease }\end{array}$ \\
\hline $\begin{array}{l}\text { Modlin et al. } \\
\text { (98); USA }\end{array}$ & $\begin{array}{l}14 \text { leprosy patients ( } 4 \\
\text { tuberculoid, } 2 \text { borderline in } \\
\text { T1R, } 1 \mathrm{BL}, 7 \text { lepromatous } \\
\text { of which } 5 \mathrm{ENL} \text { ), } 8 \mathrm{HC}\end{array}$ & ND & $\begin{array}{l}6 \text { treated } \\
\text { patients }\end{array}$ & ND & Skin & T lymphocyte subsets & $\begin{array}{l}\text { ENL lesions showed 2:1 predominance of helper cells } \\
\text { whereas in the lesions without ENL the helper: suppressor } \\
\text { ratio was 1:1 smaller }\end{array}$ \\
\hline $\begin{array}{l}\text { Sasiain et al. } \\
\text { (122); Argentina }\end{array}$ & $16 \mathrm{ENL}, 12 \mathrm{HC}$ & $\begin{array}{l}\text { First blood } \\
\text { sample } \\
\text { ND; } 9 \text { ENL } \\
\text { 20-30 days } \\
\text { after stopping } \\
\text { thalidomide }\end{array}$ & $\begin{array}{l}\text { All patients on } \\
\text { MDT }\end{array}$ & $\begin{array}{l}\text { Thalidomide in patients } \\
\text { with ENL }\end{array}$ & PBMC & $\begin{array}{l}\text { ConA-induced suppressor } \\
\text { response }\end{array}$ & $\begin{array}{l}\text { Suppressor T-cell function was reduced during ENL and after } \\
\text { ENL than } \mathrm{HC}\end{array}$ \\
\hline $\begin{array}{l}\text { Narayanan et al. } \\
\text { (89); India } \varepsilon\end{array}$ & $\begin{array}{l}7 \mathrm{LL} \text { ENL, } 6 \text { BT T1R, 5BL } \\
\text { T1R, } 18 \text { BT-LL }\end{array}$ & ND & ND & ND & Skin & T cell phenotypes & $\begin{array}{l}\text { Lesions of ENL showed increase in T cells with a } \\
\text { predominance of the helper/inducer subset; } \mathrm{CD} 4^{+} / \mathrm{CD} 8^{+} \text {ratio } \\
\text { was higher in ENL and T1R than non-reactional lesions }\end{array}$ \\
\hline
\end{tabular}

(Continued) 
TABLE 3 | Continued

\begin{tabular}{|c|c|c|c|c|c|c|c|}
\hline $\begin{array}{l}\text { Reference; } \\
\text { study site(s) }\end{array}$ & Study population & $\begin{array}{l}\text { Timing of } \\
\text { sampling }\end{array}$ & MDT status & ENL treatment status & $\begin{array}{l}\text { Type of } \\
\text { samples }\end{array}$ & Measures & Findings \\
\hline $\begin{array}{l}\text { Rea et al. (96); } \\
\text { USA } \varepsilon\end{array}$ & $\begin{array}{l}19 \mathrm{ENL}, 24 \mathrm{LL} \text { non- } \\
\text { reactional with treatment, } \\
12 \mathrm{LL} \text { non-reactional no } \\
\text { treatment, } 18 \mathrm{LL} \text { with } \\
\text { long-term treatment, } 4 \\
\text { LL with Lucio's, } 13 \mathrm{BL} \text {, } \\
13 \mathrm{~T} 1 \mathrm{R}, 18 \text { Tuberculoid, } \\
13 \text { Tuberculoid with long- } \\
\text { term treatment }\end{array}$ & ND & $\begin{array}{l}\text { Some patients } \\
\text { on MDT }\end{array}$ & $\begin{array}{l}\text { ENL before receiving } \\
\text { thalidomide }\end{array}$ & PBMC & T cell subsets & $\begin{array}{l}\text { Active LL patients have lymphopenia, a proportionate } \\
\text { reduction in the numbers of each of the three T cell subsets } \\
\text { Insignificant changes in T cell subsets expressed as } \\
\text { percentages and in the helper: suppressor ratio }\end{array}$ \\
\hline $\begin{array}{l}\text { Laal et al. (94); } \\
\text { India } \varepsilon\end{array}$ & 15 ENL, 13 LL & $\begin{array}{l}\text { During active } \\
\text { ENL and } \\
1 \text { week to } \\
4 \text { months } \\
\text { after stopping } \\
\text { treatment }\end{array}$ & On MDT & $\begin{array}{l}\text { First sample } \\
\text { before initiation of } \\
\text { antireactional treatment } \\
\text { Second sample } 1 \\
\text { week to } 4 \text { months after } \\
\text { stopping treatment }\end{array}$ & Blood & $\begin{array}{l}\text { Leukocyte migration } \\
\text { inhibition test } \\
\text { Lymphoproliferation } \\
\text { Suppressor cell activity; } \\
\text { T cell subsets }\end{array}$ & $\begin{array}{l}\text { ENL significant inhibition of antigen-induced leukocyte } \\
\text { migration } \\
\text { Lymphoproliferation enhanced during the acute phase of ENL } \\
\text { Enhanced antigen-stimulated suppression of mitogen } \\
\text { responses in ENL } \\
\text { Leukocyte migration inhibition, lymphoproliferation, and } \\
\text { suppressor cell activity were reduced in post-ENL to the } \\
\text { unresponsive state seen in stable LL } \\
\text { Lower CD4 }{ }^{+} / C D 8^{+} \text {ratio in ENL compared to LL }\end{array}$ \\
\hline $\begin{array}{l}\text { Modlin et al. } \\
\text { (99); USA }\end{array}$ & $\begin{array}{l}12 \text { ENL and } 10 \text { non- } \\
\text { reactional leprosy; } 19 \text { ENL } \\
\text { blood samples }\end{array}$ & ND & $\begin{array}{l}\text { ENL biopsies: } \\
\text { 8/12 treated } \\
\text { with dapsone; } \\
\text { ENL blood: } \\
15 / 19 \text { treated }\end{array}$ & $\begin{array}{l}\text { Some ENL were } \\
\text { treated }\end{array}$ & $\begin{array}{l}\text { Blood } \\
\text { Skin }\end{array}$ & T lymphocyte subsets & $\begin{array}{l}\text { ENL tissue more cells of the helper-inducer phenotype and } \\
\text { fewer of the suppressor-cytotoxic phenotype, as compared } \\
\text { with non-reactional LL } \\
\text { No correlation between tissue and blood helper-suppressor } \\
\text { ratios }\end{array}$ \\
\hline $\begin{array}{l}\text { Wallach et al. } \\
\text { (91); France }\end{array}$ & ND & ND & ND & ND & $\begin{array}{l}\text { Blood } \\
\text { Skin }\end{array}$ & $\begin{array}{l}\text { T cell helper-suppressor } \\
\text { (HS) ratio }\end{array}$ & $\begin{array}{l}\text { HS ratio higher in ENL lesions and blood than non-ENL } \\
\text { leprosy controls }\end{array}$ \\
\hline $\begin{array}{l}\text { Modlin et al. } \\
\text { (100); USA }\end{array}$ & $\begin{array}{l}\text { Biopsies: } 25 \mathrm{ENL}, 23 \\
\text { tuberculoid, } 23 \text { non- } \\
\text { reactional lepromatous; } \\
\text { Blood: } 18 \text { ENL }\end{array}$ & ND & $\begin{array}{l}\text { Some patients } \\
\text { received } \\
\text { treatment }\end{array}$ & $\begin{array}{l}\text { Some patients on } \\
\text { treatment? }\end{array}$ & $\begin{array}{l}\text { Blood } \\
\text { Skin }\end{array}$ & $\begin{array}{l}\text { Skin: number of T cells, } \\
\text { T cell subsets; Blood: } \\
\text { lepromin-induced } \\
\text { suppression of the Con A } \\
\text { stimulation }\end{array}$ & $\begin{array}{l}\text { Increases in both } \mathrm{CD} 4^{+} / \mathrm{CD} 8^{+} \text {ratio and the number of IL2- } \\
\text { positive cells in ENL } \\
\text { Suppressor activity decreased significantly in ENL } \\
\text { Suppressor activity returned to normal after ENL subsided }\end{array}$ \\
\hline $\begin{array}{l}\text { Rao and Rao } \\
\text { (123); India } \varepsilon\end{array}$ & $\begin{array}{l}44 \mathrm{ENL}, 39 \mathrm{BL} / \mathrm{LL}, 22 \\
\text { post-ENL }\end{array}$ & $\begin{array}{l}\text { ENL patients } \\
\text { before starting } \\
\text { ENL treatment, } \\
\text { post-ENL after } \\
\text { patient had } \\
\text { not taken anti- } \\
\text { inflammatory/ } \\
\text { steroids for } \\
\text { at least } 3 \text { and } \\
7 \text { days }\end{array}$ & $\begin{array}{l}\text { From } 39 \text { non- } \\
\text { reactional cases: } \\
20 \text { untreated } \\
\text { and } 19 \text { with } \\
\text { dapsone for less } \\
\text { than a year }\end{array}$ & $\begin{array}{l}\text { Before starting } \\
\text { treatment for ENL } \\
\text { with steroids or anti- } \\
\text { inflammatory drugs, } \\
\text { post-ENL: ensuring } \\
\text { that the patient had not } \\
\text { taken anti-inflammatory } \\
\text { drugs or steroids for } \\
\text { at least } 3 \text { and } 7 \text { days, } \\
\text { respectively }\end{array}$ & Blood & $\begin{array}{l}\text { Sub-population of T cells } \\
\text { with receptors for } F c \\
\text { portion of } \operatorname{lgG}(T r) \text { and } F c \\
\text { portion of } \operatorname{lgM}(T \mu)\end{array}$ & $\begin{array}{l}T \mu / T r \text { ratio higher in ENL than lepromatous and post-ENL } \\
\text { patients }\end{array}$ \\
\hline
\end{tabular}




\begin{tabular}{|c|c|c|c|c|c|c|c|}
\hline $\begin{array}{l}\text { Reference; } \\
\text { study site(s) }\end{array}$ & Study population & $\begin{array}{l}\text { Timing of } \\
\text { sampling }\end{array}$ & MDT status & ENL treatment status & $\begin{array}{l}\text { Type of } \\
\text { samples }\end{array}$ & Measures & Findings \\
\hline $\begin{array}{l}\text { Rao and Rao } \\
\text { (85); India }\end{array}$ & 77 leprosy: 44 ENL & $\begin{array}{l}\text { ENL: before } \\
\text { starting anti- } \\
\text { ENL treatment, } \\
\text { post-ENL: After } \\
\text { patient had } \\
\text { noe taken anti- } \\
\text { inflammatory } \\
\text { drugs or } \\
\text { steroids for } \\
\text { at least } 3 \text { and } \\
7 \text { days }\end{array}$ & $\begin{array}{l}19 \text { patients } \\
\text { treated with } \\
\text { dapsone for less } \\
\text { than } 1 \text { year }\end{array}$ & $\begin{array}{l}\text { Before starting } \\
\text { treatment for ENL with } \\
\text { anti-inflammatory drugs } \\
\text { or steroids }\end{array}$ & Blood & $\begin{array}{l}\text { Leykocyte migration } \\
\text { inhibition test (LMIT) } \\
\text { Enumeration of early and } \\
\text { total T lymphocytes }\end{array}$ & $\begin{array}{l}\text { No significant difference in mean migratory index to PHA, } \\
\text { PPD, sonicate } M \text {. leprae } \\
\text { Whole } M \text {. leprae increased response in ENL compared to LL } \\
\text { Lower migratory indices to whole } M \text {. leprae in post-ENL than } \\
\mathrm{LL} \\
\text { \%age of early T lymphocytes increased in ENL compared } \\
\text { to LL } \\
\text { \%age of early T lymphocytes remained high in post-ENL } \\
\text { compared to } L L \\
\text { Cell-mediated immune responses enhanced during ENL and } \\
\text { return to LL levels once the episode is over }\end{array}$ \\
\hline $\begin{array}{l}\text { Shen et al. } \\
\text { (101); USA }\end{array}$ & $\begin{array}{l}10 \mathrm{ENL}, 8 \mathrm{TT} / \mathrm{BT}, 10 \mathrm{BL} \\
\mathrm{LL}, 10 \mathrm{~T} 1 \mathrm{R}\end{array}$ & ND & ND & ND & $\begin{array}{l}\text { Skin } \\
\text { PBMC }\end{array}$ & $\begin{array}{l}\text { CD3, CD4, CD8 and Ta1 } \\
\text { (memory) positive cells }\end{array}$ & $\begin{array}{l}\text { CD3, CD4 and CD8 showed percentages of positive cells in } \\
\text { lesions similar between patient groups } \\
\text { No significant difference in\%age of memory T-cells in ENL } \\
\text { compared to LL }\end{array}$ \\
\hline $\begin{array}{l}\text { Bottasso et al. } \\
\text { (124); Argentina }\end{array}$ & $\begin{array}{l}8 \text { LL/ENL, } 17 \mathrm{LL}, 9 \mathrm{TT} \\
11 \mathrm{HC}\end{array}$ & ND & Patients on MDT & $\begin{array}{l}\text { Patients with ENL were } \\
\text { not on thalidomide } \\
\text { treatment but unknown } \\
\text { whether they were on } \\
\text { steroids }\end{array}$ & Blood & $\begin{array}{l}\text { T-Lymphocytes count } \\
\text { absolute and relative; } \\
\text { Lymphocyte functional } \\
\text { assay: capacity of rosetta } \\
\text { formation }\end{array}$ & $\begin{array}{l}\text { Active } L L \text { showed a decrease in T-lymhocytes } \\
\text { ENL showed a restoration of the levels of T-lymphocytes }\end{array}$ \\
\hline $\begin{array}{l}\text { Rasheed et al. } \\
\text { (125); Zambia } \\
\text { and Pakistan }\end{array}$ & $\begin{array}{l}167 \text { leprosy of which } 21 \\
\text { LLENL, } 12 \text { BLT1R, } 24 \\
\text { BT/T1R, } 46 \text { endemic HC }\end{array}$ & ND & ND & ND & $\begin{array}{l}\text { Serum } \\
\text { Lymphocytes }\end{array}$ & Lymphocytotoxic activity & $\begin{array}{l}\text { Lymphocytotoxic activity scores were significantly raised in } \\
\text { patients with reactions }\end{array}$ \\
\hline $\begin{array}{l}\text { Sasiain et al. } \\
\text { (126); Argentina }\end{array}$ & $\begin{array}{l}53 \text { leprosy patients TT/ } \\
\text { BT/BB/BLLLL and } 9 \text { LL/ } \\
\text { ENL, } 23 \text { HC }\end{array}$ & ND & Received MDT & Thalidomide for ENL & PBMC & $\begin{array}{l}\text { Proportion of } \mathrm{CD}^{+} \text {cells } \\
\text { M. leprae-induced } \\
\text { suppression of T-cell } \\
\text { proliferation; Induction of } \\
\text { IL-2R by culture with M. } \\
\text { leprae } \\
\text { PHA- and ConA-induced } \\
\text { proliferation }\end{array}$ & $\begin{array}{l}\text { Proportion of } \mathrm{CD} 8^{+} \text {cells was low in LL patients and tended } \\
\text { to normalize during ENL episodes }\end{array}$ \\
\hline $\begin{array}{l}\text { Bhoopat et al. } \\
\text { (127); Thailand } \varepsilon\end{array}$ & $\begin{array}{l}57 \text { ENL (19 acute/38 } \\
\text { chronic), } 61 \text { active LL, } 33 \\
\text { cured leprosy }\end{array}$ & $\begin{array}{l}26 \text { BL/35 } \\
\text { LL newly } \\
\text { diagnosed and } \\
\text { untreated }\end{array}$ & ND & $\begin{array}{l}\text { If corticosteroid and/ } \\
\text { or thalidomide was } \\
\text { initiated before or } \\
\text { during the study, } \\
\text { precise timing of } \\
\text { medication was } \\
\text { recorded with } \\
\text { respect to the time of } \\
\text { collection of laboratory } \\
\text { specimens }\end{array}$ & $\begin{array}{l}\text { Blisters } \\
\text { induced over a } \\
\text { representative } \\
\text { skin lesion }\end{array}$ & T cell subsets in situ & $\begin{array}{l}\text { The lesions of chronic ENL showed a decreased number of } \\
\mathrm{CD} 8^{+} \text {cells and increased helper/suppressor ratio compared } \\
\text { to those in acute ENL and non-reactional leprosy; Systemic } \\
\text { administration of corticosteroids caused a reduction in the } \\
\mathrm{CD} 4^{+} \text {cell population but did not change } \mathrm{CD} 8^{+} \text {cell population }\end{array}$ \\
\hline
\end{tabular}


TABLE 3 | Continued

\begin{tabular}{|c|c|c|c|c|c|c|c|}
\hline $\begin{array}{l}\text { Reference; } \\
\text { study site(s) }\end{array}$ & Study population & $\begin{array}{l}\text { Timing of } \\
\text { sampling }\end{array}$ & MDT status & ENL treatment status & $\begin{array}{l}\text { Type of } \\
\text { samples }\end{array}$ & Measures & Findings \\
\hline $\begin{array}{l}\text { Rea and Modlin } \\
\text { (102); USA } \delta\end{array}$ & ND & ND & ND & ND & Skin & $\begin{array}{l}\text { T-cell phenotypes: CD4+ } \\
\text { versus } C D 8^{+} \text {cells, } \gamma / \delta \\
\text { and } \alpha / \beta \text { receptor-bearing } \\
\text { lymphocytes, T-memory } \\
\text { and T-naiive cells }\end{array}$ & $\begin{array}{l}\text { ENL lesions predominance of } \mathrm{CD} 4^{+} \text {cells similar to those in } \\
\text { tuberculoid (TT/BT?) and T1R } \\
\text { LL patients showed an excess of } \mathrm{CD} 8^{+} \text {cells }\end{array}$ \\
\hline $\begin{array}{l}\text { Tyagi et al. (53); } \\
\text { India }\end{array}$ & 4 TT/BT, 5 BL/LL, 4 ENL & ND & ND & ND & Blood & $\begin{array}{l}\text { Effect of isolated } \\
\text { circulating ICs from BL/ } \\
\text { LL or ENL patients to } \\
\text { lymphocyte transformation } \\
\text { test on T cells of HC }\end{array}$ & $\begin{array}{l}\text { PEG precipitates isolated from BL/LL or ENL subjects had } \\
\text { a significant suppressive effect on lymphocyte proliferation } \\
\text { in } \mathrm{HC}\end{array}$ \\
\hline $\begin{array}{l}\text { Foss et al. (128); } \\
\text { Brazil } \delta\end{array}$ & $\begin{array}{l}28 \text { lepromatous: } 11 \mathrm{ENL} \text {, } \\
23 \text { tuberculoid, } 19 \mathrm{HC}\end{array}$ & ND & $\begin{array}{l}\text { lepromatous } \\
\text { patients } 86 \% \\
\text { treated with } \\
\text { dapsone }\end{array}$ & $\begin{array}{l}11 \text { ENL at time of } \\
\text { blood collection no } \\
\text { immunosuppressive } \\
\text { drug }\end{array}$ & Blood & $\begin{array}{l}\text { T lymphocyte response to } \\
\text { concanavalin A }\end{array}$ & $\begin{array}{l}\text { Marked reduction on concanavalin A-induced } \\
\text { lymphoproliferation in patients with ENL }\end{array}$ \\
\hline $\begin{array}{l}\text { Santos et al. } \\
\text { (129); Brazil } \varepsilon\end{array}$ & $\begin{array}{l}59 \mathrm{LL} / \mathrm{BL}, 10 \mathrm{ENL}, 4 \mathrm{~T} 1 \mathrm{R}, \\
4 \text { post-reactional }\end{array}$ & ND & On MDT & $\begin{array}{l}\text { No specific treatment } \\
\text { for reactions before } \\
\text { blood collection }\end{array}$ & PBMC & $\begin{array}{l}\text { Lymphocyte proliferation } \\
\text { after ConA and M. leprae }\end{array}$ & $\begin{array}{l}\text { T1R showed greater lymphocyte proliferation compared to all } \\
\text { other groups }\end{array}$ \\
\hline $\begin{array}{l}\text { de la Barrera } \\
\text { et al. (130); } \\
\text { Argentina }\end{array}$ & $\begin{array}{l}7 \text { TT/BT, } 20 \mathrm{BL} / \mathrm{LL} \text { of } \\
\text { which } 3 \mathrm{ENL}\end{array}$ & ND & $\begin{array}{l}\text { All patients on } \\
\text { MDT }\end{array}$ & ND & PBMC & $\begin{array}{l}\text { T-cell cytotoxic activity } \\
\text { induced by M. leprae and } \\
\text { M.tb heat shock protein } \\
\text { (HSP) }\end{array}$ & $\begin{array}{l}\text { M. leprae hsp65 induced cytotoxic responses only in those } \\
\text { MB patients undergoing ENL }\end{array}$ \\
\hline $\begin{array}{l}\text { Vieira et al. } \\
\text { (131); Brazil } \delta, \varepsilon\end{array}$ & $\begin{array}{l}95 \mathrm{MB} \text { leprosy } \\
\text { (30LL/65BL) of which } \\
51 \mathrm{ENL}\end{array}$ & $\begin{array}{l}\text { At leprosy } \\
\text { diagnosis } \\
\text { and at onset } \\
\text { of reactional } \\
\text { episode }\end{array}$ & $\begin{array}{l}\text { Time of MDT for } \\
\text { each ENL }\end{array}$ & $\begin{array}{l}\text { Sample before } \\
\text { thalidomide and } \\
\text { steroids? }\end{array}$ & PBMC & $\begin{array}{l}\text { Lymphocyte } \\
\text { transformation test (LTT) }\end{array}$ & $\begin{array}{l}\text { Some patients showed lymphoproliferative response during } \\
\text { ENL }\end{array}$ \\
\hline $\begin{array}{l}\text { Mahaisavariya } \\
\text { et al. (103); } \\
\text { Thailand }\end{array}$ & $\begin{array}{l}17 \text { non-reactional, } 8 \mathrm{~T} 1 \mathrm{R} \text {, } \\
12 \mathrm{ENL}\end{array}$ & $\begin{array}{l}\text { Biopsy at } \\
\text { the time of } \\
\text { diagnosis and } \\
\text { not the time of } \\
\text { reaction }\end{array}$ & ND & ND & Skin & T-lymphocyte subsets & $\begin{array}{l}\text { \%age of CD8 infiltration reduced in ENL compared with non- } \\
\text { reactional lepromatous } \\
\text { The } C D 4^{+} / C D 8^{+} \text {ratio of ENL statistically significant higher } \\
\text { than from the non-reactional lepromatous group }\end{array}$ \\
\hline $\begin{array}{l}\text { Tadesse et al. } \\
\text { (132); Ethiopia } \delta\end{array}$ & $\begin{array}{l}33 \text { leprosy: } 14 \mathrm{BT}, 11 \mathrm{BT} \\
\text { T1R, } 8 \mathrm{ENL}, 11 \mathrm{HC}\end{array}$ & ND & $\begin{array}{l}\text { Certain leprosy } \\
\text { patients were } \\
\text { treated on MDT }\end{array}$ & $\begin{array}{l}\text { All ENL treated with } \\
\text { steroids }\end{array}$ & PBMC & $\begin{array}{l}\text { Lymphocyte blast } \\
\text { transformation }\end{array}$ & $\begin{array}{l}\text { Thalidomide treatment did not alter the lymphoproliferative } \\
\text { response to the mycobacterial antigens during ENL }\end{array}$ \\
\hline $\begin{array}{l}\text { Mohanty et al. } \\
\text { (133); India }\end{array}$ & $\begin{array}{l}21 \mathrm{BL} / \mathrm{LL} \text { ENL, } 38 \mathrm{TT} / \mathrm{BT} / \\
\mathrm{BL} / \mathrm{LL}, 29 \mathrm{BT} / \mathrm{BL} \mathrm{T} 1 \mathrm{R} \\
19 \mathrm{HC}\end{array}$ & ND & ND & ND & $\begin{array}{l}\text { PBMC } \\
\text { Serum }\end{array}$ & $\begin{array}{l}\text { Immune responses } \\
\text { against Stress } \\
\text { proteins of } M \text {. leprae } \\
\text { (lymphoproliferation) }\end{array}$ & $\begin{array}{l}\text { ENL: no significant role of stress proteins except a } \\
\text { heightened lymphoproliferative response to the } 28 \mathrm{kDa} \\
\text { antigen }\end{array}$ \\
\hline
\end{tabular}


TABLE 3 | Continued

\begin{tabular}{|c|c|c|c|c|c|c|c|}
\hline $\begin{array}{l}\text { Reference; } \\
\text { study site(s) }\end{array}$ & Study population & $\begin{array}{l}\text { Timing of } \\
\text { sampling }\end{array}$ & MDT status & ENL treatment status & $\begin{array}{l}\text { Type of } \\
\text { samples }\end{array}$ & Measures & Findings \\
\hline $\begin{array}{l}\text { Villahermosa } \\
\text { et al. (134); } \\
\text { Philippines } \delta, \varepsilon\end{array}$ & $22 \mathrm{ENL}$ & $\begin{array}{l}\text { Before } \\
\text { thalidomide and } \\
\text { at study weeks } \\
3 \text { and } 7 \text { during } \\
\text { thalidomide }\end{array}$ & $\begin{array}{l}\text { MDT continued } \\
\text { during the study }\end{array}$ & $\begin{array}{l}\text { Samples untreated for } \\
\text { antireactional drugs } \\
\text { and during thalidomide } \\
\text { treatment }\end{array}$ & $\begin{array}{l}\text { Blood } \\
\text { PMBC }\end{array}$ & $\begin{array}{l}\text { Lymphocyte proliferation } \\
\text { assays (LPA) to } \\
\text { phytohemagglutinin and } \\
\text { concanavalin A }\end{array}$ & $\begin{array}{l}\text { Low LPA values pre-thalidomide in both PBMC and whole } \\
\text { blood }\end{array}$ \\
\hline $\begin{array}{l}\text { Attia et al. (107); } \\
\text { Egypt }\end{array}$ & 38 leprosy: 6 ENL, 38 HC & $\begin{array}{l}\text { Untreated } \\
\text { samples }\end{array}$ & $\begin{array}{l}\text { Untreated } \\
\text { samples }\end{array}$ & $\begin{array}{l}\text { Untreated samples; } \\
\text { excluded patients on } \\
\text { immunosuppressive } \\
\text { drugs }\end{array}$ & Blood & $\begin{array}{l}\text { Frequency of circulating } \\
\text { Tregs; FoxP3 expression }\end{array}$ & $\begin{array}{l}\text { Significantly lower frequency of Tregs but higher FoxP3 } \\
\text { expression in ENL }\end{array}$ \\
\hline $\begin{array}{l}\text { Massone et al. } \\
\text { (116); Brazil } \varepsilon\end{array}$ & 20 leprosy: 3 ENL & $\begin{array}{l}\text { Biopsies at } \\
\text { the time of } \\
\text { diagnosis }\end{array}$ & $\begin{array}{l}10,12 \text { and } \\
13 \text { months after } \\
\text { beginning of } \\
\text { MDT for LL }\end{array}$ & $\begin{array}{l}\text { Untreated for } \\
\text { antireactional treatment }\end{array}$ & Skin & $\begin{array}{l}\text { Presence, frequency and } \\
\text { distribution of Tregs }\end{array}$ & $\begin{array}{l}\text { No statistical difference in FoxP3 expression between TT, BT, } \\
\text { BL, and LL } \\
\text { Significant increase in FoxP3 expression in T1R compared } \\
\text { to ENL }\end{array}$ \\
\hline $\begin{array}{l}\text { Rada et al. (135); } \\
\text { Venezuela } \varepsilon\end{array}$ & $\begin{array}{l}\text { ? ENL81 LL, } 41 \mathrm{BL}, 41 \\
\mathrm{BB}, 3 \% \mathrm{BT}\end{array}$ & ND & ND & ND & Blood & $\begin{array}{l}\text { Cell-mediated } \\
\text { immunological tests to } \\
\text { mycobacterial proteins }\end{array}$ & $\begin{array}{l}\text { T-lymphocyte proliferative response in reactional and non- } \\
\text { reactional patients was negative }\end{array}$ \\
\hline $\begin{array}{l}\text { Saini et al. (136); } \\
\text { India } \delta\end{array}$ & $21 \mathrm{MB}: 16 \mathrm{ENL}, 5 \mathrm{~T} 1 \mathrm{R}$ & $\begin{array}{l}\text { ENL blood } \\
\text { during reaction } \\
\text { and at } 0.5 \text { and } \\
1 \text { year after } \\
\text { the onset of } \\
\text { reaction }\end{array}$ & $\begin{array}{l}\text { Duration of MDT } \\
\text { described }\end{array}$ & $\begin{array}{l}\text { ENL patients received } \\
\text { steroids }\end{array}$ & PBMC & $\begin{array}{l}\text { Lymphoproliferation of } \\
\text { PBMC stimulated with M. } \\
\text { leprae, recombinant Lsr2 } \\
\text { and } 6 \text { synthetic peptides } \\
\text { spanning the Lsr2 }\end{array}$ & $\begin{array}{l}\text { All patients with active } E N L \text { showed lymphoproliferation in } \\
\text { response to peptides } A \text { and } F\end{array}$ \\
\hline $\begin{array}{l}\text { Abdallah et al. } \\
\text { (109); Egypt } \delta\end{array}$ & 43 leprosy: 6 ENL, $40 \mathrm{HC}$ & $\begin{array}{l}\text { Untreated } \\
\text { patients }\end{array}$ & $\begin{array}{l}\text { Untreated } \\
\text { samples }\end{array}$ & Untreated & Blood & Circulating Tregs & Tregs/Teffs lowest in ENL \\
\hline $\begin{array}{l}\text { Attia et al. (110); } \\
\text { Egypt } \delta\end{array}$ & 43 leprosy: 6 ENL, 40 HC & $\begin{array}{l}\text { Untreated } \\
\text { patients }\end{array}$ & $\begin{array}{l}\text { Untreated } \\
\text { samples }\end{array}$ & Untreated & Blood & $\begin{array}{l}\mathrm{CD} 4(+) \mathrm{CD} 25 \text { (high)Foxp3 } \\
\text { (+) regulatory cells }\end{array}$ & $\begin{array}{l}\text { CD4(+)CD25(high)FoxP3(+) Treg levels lowest in ENL } \\
\text { Treg/Teffs lowest in ENL }\end{array}$ \\
\hline $\begin{array}{l}\text { Hussain et al. } \\
\text { (92); India }\end{array}$ & $\begin{array}{l}50 \text { leprosy (28 without } \\
\text { reactions, } 11 \text { T1R, } \\
11 \text { ENL), } 50 \text { HC, } 50 \\
\text { pulmonary TB ( } 25 \text { HIV- } \\
\text { TB co-infected and } 25 \\
\text { without HIV infection), } 50 \\
\text { HIV-positive }\end{array}$ & ND & $\begin{array}{l}\text { Reactional } \\
\text { episodes } \\
\text { following } \\
\text { antileprosy } \\
\text { treatment }\end{array}$ & ND & Blood & $\begin{array}{l}\mathrm{CD} 3^{+}, \mathrm{CD} 4^{+}, \mathrm{CD} 8^{+} \text {and } \\
\mathrm{CD} 4^{+} / \mathrm{CD} 8^{+} \text {ratio with flow } \\
\text { cytometry }\end{array}$ & $\begin{array}{l}\mathrm{CD} 4^{+} \text {counts raised during ENL compared to MB patients } \\
\text { whereas } \mathrm{CD} 8^{+} \text {counts lower The } \mathrm{CD} 4^{+} / \mathrm{CD} 8^{+} \text {ratio doubled } \\
\text { during reactional episodes of } \mathrm{T} 1 \mathrm{R} \text { and } \mathrm{ENL}\end{array}$ \\
\hline $\begin{array}{l}\text { Parente et al. } \\
\text { (137); Brazil }\end{array}$ & $\begin{array}{l}2 \text { ENL, } 103 \text { leprosy } \\
\pi / B T / B B / B L / L L 9 \\
\text { indeterminate, } 8 \text { T1R }\end{array}$ & $\begin{array}{l}2 \text { ENL: } 12 \text { and } \\
10 \text { months } \\
\text { after initiation of } \\
\text { MDT }\end{array}$ & $\begin{array}{l}2 \text { ENL after } \\
\text { initiation of MDT }\end{array}$ & ND & Skin & $\begin{array}{l}\text { Frequency and distribution } \\
\text { of regulatory } T \text { cells }\end{array}$ & No significant differences in ENL \\
\hline
\end{tabular}




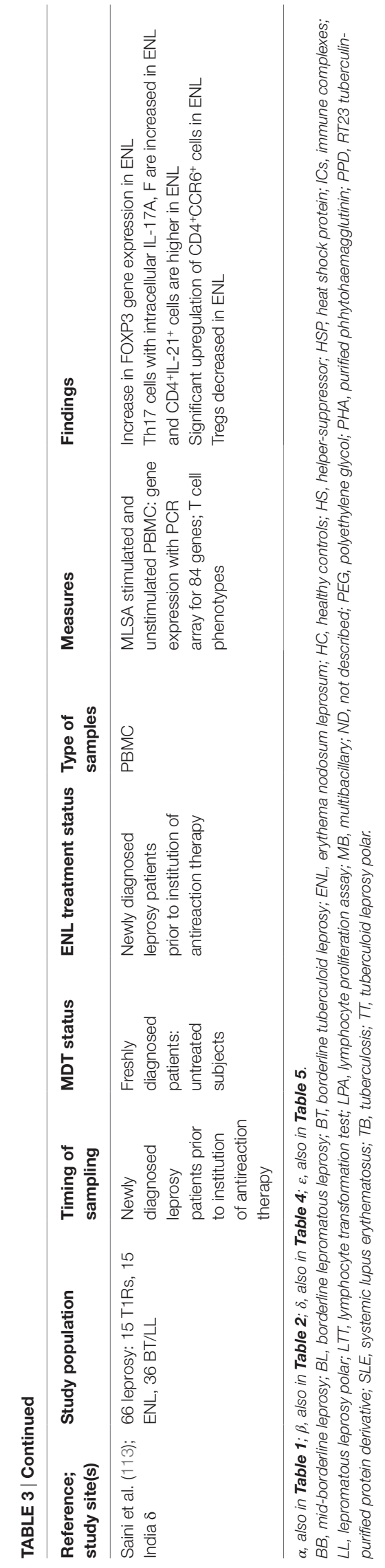

\section{WHAT IS THE ROLE OF TNF- $\alpha$ OR OTHER CYTOKINES IN ENL?}

A role for TNF- $\alpha$ in ENL was first suggested by a Brazilian study that included 18 ENL patients at various stages of treatment with steroids or thalidomide (138). Serum TNF- $\alpha$ levels varied widely: from undetectable to extremely high levels (138). There was no obvious correlation between severity of ENL and cytokine levels, while patients who had received treatment had lower levels of TNF- $\alpha$ (138). High serum TNF- $\alpha$ levels were subsequently shown to decrease significantly during thalidomide treatment (139). These findings have been reproduced in other populations measuring serum TNF- $\alpha$ levels $(128,131$, $140-147)$, whereas two studies failed to show increased levels of serum TNF- $\alpha$ during ENL $(148,149)$. The high variability in serum TNF- $\alpha$ between studies might be due to patient differences. Although genetic differences between different ethnic groups cannot be ruled out, it still remains unclear why there is such a high variability in the TNF- $\alpha$ levels between individuals presenting ENL.

A study of the plasma levels of TNF- $\alpha$ reported increased levels during ENL (150) while other studies contradicted this finding $(115,134,151)$. In fact, Haslett et al., which included 20 male ENL patients excluding patients with moderate or severe ENL-associated neuritis, reported circulating plasma TNF- $\alpha$ levels to be lower at time of ENL diagnosis than LL controls (115). There was an upward trend in plasma TNF- $\alpha$ levels during thalidomide treatment which returned to baseline levels after discontinuation of thalidomide (115). This is an indication that thalidomide may in fact stimulate paradoxical overproduction of TNF- $\alpha$ (115). The inhibition of TNF- $\alpha$ by thalidomide may be prominent when macrophage production of this cytokine is high but in mild disease plasma levels may not reflect lesional TNF- $\alpha$ production (115). Increased TNF- $\alpha$ levels after thalidomide treatment has been described in other conditions such as toxic epidermal necrolysis (152) and aphthous ulcers in patients with human immunodeficiency virus infection (153). It has been suggested that the mechanism of the paradoxical overproduction of TNF- $\alpha$ by thalidomide could be due to the propensity of thalidomide to costimulate T-cells to produce cytokines including TNF- $\alpha$ (154). All the patients in the study of Haslett et al. showed improvement in ENL after receiving thalidomide during the first 21 days of treatment (115).

Interestingly, the studies that measured the ex vivo PBMC production of TNF- $\alpha$ in response to lipopolysaccharide, BCG, or M. leprae in patients with ENL as compared to BL/LL patients showed consistently greater amounts of TNF- $\alpha$ secretion in patients with ENL (150, 155-157).

The successful use of the anti-TNF therapy with infliximab and etanercept in three patients with ENL, resulting reduction of inflammation and treatment of ENL, is additional evidence of the inflammatory role of TNF- $\alpha$ in ENL (158-160).

The results of studies on IFN- $\gamma$ are more consistent than those on TNF- $\alpha$ suggesting an important role for IFN- $\gamma$ in the pathophysiology and occurrence of ENL. A clinical trial administered recombinant IFN- $\gamma$ to BL/LL patients as a replacement therapy because LL is characterized by anergy to antigens of $M$. leprae 
and inability to produce IFN- $\gamma$ (150). Repeated intradermal injection of recombinant IFN- $\gamma$ induced ENL in 6 out of $10 \mathrm{BL} /$ LL patients within 7 months compared to an incidence of $15 \%$ per year in patients who received MDT alone (150). Elevated serum IFN- $\gamma$ was found in patients with ENL who also had high TNF- $\alpha$ levels (139). Other studies have demonstrated an increase of serum IFN- $\gamma(143,144,148)$ and an increase of IFN- $\gamma$ mRNA in PBMC (161-163) and in skin biopsies (161, 164) during ENL. There is a study reporting serum IFN- $\gamma$ to be significantly lower in patients at the onset of ENL, which increased after thalidomide treatment (142). However, IFN- $\gamma$ has been identified by Ingenuity Pathway Analysis networks as the second most significant upstream regulator (after CCL5) of the expression changes in microarrays performed in PBMC derived from patients with ENL (58).

There are contradictory findings about the role of serum IL-1 $\beta$ levels. Most studies have reported that serum IL-1 $\beta$ levels may have a prognostic value for developing $\operatorname{ENL}(144,148,165,166)$ and that there is a statistically significant correlation between TNF- $\alpha$ and IL-1 $\beta$ (140). However, studies failed to show any association of serum IL-1 $\beta$ or plasma IL- $1 \beta$ with $\operatorname{ENL~}(138,151)$. IL-1 $\beta$ mRNA in PBMC was upregulated at the onset of ENL (161) but not in skin lesions (167).

IL-2 has a key role in the immune system primarily by its direct effects on T-cells such as promoting differentiation of different T-cell subsets and contributing to the development of T-cell immunological memory. IL-2 signals through the IL-2 receptor (IL2R), which is essential for the signaling in T-cells. There were no differences in the serum IL-2 or IL2 mRNA in skin biopsies between ENL and patients with LL (115, 148, 151). However, four studies reported an increase in soluble IL-2 receptor (sIL2R) levels $(115,131,165,168)$ or IL2Rp55 mRNA in PBMC (161) in patients with ENL.

Serum IL-6 $(147,151,169,170)$ and IL-6 mRNA in PBMC and skin (161) have been reported to be elevated during ENL. IL-6 tag single-nucleotide polymorphisms have been reported to be a risk factor for ENL (170) and IL-6 plasma levels were correlated with the IL-6 genotypes (170). A study reported increased serum IL-6 receptor (sIL6R) levels in ENL, which declined significantly after the completion of a corticosteroid treatment (143). However, other studies did not show associations of IL-6 serum levels with ENL $(134,139,143)$.

An ex vivo study in PBMC isolated from ENL patients and LL controls showed a correlation of raised levels of cytokines IL-17A and its isomers as well as other Th17-associated cytokines IL-21, IL-22, and IL-23 with ENL (113). However, other studies failed to detect an association of ENL with serum IL-17 $(110,151,171)$.

There are 49 studies measuring cytokines in ENL (Table 4), and the majority of these studies show a significant increase of the pro-inflammatory cytokines during ENL. TNF- $\alpha$ appears to be a regulator of the condition while there is substantial evidence supporting a role for IFN- $\gamma$ as well. There is also evidence that other cytokines such as IL-1 $\beta$ and IL-6 or cytokine receptors such as sIL2R and sIL6R are also involved. Therefore, inhibitors of these molecules may be useful in a clinical setting. It is possible that genetic differences could account for differences observed between studies but methodological differences are also likely factors.

\section{WHAT OTHER IMMUNE MECHANISMS ARE IMPLICATED IN ENL?}

Sixty-four studies on other immunological factors in ENL have been performed (Table 5).

\section{Innate Immunity}

Genetic studies have shown associations between several singlenucleotide polymorphisms (SNP) of innate immunity genes such as NOD2 (210), the natural resistance-associated macrophage protein (NRAMP1) (211), and TLR1 $(212,213)$ with ENL.

A recent study from Brazil, which investigated whether DNA sensing via TLR9, constitutes a major inflammatory pathway during ENL (80) showed that both the skin lesions and peripheral leukocytes (B-cells, monocytes, and plasmacytoid dendritic cells) of ENL patients express higher TLR9 levels than BL/LL controls (80). In addition, the levels of endogenous human and pathogenderived TLR9 ligands (human and mycobacterial DNA-histone complexes) were also higher in the circulation of ENL patients than BL/LL controls (80). Furthermore, stimulation of PBMC isolated from ENL patients with TLR9 agonist led to higher levels of TNF- $\alpha$, IL- 6 , and IL- $1 \beta$, than those of non-reactional leprosy and healthy controls. Usage of a TLR9 synthetic antagonist was able to significantly inhibit the secretion of pro-inflammatory cytokines after stimulation with $M$. leprae lysate (80). This is the first study to support the potential of TLR signaling inhibitors as a therapeutic strategy for ENL (80).

\section{B-Lymphocytes and Immunoglobulins}

Early studies enumerated B lymphocytes in skin lesions (89) and in peripheral blood $(76,78,94,123)$ of patients with ENL, while most of these studies did not find any association between B-cells and the development of ENL. Other studies looked at the IgM PGL-I in sera as a marker for ENL $(40,184,192,206)$, but most of these studies did not show an association (50, 82, 149, 187, 194, 205). Significantly lower serum levels of IgG1 and IgG3 subclasses of $M$. leprae-specific antibodies have been demonstrated in ENL patients compared to the BL/LL controls (190). This decrease of M. leprae-specific IgG1 and IgG3 antibodies in sera has not been related to downregulation of $\mathrm{B}$ cell responses since ENL episodes were characterized by an increase of polyclonal IgG1 antibody synthesis by the B cells, declining after subsidence of the reaction (191). The authors suggested that activation of B-cells is restricted to IgG1-secreting B cells in the blood of patients with lepromatous disease (191), while the lower serum concentrations of M. leprae-specific IgG1 and IgG3 (190) could be due to antibody deposition in the tissues (191). Interestingly, surface CD64 (Fc $\gamma \mathrm{RI}$ ), the high-affinity receptor for monomeric IgG1 and IgG3 is expressed at higher levels on circulating neutrophils derived from ENL patients compared to non-reactional leprosy controls (25). The higher CD64 neutrophil expression could explain the presence of lower serum IgG1 and IgG3 levels in ENL patients compared to BL/LL controls. 
TABLE 4 | Human studies on ENL investigating cytokines.

\begin{tabular}{|c|c|c|c|c|c|c|c|}
\hline $\begin{array}{l}\text { Reference; } \\
\text { study site(s) }\end{array}$ & Study population & $\begin{array}{l}\text { Timing of } \\
\text { sampling }\end{array}$ & MDT status & ENL treatment status & Type of samples & Measures & Findings \\
\hline $\begin{array}{l}\text { Filley et al. (168); } \\
\text { India } \varepsilon\end{array}$ & $7 \mathrm{ENL}$ & $\begin{array}{l}\text { Before, during and } \\
\text { after the episode }\end{array}$ & $\begin{array}{l}\text { All patients on } \\
\text { MDT }\end{array}$ & $\begin{array}{l}\text { ENL treated with } \\
\text { steroids and/or } \\
\text { thalidomide }\end{array}$ & Serum & IL2R & IL2R increase during ENL \\
\hline $\begin{array}{l}\text { Rea and Modlin } \\
\text { (102); USA } \gamma\end{array}$ & ND & ND & ND & ND & Skin & $\begin{array}{l}\text { IL-2 positive and } \\
\text { IFN- } \gamma \text { positive mRNA- } \\
\text { bearing lymphocytes }\end{array}$ & $\begin{array}{l}\text { IL2- positive lymphocytes prevalent in ENL and in tuberculoid } \\
\text { lesions } \\
\text { Cells expressing IFN- } \gamma \text { mRNA in ENL lesions slightly increased } \\
\text { compared to lepromatous }\end{array}$ \\
\hline $\begin{array}{l}\text { Sarno et al. (138); } \\
\text { Brazil }\end{array}$ & $\begin{array}{l}18 \mathrm{ENL}, 39 \mathrm{BT} / \\
\mathrm{BL} / \mathrm{BB} / \mathrm{LL}, 4 \mathrm{~T} 1 \mathrm{R}\end{array}$ & ND & $\begin{array}{l}16 / 18 \text { patients on } \\
\text { various stages of } \\
\text { MDT/2 untreated }\end{array}$ & $\begin{array}{l}3 \text { ENL on thalidomide } \\
\text { and } 7 \text { ENL on } \\
\text { prednisone; others } \\
\text { untreated for reaction }\end{array}$ & Serum & $\begin{array}{l}\text { Tumor necrosis factor } \\
\text { (TNF)- } \alpha \text { and IL-1 }\end{array}$ & $\begin{array}{l}\text { TNF varied from undetectable to extremely high levels in ENL } \\
\text { No correlation between severity of ENL and cytokine level } \\
\text { Neither TNF nor IL-1 correlate with number or duration of ENL } \\
\text { episodes } \\
\text { Treated patients with steroids or thalidomide lower TNF }\end{array}$ \\
\hline $\begin{array}{l}\text { Sehgal et al. } \\
\text { (172); India }\end{array}$ & $\begin{array}{l}11 \mathrm{ENL}, 14 \mathrm{~T} 1 \mathrm{R}, \\
20 \text { leprosy non- } \\
\text { reactional, } 10 \mathrm{HC}\end{array}$ & $\begin{array}{l}\text { Before starting } \\
\text { antireactional } \\
\text { treatment and when } \\
\text { clinical signs of } \\
\text { reaction had abated }\end{array}$ & On MDT & $\begin{array}{l}\text { Samples before } \\
\text { and after starting } \\
\text { antireactional treatment }\end{array}$ & Serum & $\mathrm{IL}-2 \mathrm{R}$ & T1R upgrading group higher IL-2R than ENL \\
\hline $\begin{array}{l}\text { Sullivan et al. } \\
\text { (173); USA } \varepsilon\end{array}$ & ND & ND & ND & ND & Skin & $\begin{array}{l}\text { IFN- } \gamma \text { and TNF- } \alpha \\
\text { mRNA }\end{array}$ & $\begin{array}{l}\text { IFN- } \gamma \text { mRNA in ENL similar to tuberculoid } \\
\text { In LL and ENL lesions about } 0.2 \% \text { of cells expressed TNF- } \alpha\end{array}$ \\
\hline $\begin{array}{l}\text { Barnes et al. } \\
\text { (155); USA }\end{array}$ & $\begin{array}{l}12 \text { active ENL, } 14 \\
\text { inactive ENL, } 6 \\
\text { T1R; } 11 \mathrm{LL}\end{array}$ & ND & $\begin{array}{l}\text { All patients had } \\
\text { received less } \\
\text { than } 5 \text { years } \\
\text { chemotherapy }\end{array}$ & ND & PBMC & TNF- $\alpha$ & $\begin{array}{l}\text { ENL: the levels of TNF- } \alpha \text { release by PBMC were higher than } \\
\text { any other leprosy } \\
\text { Thalidomide reduced TNF- } \alpha \text { by more than } 90 \%\end{array}$ \\
\hline $\begin{array}{l}\text { Parida et al. } \\
\text { (140); India }\end{array}$ & $\begin{array}{l}12 \text { ENL, } 64 \\
\text { leprosy TT/BT/BB/ } \\
\text { BL/LL, } 14 \text { T1R }\end{array}$ & ND & $\begin{array}{l}\text { Most patients } \\
\text { before MDT } \\
\text { treatment }\end{array}$ & ND & Serum & TNF and IL-1 & $\begin{array}{l}\text { Patients undergoing T1R or ENL showed high TNF levels } \\
\text { Significant correlation between TNF and IL-1 in reaction }\end{array}$ \\
\hline $\begin{array}{l}\text { Sampaio et al. } \\
\text { (150); Brazil and } \\
\text { USA }\end{array}$ & $\begin{array}{l}13 \mathrm{LL} E N L, 15 \mathrm{LL}, \\
9 \mathrm{HC}\end{array}$ & ND & $\begin{array}{l}\text { All patients were } \\
\text { receiving MDT } \\
\text { during the study. }\end{array}$ & $\begin{array}{l}7 \text { ENL patient blood } \\
\text { samples before } \\
\text { starting treatment } \\
\text { with thalidomide and } \\
61-2 \text { weeks after } \\
\text { thalidomide }\end{array}$ & $\begin{array}{l}\text { Plasma } \\
\text { PBMC } \\
\text { Monocytes }\end{array}$ & TNF- $\alpha$ & $\begin{array}{l}\text { ENL patients greater release of TNF- } \alpha \text { from monocytes } \\
\text { High plasma TNF- } \alpha \text { in ENL }\end{array}$ \\
\hline $\begin{array}{l}\text { Bhattacharaya } \\
\text { et al. (146); India }\end{array}$ & $\begin{array}{l}11 \mathrm{ENL}, 14 \mathrm{T1R}, \\
20 \text { leprosy without } \\
\text { reactions, } 20 \mathrm{HC}\end{array}$ & $\begin{array}{l}\text { Before treatment } \\
\text { and after clinical } \\
\text { remission of reaction }\end{array}$ & on MDT & $\begin{array}{l}\text { Before antireactional } \\
\text { treatment with steroids }\end{array}$ & Serum & TNF & $\begin{array}{l}\text { TNF levels in acute ENL were higher but not significant and } \\
\text { rose to become significant following treatment and clinical } \\
\text { remission than } \mathrm{HC} \text { and MB controls }\end{array}$ \\
\hline $\begin{array}{l}\text { Foss et al. (128); } \\
\text { Brazil } \gamma\end{array}$ & $\begin{array}{l}28 \text { lepromatous: } \\
11 \text { ENL, } 23 \\
\text { tuberculoid, } 19 \\
\text { HC }\end{array}$ & ND & $\begin{array}{l}86 \% \text { of } \\
\text { lepromatous } \\
\text { patients treated } \\
\text { with dapsone }\end{array}$ & $\begin{array}{l}\text { Time of blood collection } \\
\text { no immunosuppressive } \\
\text { drug }\end{array}$ & Serum & TNF- $\alpha$ & TNF was elevated in the serum of ENL patients \\
\hline
\end{tabular}


TABLE 4 | Continued

\begin{tabular}{|c|c|c|c|c|c|c|c|}
\hline $\begin{array}{l}\text { Reference; } \\
\text { study site(s) }\end{array}$ & Study population & $\begin{array}{l}\text { Timing of } \\
\text { sampling }\end{array}$ & MDT status & ENL treatment status & Type of samples & Measures & Findings \\
\hline $\begin{array}{l}\text { Sampaio et al. } \\
\text { (139); Brazil } \varepsilon\end{array}$ & $\begin{array}{l}49 \text { BL/LL: } 24 \\
\text { developed ENL }\end{array}$ & $\begin{array}{l}\text { At the time of } \\
\text { developing ENL, } \\
\text { during thalidomide } \\
\text { treatment, or } \\
\text { after thalidomide } \\
\text { treatment was } \\
\text { discontinued; } \\
\text { collected at } \\
1-3,6-7 \text {, and/ } \\
\text { or } 13-21 \text { days of } \\
\text { thalidomide and } \\
1-2 \text { months after } \\
\text { thalidomide }\end{array}$ & $\begin{array}{l}\text { MDT was } \\
\text { continued through } \\
\text { the study }\end{array}$ & $\begin{array}{l}\text { Thalidomide treatment } \\
\text { for ENL }\end{array}$ & Sera & TNF- $\alpha$, IL-6, IFN- $\gamma$ & $\begin{array}{l}\text { ENL highest TNF- } \alpha \text { levels, which decreased significantly } \\
\text { during thalidomide treatment Serum IFN- } \gamma \text { elevated in patients } \\
\text { with high TNF- } \alpha \text { levels }\end{array}$ \\
\hline $\begin{array}{l}\text { Santos et al. } \\
\text { (156); Brazil }\end{array}$ & $\begin{array}{l}14 \mathrm{ENL}(4 \mathrm{BL} / 10 \\
\mathrm{LL}), 12 \mathrm{BL} / \mathrm{LL} \\
11 \mathrm{HC}, 4 \mathrm{ENL} \\
\text { post-reactions }\end{array}$ & ND & $\begin{array}{l}\text { Half untreated } \\
\text { and the other half } \\
\text { treated with MDT }\end{array}$ & $\begin{array}{l}\text { ENL patients } \\
\text { were treated with } \\
\text { thalidomide? }\end{array}$ & PBMC & $\begin{array}{l}\text { TNF- } \alpha \text { : spontaneous } \\
\text { and } M \text {. leprae } \\
\text { stimulated }\end{array}$ & $\begin{array}{l}\text { ENL patients showed significantly greater release of TNF- } \alpha \\
\text { both spontaneously and induced by } M \text {. leprae-induced } \\
\text { release in ENL patients }\end{array}$ \\
\hline $\begin{array}{l}\text { Vieira et al. (131); } \\
\text { Brazil } \gamma, \varepsilon\end{array}$ & $\begin{array}{l}95 \mathrm{MB}(30 \mathrm{LL} / 65 \\
\mathrm{BL}) \text { of which } 51 \\
\text { ENL }\end{array}$ & $\begin{array}{l}\text { At leprosy diagnosis } \\
\text { and at onset of } \\
\text { reactional episode }\end{array}$ & $\begin{array}{l}\text { Time of MDT for } \\
\text { each ENL }\end{array}$ & $\begin{array}{l}\text { Sample before } \\
\text { thalidomide and } \\
\text { steroids? }\end{array}$ & Serum & TNF- $\alpha$, soluble IL-2R & TNF- $\alpha$ increased in $70.6 \%$ of ENL patients \\
\hline $\begin{array}{l}\text { Memon et al. } \\
\text { (141); Pakistan }\end{array}$ & $\begin{array}{l}12 \text { ENL, } 27 \\
\text { leprosy (TT/BT/BL } \\
\text { LL), } 14 \text { household } \\
\text { contacts and } 22 \\
\text { endemic HC with } \\
\text { no known leprosy } \\
\text { contact }\end{array}$ & $\begin{array}{l}\text { At the onset of ENL } \\
\text { before initiation } \\
\text { of treatment for } \\
\text { reaction and after } \\
\text { the reaction had } \\
\text { subsided }\end{array}$ & $\begin{array}{l}\text { 10/12 ENL } \\
\text { received previous } \\
\text { MDT }\end{array}$ & $\begin{array}{l}\text { Samples before } \\
\text { antireactional treatment }\end{array}$ & Serum & TNF- $\alpha$ & $\begin{array}{l}\text { TNF levels higher during acute phase of ENL and declined } \\
\text { after clinical remission of the reaction }\end{array}$ \\
\hline $\begin{array}{l}\text { Moubasher et al. } \\
\text { (148); Egypt }\end{array}$ & $\begin{array}{l}35 \text { reactional }(19 \\
\text { ENL/16 T1R), } 55 \\
\text { leprosy, } 20 \mathrm{HC}\end{array}$ & ND & Untreated ENL? & Untreated ENL? & Serum & $\begin{array}{l}\text { IFN- } \gamma, \mathrm{IL}-2, \mathrm{IL}-2 \mathrm{R} \\
\mathrm{IL}-10, \mathrm{TNF}-\alpha, \mathrm{IL}-1 \beta\end{array}$ & $\begin{array}{l}\text { Both T1R and ENL showed significantly higher serum IFN- } \gamma \text {, } \\
\text { IL-2R and IL-1 } \beta \text { compared to non-reactional leprosy ENL } \\
\text { showed increased levels of IL-10 compared to T1R }\end{array}$ \\
\hline $\begin{array}{l}\text { Moubasher et al. } \\
\text { (165); Egypt }\end{array}$ & $\begin{array}{l}35 \text { reactional (19 } \\
\text { ENL), } 36 \text { non- } \\
\text { reactional, } 20 \mathrm{HC}\end{array}$ & $\begin{array}{l}\text { PB patients } \\
\text { assessed after } 6 \\
\text { and } 12 \text { months of } \\
\text { MDT/MB assessed } \\
\text { after } 12 \text { months of } \\
\text { MDT; Before and at } \\
\text { the end of treatment } \\
\text { with MDT }\end{array}$ & $\begin{array}{l}\text { Before and after } \\
\text { treatment with } \\
\text { MDT }\end{array}$ & $\begin{array}{l}\text { Corticosteroids were } \\
\text { given to control the } \\
\text { reactions }\end{array}$ & Serum & IL-2R, IL-10, IL-1 $\beta$ & $\begin{array}{l}\text { IL-1 } 1 \beta \text { levels may have a prognostic marker for the } \\
\text { development of reactions }\end{array}$ \\
\hline $\begin{array}{l}\text { Partida-Sanchez } \\
\text { et al. (142); } \\
\text { Mexico } \varepsilon\end{array}$ & $\begin{array}{l}9 \mathrm{ENL}, 10 \text { non- } \\
\text { ENL, } 10 \mathrm{HC}\end{array}$ & $\begin{array}{l}\text { Beginning of } \\
\text { reaction and after } \\
1 \text { and } 2 \text { months of } \\
\text { thalidomide }\end{array}$ & $\begin{array}{l}\text { All patients on } \\
\text { MDT }\end{array}$ & $\begin{array}{l}\text { Untreated samples and } \\
\text { after } 1 \text { and } 2 \text { months of } \\
\text { thalidomide }\end{array}$ & Serum & TNF- $\alpha$, IFN- $\gamma$ & $\begin{array}{l}\text { TNF- } \alpha \text { was significantly higher in ENL compared to non-ENL } \\
\text { TNF levels decreased after ENL treatment } \\
\text { IFN- } \gamma \text { significantly lower in patients at the onset of ENL and } \\
\text { increased after thalidomide }\end{array}$ \\
\hline
\end{tabular}




\begin{tabular}{|c|c|c|c|c|c|c|c|}
\hline $\begin{array}{l}\text { Reference; } \\
\text { study site(s) }\end{array}$ & Study population & $\begin{array}{l}\text { Timing of } \\
\text { sampling }\end{array}$ & MDT status & ENL treatment status & Type of samples & Measures & Findings \\
\hline $\begin{array}{l}\text { Sampaio et al. } \\
\text { (147); Brazil }\end{array}$ & $\begin{array}{l}18 \mathrm{MB} \text { with ENL } \\
(5 \mathrm{BL} / 13 \mathrm{LL})\end{array}$ & $\begin{array}{l}\text { Biopsies at } \\
\text { diagnosis, at onset } \\
\text { of reaction, and after } \\
3 \text { and/or } 7 \text { days } \\
\text { of pentoxifylline; } \\
\text { Serum: day } 0 \\
\text { (during ENL), } \\
\text { 3-7, 10-14, } 30 \\
\text { and } 60 \text { days after } \\
\text { pentoxifylline }\end{array}$ & $\begin{array}{l}7 \text { patients with } \\
\text { ENL newly } \\
\text { diagnosed; others } \\
\text { on MDT }\end{array}$ & $\begin{array}{l}\text { Pentoxyfylline, } 2 \text { ENL } \\
\text { patients on thalidomide }\end{array}$ & $\begin{array}{l}\text { PBMC } \\
\text { Serum } \\
\text { Skin }\end{array}$ & $\begin{array}{l}\text { Serum TNF- } \alpha, \text { IL-6, } \\
\text { IL-10 } \\
\text { TNF- } \alpha \text {, L-6, IL-10 } \\
\text { release by PBMC } \\
\text { following M. leprae } \\
\text { stimulation or LPS } \\
\text { stimulation } \\
\text { TNF- } \alpha \text {, IL-6, IL-10 } \\
\text { gene expression at } \\
\text { skin }\end{array}$ & $\begin{array}{l}\text { Elevated TNF- } \alpha \text { in the sera of ENL } \\
\text { Treatment with pentoxifylline reduced TNF- } \alpha \\
\text { Serum levels of IL-6 increased during ENL } \\
\text { High TNF- } \alpha \text { mRNA expression in lesions during ENL which } \\
\text { decreased following treatment with pentoxifylline } \\
\text { IL-6 mRNA reduced by up to } 50 \text {-fold after treatment }\end{array}$ \\
\hline $\begin{array}{l}\text { Moraes et al. } \\
\text { (161); Brazil }\end{array}$ & $\begin{array}{l}53 \text { leprosy: } 20 \\
\text { ENL, } 11 \text { T1R }\end{array}$ & $\begin{array}{l}\text { At the time of } \\
\text { leprosy diagnosis } \\
\text { (unreactional) and } \\
\text { at the onset of first } \\
\text { reactional episode } \\
\text { (reactional) }\end{array}$ & $\begin{array}{l}\text { MDT was } \\
\text { continued through } \\
\text { the study }\end{array}$ & $\begin{array}{l}\text { No anti-inflammatory } \\
\text { drugs at the time of } \\
\text { sample collection } \\
3 \text { patients sequential } \\
\text { sampling and after } \\
\text { thalidomide }\end{array}$ & PBMC & $\begin{array}{l}\text { IL-1 } \beta \text {, IL-6, IL-8, } \\
\text { GM-CSF, IFN- } \gamma \text {,IL- } \\
\text { 2Rp55, perforin, } \\
\text { TNF } \beta \text {, TNF- } \alpha \text { mRNA } \\
\text { in PBMC; } \\
\text { IL-4, IL-6, IL-8, IL10, } \\
\text { IL-12, IFN } \gamma \text {, TNF } \alpha \\
\text { mRNA in skin }\end{array}$ & $\begin{array}{l}\text { In } 7 \text { ENL higher incidence of IFN- } \gamma \text {, perforin, GM-CSF, IL2R } \\
\text { mRNA in blood } \\
\text { Upregulation of IL-1 } \beta \text {, IL-6, GM-CSF, IL-2R, IFN- } \gamma \text { mRNA in } \\
\text { blood at onset of ENL at } 3 \text { ENL follow-up } \\
\text { Skin lesions ENL: IFN } \gamma \text { and IL-4 differentially expressed }\end{array}$ \\
\hline $\begin{array}{l}\text { Oliveira et al. } \\
\text { (33);Brazil } \alpha\end{array}$ & $\begin{array}{l}10 \mathrm{BL} / \mathrm{LL}: 6 \mathrm{ENL} \\
10 \mathrm{HC}\end{array}$ & ND & On MDT & ND & $\begin{array}{l}\text { Blood, } \\
\text { P.B.Neutrophils }\end{array}$ & TNF- $\alpha$, IL-8 & $\begin{array}{l}\text { Stimulated neutrophils secrete IL- } 8 \text { and TNF } \alpha \\
\text { Increased TNF- } \alpha \text { secretion from neutrophils after LPS } \\
\text { stimulation } \\
\text { Thalidomide inhibited TNF- } \alpha \text { by neutrophils }\end{array}$ \\
\hline $\begin{array}{l}\text { Goulart et al. } \\
\text { (174); Brazil }\end{array}$ & $\begin{array}{l}19 \text { leprosy: } 5 \\
\text { ENL/3 T1R, } 9 \text { HC }\end{array}$ & Untreated samples & $\begin{array}{l}\text { Untreated } \\
\text { samples }\end{array}$ & Untreated samples & PBMC & $\begin{array}{l}\text { TGF- } \beta 1 \text { in } \\
\text { supernatants from } \\
\text { adherent PBMC after } \\
\text { stimulation with PGL- } \\
\text { 1, LPS or serum-free } \\
\text { RPMI }\end{array}$ & Adherent PBMC from ENL secrete higher TGF- $\beta 1$ \\
\hline $\begin{array}{l}\text { Moraes et al. } \\
\text { (164); Brazil }\end{array}$ & $\begin{array}{l}13 \mathrm{MB}: 10 \mathrm{ENL} \\
3 \mathrm{~T} 1 \mathrm{R}\end{array}$ & $\begin{array}{l}\text { Before and during } \\
\text { pentoxyfilline or } \\
\text { thalidomide }\end{array}$ & $\begin{array}{l}\text { All patients on } \\
\text { MDT }\end{array}$ & $\begin{array}{l}\text { Before and during } \\
\text { pentoxyfilline or } \\
\text { thalidomide }\end{array}$ & Skin & $\begin{array}{l}\text { mRNA expression: } \\
\text { IFN- } \gamma \text {, IL-6, IL-10, } \\
\text { IL-12 p40, TNF- } \alpha \\
\text { IL-4 }\end{array}$ & $\begin{array}{l}\text { Expression of IFN- } \gamma \text {, IL-6, IL-10, IL-12 p40, TNF- } \alpha \text { at the onset } \\
\text { of reactional episodes (T1R and ENL) but IL-4 rarely detected } \\
\text { Follow-up: TNF- } \alpha \text { mRNA and IFN- } \gamma \text {, IL- } 6 \text { and IL12p40 mRNA } \\
\text { decreased after thalidomide or pentoxyfylline }\end{array}$ \\
\hline $\begin{array}{l}\text { Nath et al. (162); } \\
\text { India }\end{array}$ & $\begin{array}{l}36 \mathrm{ENL}, 105 \mathrm{TT/} \\
\mathrm{BL} / \mathrm{LL} 7 \mathrm{~T} 1 \mathrm{R}, 9 \mathrm{HC}\end{array}$ & ND & $\begin{array}{l}\text { All patients on } \\
\text { MDT }\end{array}$ & $\begin{array}{l}\text { ENL patients before } \\
\text { antireactional treatment }\end{array}$ & PMBC & $\begin{array}{l}\text { IFN- } \gamma, \mathrm{IL}-4, \mathrm{IL}-10 \\
\mathrm{IL}-12\end{array}$ & $\begin{array}{l}\text { ENL: } 58 \% \text { demonstrated a polarized Th1 pattern with only } \\
30 \% \text { expressing both cytokines }\end{array}$ \\
\hline $\begin{array}{l}\text { Nath et al. (163); } \\
\text { India }\end{array}$ & $\begin{array}{l}1 \mathrm{BL} / 7 \mathrm{LL} \text { ENL, } 2 \\
\text { BL/6 LL8 stable }\end{array}$ & ND & $\begin{array}{l}\text { Most patients on } \\
\text { MDT }\end{array}$ & $\begin{array}{l}\text { ENL patients prior to } \\
\text { antireactional therapy }\end{array}$ & PBMC & $\begin{array}{l}\text { Real-time PCR } \\
\text { forlFN- } \gamma \text {, IL4, IL10, } \\
\text { p40 IL12 }\end{array}$ & $\begin{array}{l}\text { IFN- } \gamma \text { detectable in all and IL12p40 in half of ENL IL12p40 } \\
\text { mRNA higher in ENL compared to stable lepromatous }\end{array}$ \\
\hline $\begin{array}{l}\text { Sampaio et al. } \\
\text { (157); Brazil }\end{array}$ & $\begin{array}{l}15 \text { leprosy: } 10 \\
\text { ENL }\end{array}$ & ND & On MDT & ND & $\begin{array}{l}\text { PBMC, } \\
\text { monocytes, } \\
\text { monocytes/T- } \\
\text { lymphocytes } \\
\text { cocultures }\end{array}$ & $\begin{array}{l}\text { TNF- } \alpha \text { after } \\
\text { stimulation with } M \text {. } \\
\text { leprae }\end{array}$ & $\begin{array}{l}\text { Isolated monocytes from ENL released significantly more } \\
\text { TNF- } \alpha \text { in response to } M \text {. leprae than monocytes from } \\
\text { non-reactional }\end{array}$ \\
\hline
\end{tabular}




\begin{tabular}{|c|c|c|c|c|c|c|c|}
\hline $\begin{array}{l}\text { Reference; } \\
\text { study site(s) }\end{array}$ & Study population & $\begin{array}{l}\text { Timing of } \\
\text { sampling }\end{array}$ & MDT status & ENL treatment status & Type of samples & Measures & Findings \\
\hline $\begin{array}{l}\text { Tadesse et al. } \\
\text { (132); Ethiopia } \gamma\end{array}$ & $\begin{array}{l}14 \mathrm{BT}, 11 \mathrm{BT} \mathrm{T} 1 \mathrm{R}, \\
8 \mathrm{ENL}, 11 \mathrm{HC}\end{array}$ & ND & ND & $\begin{array}{l}\text { All ENL treated with } \\
\text { steroids }\end{array}$ & PBMC & $\begin{array}{l}\text { TNF- } \alpha \text { in culture } \\
\text { supernatants }\end{array}$ & Thalidomide resulted in suppression of TNF- $\alpha$ production \\
\hline $\begin{array}{l}\text { Haslett et al. } \\
\text { (115); Nepal }\end{array}$ & $\begin{array}{l}20 \text { ENL, } 20 \mathrm{LL} \\
\text { with no history } \\
\text { of ENL within the } \\
\text { preceding } 30 \text { days }\end{array}$ & $\begin{array}{l}\text { Blood samples: } \\
\text { days } 0,3,7,14 \text {, and } \\
28 \text { of thalidomide; } \\
\text { ELISPOT: days } 0,7 \text {, } \\
21 \text {, and } 28 \\
\text { Flow cytometry: } \\
\text { days } 0,7 \text {, and } 21 \text {; } \\
\text { qRT-PCR: PBMCs } \\
\text { days } 0,7,21\end{array}$ & $\begin{array}{l}\text { All (except } 1 \\
\text { patient) on MDT }\end{array}$ & $\begin{array}{l}\text { Excluded patients } \\
\text { who had received } \\
\text { immunomodulating } \\
\text { therapy within the } \\
\text { preceding month }\end{array}$ & $\begin{array}{l}\text { Plasma } \\
\text { T-cells } \\
\text { Skin }\end{array}$ & $\begin{array}{l}\text { Plasma levels of } \\
\text { IFN- } \gamma \text {, TNF- } \alpha \text {, soluble } \\
\text { IL2R, IL-12, IL-12 } \\
\text { p40 and IL-12 p70 } \\
\text { ELISPOT for IFN- } \gamma \text {; } \\
\text { Flow cytometry for } \\
\text { cytokine production } \\
\text { by T cells } \\
\text { qPCR: IL-2 genes }\end{array}$ & $\begin{array}{l}\text { Circulating TNF- } \alpha \text { levels lower at ENL diagnosis than controls } \\
\text { Upward trend during thalidomide ENL baseline plasma levels } \\
\text { of IL-12 lower than control } \\
\text { Baseline levels of sIL2R higher in ENL than controls } \\
\text { Thalidomide increased T cell subsets expressing both IL-2 } \\
\text { and IFN- } \gamma\end{array}$ \\
\hline $\begin{array}{l}\text { Villahermosa } \\
\text { et al. (134); } \\
\text { Philippines } \gamma, \varepsilon\end{array}$ & $22 \mathrm{ENL}$ & $\begin{array}{l}\text { Before thalidomide } \\
\text { and at study weeks } \\
3 \text { and } 7 \text { during } \\
\text { thalidomide }\end{array}$ & $\begin{array}{l}\text { MDT was } \\
\text { continued }\end{array}$ & $\begin{array}{l}\text { Samples untreated for } \\
\text { antireactional drugs and } \\
\text { during thalidomide }\end{array}$ & Plasma & TNF- $\alpha$, IL-6 & $\begin{array}{l}\text { TNF- } \alpha \text { levels not detected } \\
\text { IL-6 unchanged or reduced following thalidomide from week } \\
0 \text { to week } 3 \\
\text { IL- } 6 \text { undetectable at weeks } 3 \text { and } 7\end{array}$ \\
\hline $\begin{array}{l}\text { Belgaumkar et al. } \\
\text { (169); India }\end{array}$ & $\begin{array}{l}71 \mathrm{BT} / \mathrm{BB} / \mathrm{BL}, \\
11 \text { pure neuritic, } \\
6 \mathrm{~T} 1 \mathrm{R}, 1 \mathrm{ENL} \\
30 \mathrm{HC}\end{array}$ & Untreated samples & $\begin{array}{l}\text { Untreated } \\
\text { samples }\end{array}$ & $\begin{array}{l}\text { Patients on antileprosy } \\
\text { treatment or steroids } \\
\text { were excluded }\end{array}$ & Serum & $\mathrm{IL}-6, \mathrm{IFN}-\gamma$ & $\begin{array}{l}\text { The one patient with ENL had higher levels of IL- } 6 \text { and IFN- } \gamma \\
\text { in comparison to the BL/LL patients without reactions }\end{array}$ \\
\hline $\begin{array}{l}\text { lyer et al. (143); } \\
\text { Indonesia } \varepsilon\end{array}$ & $\begin{array}{l}131 \mathrm{TT} / \mathrm{BT} / \mathrm{BB} / \\
\mathrm{BL} / \mathrm{LL}, 44 \mathrm{ENL}, 5 \\
\mathrm{~T} 1 \mathrm{R}, 112 \mathrm{HC}\end{array}$ & ND & Patients on MDT & $\begin{array}{l}\text { Prednisolone to treat } \\
\text { reactions }\end{array}$ & Serum & $\begin{array}{l}\text { IL-6, IFN- } \gamma \text {, TNF- } \alpha \\
\text { IL-6R, IL-10, IL-4, } \\
\text { sCD27 }\end{array}$ & $\begin{array}{l}\text { IFN- } \gamma \text { and IL-6R increased in ENL compared to non-ENL } \\
\text { Completion of corticosteroid treatment: IFN- } \gamma \text {, TNF- } \alpha \text {, sIL6R } \\
\text { declined }\end{array}$ \\
\hline $\begin{array}{l}\text { Stefani et al. } \\
\text { (151); Brazil }\end{array}$ & $\begin{array}{l}10 \mathrm{ENL}, 10 \mathrm{~T} 1 \mathrm{R}, \\
29 \text { non-reactional } \\
\text { controls }\end{array}$ & $\begin{array}{l}\text { Newly detected } \\
\text { untreated patients }\end{array}$ & $\begin{array}{l}\text { Untreated } \\
\text { samples }\end{array}$ & Untreated samples & Plasma & $\begin{array}{l}\text { TNF- } \alpha \text {, IFN- } \gamma \text {, } \\
\text { IL12p70, IL-2, IL-17, } \\
\text { IL-1 } \beta, \text { IL-6, IL-15, } \\
\text { IL-5, IL-8, MIP- } \alpha \text {, } \\
\text { MIP- } \beta, \text { RANTES, } \\
\text { MCPI, CCL11/ } \\
\text { eotaxin, CXCL10, } \\
\text { IL-4, IL-10, IL13, } \\
\text { IL-1R } \alpha, \text { IL-7, IL-9, } \\
\text { G-CSF, PDGF BB, } \\
\text { bFGF, VEGF }\end{array}$ & IL-6, IL-7 and PDGF BB elevated in ENL \\
\hline $\begin{array}{l}\text { Motta et al. (175); } \\
\text { Brazil }\end{array}$ & $\begin{array}{l}44 \text { leprosy of } \\
\text { which } 15 \mathrm{ENL} \text {, } \\
10 \mathrm{HC}\end{array}$ & $\begin{array}{l}\text { Baseline and } 7 \text { days } \\
\text { after therapy for oral } \\
\text { infection }\end{array}$ & ND & ND & Serum & $\begin{array}{l}\text { IL-1, TNF- } \alpha, \text { IL-6, } \\
\text { IFN- } \gamma, \mathrm{IL}-10\end{array}$ & No specific finding for ENL \\
\hline $\begin{array}{l}\text { Teles et al. (176); } \\
\text { Brazil } \varepsilon\end{array}$ & $\begin{array}{l}32 \text { leprosy: } 10 \\
\text { ENL, } 8 \text { T1R }\end{array}$ & $\begin{array}{l}4 \text { ENL patients } \\
\text { before and during } \\
\text { reaction }\end{array}$ & $\begin{array}{l}\text { All patients on } \\
\text { MDT }\end{array}$ & ND & $\begin{array}{l}\text { Skin } \\
\text { PBMC }\end{array}$ & $\begin{array}{l}\text { TNF- } \alpha \text { gene } \\
\text { expression and levels } \\
\text { in supernatants }\end{array}$ & $\begin{array}{l}\text { PBMC stimulated with } M \text {. leprae: upregulation of gene } \\
\text { expression of TNF- } \alpha \text { and increase of TNF- } \alpha \text { in supernatants } \\
\text { after } 1,3 \text {, and } 6 \mathrm{~h}\end{array}$ \\
\hline
\end{tabular}


TABLE 4 | Continued

\begin{tabular}{|c|c|c|c|c|c|c|c|}
\hline $\begin{array}{l}\text { Reference; } \\
\text { study site(s) }\end{array}$ & Study population & $\begin{array}{l}\text { Timing of } \\
\text { sampling }\end{array}$ & MDT status & ENL treatment status & Type of samples & Measures & Findings \\
\hline $\begin{array}{l}\text { Jadhav et al. } \\
\text { (149); India } \varepsilon\end{array}$ & 303 MB: 5 ENL & $\begin{array}{l}\text { Serum samples } \\
\text { at the time of } \\
\text { recruitment }\end{array}$ & $\begin{array}{l}\text { Newly registered: } \\
\text { no MDT }\end{array}$ & Untreated & Serum & TNF- $\alpha$ & No significant outcome for ENL \\
\hline $\begin{array}{l}\text { Madan et al. } \\
\text { (144); India }\end{array}$ & $\begin{array}{l}61 \text { leprosy: } 4 \text { ENL } \\
\text { and } 2 \text { ENL during } \\
\text { study }\end{array}$ & $\begin{array}{l}\text { Untreated samples, } \\
\text { during reactional } \\
\text { episodes and after } \\
\text { completion of } \\
\text { treatment }\end{array}$ & $\begin{array}{l}\text { Untreated } \\
\text { patients }\end{array}$ & $\begin{array}{l}\text { Patients on steroids } \\
\text { were excluded }\end{array}$ & Serum & $\begin{array}{l}\text { TNF- } \alpha, \text { IFN- } \gamma, \| L-1 \beta \\
\text { IL-10 }\end{array}$ & $\begin{array}{l}\text { All cytokines were raised in reactional (both T1R and ENL) } \\
\text { compared to non-reactional IFN- } \gamma \text {, IL-1 } 1 \beta \text { and IL-10 were } \\
\text { higher in ENL but only IL-10 was statistically significant } \\
\text { compared to T1R } \\
\text { Levels of all cytokines decreased after MDT }\end{array}$ \\
\hline $\begin{array}{l}\text { Rodrigues et al. } \\
\text { (145); Brazil }\end{array}$ & $\begin{array}{l}18 \mathrm{LL} \text { with ENL } \\
\text { during treatment; } \\
13 \text { non-reactional } \\
\mathrm{BT}, 37 \text { non- } \\
\text { reactional BL/LL, } \\
25 \mathrm{BL} \text { with T1R } \\
\text { during treatment; } \\
21 \mathrm{HC}\end{array}$ & $\begin{array}{l}\text { Beginning of } \\
\text { leprosy treatment, } \\
\text { at diagnosis of } \\
\text { reactional episode } \\
\text { and at 3-5 years } \\
\text { post-treatment }\end{array}$ & $\begin{array}{l}\text { Samples before } \\
\text { and during MDT }\end{array}$ & $\begin{array}{l}\text { Untreated samples and } \\
\text { after treatment with } \\
\text { prednisolone }\end{array}$ & Serum & TNF- $\alpha$ & TNF- $\alpha$ higher during ENL than prior to the reaction \\
\hline $\begin{array}{l}\text { Chaitanya et al. } \\
\text { (177); India }\end{array}$ & $\begin{array}{l}21 \text { ENL, } 80 \text { T1R, } \\
80 \text { leprosy without } \\
\text { reaction, } 94 \\
\text { non-leprosy }\end{array}$ & Untreated samples & $\begin{array}{l}\text { Untreated } \\
\text { samples }\end{array}$ & Untreated samples & Serum & $\mathrm{IL}-17 \mathrm{~F}$ & IL-17F elevated during T1R but no significant difference in ENL \\
\hline $\begin{array}{l}\text { Lockwood et al. } \\
\text { (178); India } \varepsilon\end{array}$ & $\begin{array}{l}303 \mathrm{MB} \text { leprosy: } \\
13 \mathrm{ENL}\end{array}$ & $\begin{array}{l}\text { Skin biopsies at } \\
\text { enrollment }\end{array}$ & Before MDT & $\begin{array}{l}\text { Before antireactional } \\
\text { treatment }\end{array}$ & Skin & $\begin{array}{l}\text { TNF- } \alpha \text { and TGF- } \beta \\
\text { immunostaining }\end{array}$ & $\begin{array}{l}\text { TNF- } \alpha \text { : similar levels ENL and non-ENL TGF- } \beta \text { : no difference in } \\
\text { ENL and non-ENL }\end{array}$ \\
\hline $\begin{array}{l}\text { Martiniuk et al. } \\
\text { (179); Nepal and } \\
\text { USA } \varepsilon\end{array}$ & $7 \mathrm{ENL}$ & $\begin{array}{l}\text { Pre- and post- } \\
\text { treatment with } \\
\text { thalidomide }\end{array}$ & ND & $\begin{array}{l}\text { Pre- and post- } \\
\text { treatment with } \\
\text { thalidomide }\end{array}$ & Skin biopsies & $\begin{array}{l}\text { RT-PCR for hIL-17A, } \\
\text { hIL-17B, hIL-17C, } \\
\text { hIL-17D, hIL-17E, } \\
\text { hIL17F }\end{array}$ & $\begin{array}{l}\text { IL17A, was consistently seen before and after thalidomide } \\
\text { Reduction in IL17B, IL17E and increase of IL17C following } \\
\text { thalidomide }\end{array}$ \\
\hline $\begin{array}{l}\text { Sousa et al. } \\
\text { (170); Brazil }\end{array}$ & $\begin{array}{l}33 \text { ENL, } 54 \text { T1R, } \\
16 \text { reaction-free } \\
\text { leprosy }\end{array}$ & ND & $\begin{array}{l}63.8 \% \text { presented } \\
\text { ENL during MDT }\end{array}$ & ND & Plasma & IL-6 & Higher IL-6 in ENL and T1R compared to non-reactional \\
\hline $\begin{array}{l}\text { Abdallah et al. } \\
\text { (171); Egypt }\end{array}$ & $\begin{array}{l}43 \text { leprosy: } 6 \text { ENL, } \\
43 \text { HC }\end{array}$ & Untreated samples & $\begin{array}{l}\text { Untreated } \\
\text { samples }\end{array}$ & Untreated samples & Serum & IL-17, IL-4 & Overproduction of IL-4 in LL patients \\
\hline $\begin{array}{l}\text { Saini et al. (136); } \\
\text { India } \gamma\end{array}$ & $\begin{array}{l}21 \mathrm{MB}: 16 \mathrm{ENL} \\
5 \mathrm{~T} 1 \mathrm{R}\end{array}$ & $\begin{array}{l}\text { ENL blood during } \\
\text { reaction and at } 0.5 \\
\text { and } 1 \text { year after the } \\
\text { onset of reaction }\end{array}$ & $\begin{array}{l}\text { Duration of MDT } \\
\text { described }\end{array}$ & $\begin{array}{l}\text { ENL patients received } \\
\text { steroids }\end{array}$ & PBMC & $\begin{array}{l}\text { PBMC stimulated } \\
\text { with } M \text {. leprae, } \\
\text { recombinant Lsr2 and } \\
6 \text { synthetic peptides } \\
\text { spanning the Lsr2 } \\
\text { sequence: IFN- } \gamma\end{array}$ & During ENL stimulated PBMC showed IFN- $\gamma$ release \\
\hline $\begin{array}{l}\text { Abdallah et al. } \\
\text { (109); Egypt } \gamma\end{array}$ & $\begin{array}{l}43 \text { leprosy: } 6 \text { ENL, } \\
40 \mathrm{HC}\end{array}$ & Untreated patients & $\begin{array}{l}\text { Untreated } \\
\text { samples }\end{array}$ & Untreated samples & Serum & $\begin{array}{l}\text { IL-1 } \beta, \text { IL-4, IL12p70, } \\
\text { IFN- } \gamma\end{array}$ & IL-4 highest among LL compared to ENL \\
\hline
\end{tabular}


TABLE 4 | Continued

\begin{tabular}{|c|c|c|c|c|c|c|c|}
\hline $\begin{array}{l}\text { Reference; } \\
\text { study site(s) }\end{array}$ & Study population & $\begin{array}{l}\text { Timing of } \\
\text { sampling }\end{array}$ & MDT status & ENL treatment status & Type of samples & Measures & Findings \\
\hline $\begin{array}{l}\text { Attia et al. (110); } \\
\text { Egypt } \gamma\end{array}$ & $\begin{array}{l}43 \text { leprosy: } 6 \mathrm{ENL} \text {, } \\
40 \mathrm{HC}\end{array}$ & Untreated samples & $\begin{array}{l}\text { Untreated } \\
\text { samples }\end{array}$ & Untreated samples & Serum & $\begin{array}{l}\text { IL-17, IL-22, IL-10, } \\
\text { TGF- } \beta\end{array}$ & No statistically significant difference between groups \\
\hline $\begin{array}{l}\text { Berrington et al. } \\
\text { (167); Nepal }\end{array}$ & $\begin{array}{l}85 \text { leprosy: } 9 \\
\text { ENL, } 35 \text { BL/LL } \\
\text { non-reactional }\end{array}$ & ND & ND & ND & Skin & $\begin{array}{l}\text { RT-PCR for CCL1, } \\
\text { CCL2, CCL17, } \\
\text { CCL18, IFNA1, } \\
\text { IFNA8, IFNB1, IFNG, } \\
\text { IL10, IL12a, IL12b, } \\
\text { IL13, IL17a, IL18, } \\
\text { IL1b, IL1ra, IL21, } \\
\text { IL22, IL23, IL27, IL29, } \\
\text { IL4, IL6, TNF }\end{array}$ & $\begin{array}{l}\text { CCL18, IL 12b and CD14 elevated in lesions of ENL but failed } \\
\text { to reach significance when adjusted for multiple comparisons }\end{array}$ \\
\hline $\begin{array}{l}\text { Sallam et al. } \\
\text { (166); Egypt }\end{array}$ & $\begin{array}{l}43 \text { leprosy: } 6 \mathrm{ENL} \text {, } \\
43 \mathrm{HC}\end{array}$ & Untreated samples & $\begin{array}{l}\text { Untreated } \\
\text { samples }\end{array}$ & $\begin{array}{l}\text { Untreated samples, } \\
\text { excluded patients on } \\
\text { corticosteroids }\end{array}$ & Serum & $\mathrm{IL}-1 \beta, \mathrm{IL}-12$ & $\begin{array}{l}\text { Higher IL-1 } \beta \text { in ENL compared to non- reactional } \\
\text { No significant difference for IL-12 }\end{array}$ \\
\hline $\begin{array}{l}\text { Dupnik et al. (58); } \\
\text { Brazil } \beta, \varepsilon\end{array}$ & $\begin{array}{l}11 \text { ENL, } 11 \\
\text { T1R, } 19 \text { leprosy } \\
\text { without reactions } \\
\text { for microarray; } 6 \\
\text { ENL, } 11 \text { T1R, } 11 \\
\text { non-reactional } \\
\text { for qPCR; } 3 \text { ENL } \\
\text { for ICH }\end{array}$ & ND & $\begin{array}{l}\text { 3/11 ENL pre- } \\
\text { treatment, } 2 / 11 \\
\text { ENL on treatment } \\
\text { and 6/11 post- } \\
\text { treatment; leprosy } \\
\text { controls matched } \\
\text { for length of } \\
\text { treatment }\end{array}$ & $\begin{array}{l}\text { Excluded patients on } \\
\text { steroids within } 7 \text { days } \\
\text { and thalidomide within } \\
28 \text { days of enrollment }\end{array}$ & PBMC & $\begin{array}{l}\text { Microarrays followed } \\
\text { by qPCR }\end{array}$ & $\begin{array}{l}\text { Cytokine-cytokine receptor interaction has been in the top } \\
3 \mathrm{KEGG} \text { pathways in ENL CCL5 followed by IFN- } \gamma \text { was the } \\
\text { most significant upstream regulator of the expression changes } \\
\text { in the array }\end{array}$ \\
\hline $\begin{array}{l}\text { Saini et al. (113); } \\
\text { India } \gamma\end{array}$ & $\begin{array}{l}66 \text { leprosy: } 15 \\
\text { T1R, } 15 \text { ENL, } 36 \\
\text { stable leprosy } \\
\text { without previous } \\
\text { history or clinical } \\
\text { evidence of } \\
\text { reactions }\end{array}$ & $\begin{array}{l}\text { Newly diagnosed } \\
\text { leprosy patients } \\
\text { prior to institution of } \\
\text { antireaction therapy }\end{array}$ & $\begin{array}{l}\text { Untreated } \\
\text { samples }\end{array}$ & Untreated samples & PBMC & $\begin{array}{l}\text { Antigen (MLSA) } \\
\text { stimulated and } \\
\text { unstimulated PBMC: } \\
\text { gene expression with } \\
\text { PCR array for } 84 \\
\text { genes } \\
\text { ELISA for cytokines } \\
\text { IL-17A/F, IL-21, } \\
\text { IL-22, IL-23A, IL-6, } \\
\text { IL-1 } 1 \beta \text {, IFN- } \gamma \text {, TGF- } \beta \text { in } \\
\text { supernatants }\end{array}$ & $\begin{array}{l}\text { IL-23A mRNA expression increased in ENL } \\
\text { IL-23R expression increased in ENL } \\
\text { High expression of CCL20 and CCL22 in ENL } \\
\text { ENL significant fold increase in IFN- } \gamma \\
\text { Culture supernatants: } \\
\text { Higher IL-17A/F in ENL patients compared to LL } \\
\text { IL23A increased compared to LL } \\
\text { IL-1 } \beta \text { increased in ENL }\end{array}$ \\
\hline $\begin{array}{l}\text { Dias et al. (80); } \\
\text { Brazil } \varepsilon\end{array}$ & $\begin{array}{l}30 \mathrm{ENL}, 24 \mathrm{BL} / \mathrm{LL}, \\
31 \mathrm{HC}\end{array}$ & $\begin{array}{l}\text { Upon diagnosis of } \\
\text { reaction }\end{array}$ & $\begin{array}{l}\text { BL/LL before MDT } \\
\text { but most ENL } \\
\text { patients on MDT }\end{array}$ & $\begin{array}{l}\text { Before treatment with } \\
\text { thalidomide or steroids }\end{array}$ & PBMC & $\begin{array}{l}\text { TNF, IL-6 and IL-1 } \beta \\
\text { in response to TLR9 } \\
\text { agonist }\end{array}$ & $\begin{array}{l}\text { Higher production of TNF- } \alpha, I L-6, I L-1 \beta \text { in response to TLR9 } \\
\text { agonist } \\
\text { TLR9 antagonist inhibited the secretion of cytokines in } \\
\text { response to } M \text {. leprae lysate }\end{array}$ \\
\hline
\end{tabular}

$\alpha$, also in Table 1; $\beta$, also in Table 2; $\gamma$, also in Table 3; $\varepsilon$, also in Table 5.

BB, mid-borderline leprosy; BL, borderline lepromatous leprosy; BT, borderline tuberculoid leprosy; ENL, erythema nodosum leprosum; HC, healthy controls; ICS, immune complexes; LL, lepromatous leprosy polar; ND, not described;

P.B.neutrophils, peripheral blood neutrophils; SLE, systemic lupus erythematosus; TB, tuberculosis; TT, tuberculoid leprosy polar. 
TABLE 5 | Human studies on ENL investigating other immunological factors.

\begin{tabular}{|c|c|c|c|c|c|c|c|}
\hline $\begin{array}{l}\text { Reference; } \\
\text { study site(s) }\end{array}$ & Study population & $\begin{array}{l}\text { Timing of } \\
\text { sampling }\end{array}$ & MDT status & $\begin{array}{l}\text { ENL treatment } \\
\text { status }\end{array}$ & Type of samples & Measures & Findings \\
\hline $\begin{array}{l}\text { Waters et al. (22); } \\
\text { United Kingdom } \\
\text { and Malaysia } \beta\end{array}$ & 38 lepromatous ENL & ND & ND & ND & Serum & Immunoglobulins & No differences in immunoglobulin levels \\
\hline $\begin{array}{l}\text { Reichlin et al. } \\
\text { (180); Malaysia }\end{array}$ & $13 \mathrm{LL}$ of which $7 \mathrm{ENL}$ & ND & ND & ND & Blood & $\begin{array}{l}\text { Euglobulin } \lg G \\
\text { Serum IgG }\end{array}$ & $\begin{array}{l}\text { Levels of euglobulin lgG higher in the ENL-positive patients than } \\
\text { in ENL-negative patients }\end{array}$ \\
\hline $\begin{array}{l}\text { Anthony et al. } \\
\text { (60); India } \beta\end{array}$ & $\begin{array}{l}25 \mathrm{LL} \mathrm{ENL,} 10 \mathrm{LL} \\
\text { without ENL }\end{array}$ & $\begin{array}{l}\text { Active ENL } \\
\text { lesions? }\end{array}$ & ND & ND & Serum & Immunoglobulins & High levels of immunoglobulins in both LL and ENL \\
\hline $\begin{array}{l}\text { Harikrishan et al. } \\
\text { (71); India } \beta\end{array}$ & $\begin{array}{l}20 \text { active LL; } 15 \mathrm{ENL} \\
\text { during active and } \\
\text { subsided phase; } 20 \mathrm{HC}\end{array}$ & $\begin{array}{l}\text { ENL: during } \\
\text { the active and } \\
\text { subsided phase }\end{array}$ & ND & ND & Plasma & $\begin{array}{l}\text { Immunoglobulins IgG, } \\
\operatorname{lgM} \text {, IgA }\end{array}$ & $\begin{array}{l}\text { Serum levels of } \operatorname{lgG} \text { and IgM during subsidence of ENL were } \\
\text { significantly lower compared to that during the active phase of } \\
\text { ENL }\end{array}$ \\
\hline $\begin{array}{l}\text { Humphres et al. } \\
\text { (181); USA }\end{array}$ & $\begin{array}{l}14 \mathrm{LL} \text { ENL, } 28 \mathrm{BL} / \mathrm{LL} \text {, } \\
21 \mathrm{HC}\end{array}$ & $\begin{array}{l}\text { Multiple Serial } \\
\text { sampling }\end{array}$ & $\begin{array}{l}\text { 10/19 LL } \\
\text { patients } \\
\text { untreated, 9/19 } \\
\text { LL patients } \\
\text { Dapsone }\end{array}$ & $\begin{array}{l}\text { Corticosteroids day } \\
\text { prior to initial assay } \\
\text { for NK activity and } \\
\text { was continued } \\
\text { through treatment }\end{array}$ & PBMC & $\begin{array}{l}\text { Natural killer cell } \\
\text { activity }\end{array}$ & Natural killer cell activity significantly depressed in ENL \\
\hline $\begin{array}{l}\text { Rea and Yoshida } \\
\text { (182); USA }\end{array}$ & $\begin{array}{l}108 \text { leprosy (4 } \\
\text { untreated ENL, } 14 \\
\text { dapsone-treated active } \\
\text { ENL, } 10 \text { dapsone- } \\
\text { treated inactive ENL), } \\
25 \mathrm{HC}\end{array}$ & ND & $\begin{array}{l}54 \text { untreated } \\
\text { patients } \\
\text { and others } \\
\text { dapsone-treated }\end{array}$ & Untreated & Blood & $\begin{array}{l}\text { Macrophage } \\
\text { migration inhibition } \\
\text { activity }\end{array}$ & $\begin{array}{l}\text { Positive serum inhibitory activity strongly associated with } \\
\text { reactional states (ENL or T1R or Lucio's reaction) in both treated } \\
\text { and untreated patients }\end{array}$ \\
\hline $\begin{array}{l}\text { Miller et al. (183); } \\
\text { USA }\end{array}$ & $\begin{array}{l}9 \text { leprosy: } 3 \text { T1Rs and } \\
2 \text { ENL }\end{array}$ & $\begin{array}{l}\text { Serial sampling } \\
\text { from date of } \\
\text { initiation of therapy } \\
\text { until the first year } \\
\text { of treatment }\end{array}$ & On MDT & $\begin{array}{l}\text { Reactional } \\
\text { episodes were } \\
\text { treated with } \\
\text { corticosteroids and } \\
1 \text { ENL received } \\
\text { thalidomide }\end{array}$ & Plasma & $\begin{array}{l}\text { Antibodies to } \\
\text { Mycobacterial } \\
\text { Arabinomannan }\end{array}$ & High levels of antibody to Arabinomannan in 2 ENL patients \\
\hline $\begin{array}{l}\text { Narayanan et al. } \\
\text { (89); India } \gamma\end{array}$ & $\begin{array}{l}35 \text { leprosy patients: } 7 \\
\text { LL with ENL, } 6 \text { BT, } 6 \\
\text { BT with T1R, 4 BL, 5BL } \\
\text { with T1R, } 8 \text { LL }\end{array}$ & ND & ND & ND & Skin & B cells & No increase of B cells in any of the lesions \\
\hline $\begin{array}{l}\text { Rea et al. (96); } \\
\text { USA } \gamma\end{array}$ & $\begin{array}{l}19 \text { ENL, } 67 \text { BL/LL } 4 \text { LL } \\
\text { with Lucio's, } 13 \text { T1R, } \\
18 \text { Tuberculoid, } 13 \\
\text { Tuberculoid long-term } \\
\text { treatment }\end{array}$ & ND & $\begin{array}{l}\text { Some patients } \\
\text { on MDT }\end{array}$ & $\begin{array}{l}\text { ENL before } \\
\text { receiving } \\
\text { thalidomide }\end{array}$ & PBMC & B-cells & B-cell percentage in the PBMC of ENL similar LL \\
\hline
\end{tabular}


TABLE 5 | Continued

\begin{tabular}{|c|c|c|c|c|c|c|c|}
\hline $\begin{array}{l}\text { Reference; } \\
\text { study site(s) }\end{array}$ & Study population & $\begin{array}{l}\text { Timing of } \\
\text { sampling }\end{array}$ & MDT status & $\begin{array}{l}\text { ENL treatment } \\
\text { status }\end{array}$ & Type of samples & Measures & Findings \\
\hline $\begin{array}{l}\text { Schwerer et al. } \\
\text { (184); USA }\end{array}$ & $\begin{array}{l}121 \text { leprosy (including } \\
\text { ENL), } 28 \text { contacts, } \\
15 \mathrm{HC}\end{array}$ & ND & ND & ND & Serum & Anti-PGL I lgM levels & $\begin{array}{l}\text { Serum anti-PGL I lgM levels lower in ENL compared to patients } \\
\text { with comparable BI }\end{array}$ \\
\hline $\begin{array}{l}\text { Andreoli et al. } \\
\text { (40); India }\end{array}$ & $12 \mathrm{ENL}$ & ND & $\begin{array}{l}\text { All patients } \\
\text { on MDT with } \\
\text { specified } \\
\text { duration }\end{array}$ & $\begin{array}{l}\text { Treated with } \\
\text { prednisone and/or } \\
\text { thalidomide }\end{array}$ & Serum & $\begin{array}{l}\text { Circulatory IgM } \\
\text { antibody levels to the } \\
\text { PGL I; IgM, IgG, IgA } \\
\text { antibody levels to } \\
\text { M. leprae antigenic } \\
\text { preparation }\end{array}$ & $\begin{array}{l}\text { During ENL: decrease of circulatory IgM antibody levels to PGL } \\
\text { I but no significant change to IgG, IgM or IgA antibody levels to } \\
\text { the soluble antigens from } M \text {. leprae }\end{array}$ \\
\hline $\begin{array}{l}\text { Laal et al. (94); } \\
\text { India } \gamma\end{array}$ & $15 \mathrm{ENL}, 13 \mathrm{LL}$ & $\begin{array}{l}\text { During active ENL } \\
\text { and } 1 \text { week to } \\
4 \text { months after } \\
\text { stopping treatment }\end{array}$ & $\begin{array}{l}\text { Treatment with } \\
\text { combination } \\
\text { antileprosy } \\
\text { drugs was } \\
\text { continued } \\
\text { throughout }\end{array}$ & $\begin{array}{l}\text { First sample } \\
\text { before initiation } \\
\text { of antireactional } \\
\text { treatment; second } \\
\text { sample } 1 \text { week } \\
\text { to } 4 \text { months after } \\
\text { treatment }\end{array}$ & PBMC & B cells & $\begin{array}{l}\text { B-cell percentages in PBMC of ENL patients were similar to } \\
\text { those of uncomplicated LL }\end{array}$ \\
\hline $\begin{array}{l}\text { Blavy et al. (185); } \\
\text { Senegal }\end{array}$ & $\begin{array}{l}34 \mathrm{ENL} \text { and } 50 \text { leprosy } \\
\text { patients }\end{array}$ & ND & ND & ND & Lymphocytes & HLA phenotyping & Not significant findings of any HLA phenotype regarding ENL \\
\hline $\begin{array}{l}\text { Levis et al. (186); } \\
\text { USA }\end{array}$ & ND & ND & ND & ND & Serum & $\begin{array}{l}\text { IgM and IgG } \\
\text { antibodies to PGL-I }\end{array}$ & ENL lower anti-PGL-I IgM than non-ENL of comparable BI \\
\hline $\begin{array}{l}\text { Rao and Rao } \\
\text { (123); India } \gamma\end{array}$ & $\begin{array}{l}44 \mathrm{ENL}, 39 \mathrm{LL}, 22 \\
\text { post-ENL }\end{array}$ & $\begin{array}{l}\text { ENL cases before } \\
\text { starting treatment } \\
\text { for ENL, post-ENL } \\
\text { after the patient } \\
\text { had not taken } \\
\text { anti-inflammatory } \\
\text { drugs or steroids } \\
\text { for at least } 3 \text { and } \\
7 \text { days }\end{array}$ & $\begin{array}{l}\text { From } 39 \\
\text { non-reactional: } \\
20 \text { untreated } \\
\text { and } 19 \text { with } \\
\text { dapsone for less } \\
\text { than a year }\end{array}$ & $\begin{array}{l}\text { ENL before starting } \\
\text { ENL treatment, } \\
\text { post-ENL after } \\
\text { the patient had } \\
\text { not taken anti- } \\
\text { inflammatory drugs } \\
\text { or steroids for at } \\
\text { least } 3 \text { and } 7 \text { days }\end{array}$ & Blood & $\begin{array}{l}\text { B lymphocytes in } \\
\text { peripheral blood }\end{array}$ & B cells: no difference between groups \\
\hline $\begin{array}{l}\text { Sehgal et al. (76); } \\
\text { India } \beta\end{array}$ & $\begin{array}{l}21 \text { patients with leprosy } \\
\text { reactions either T1R } \\
\text { or ENL }\end{array}$ & ND & ND & ND & $\begin{array}{l}\text { B-cells } \\
\text { Serum }\end{array}$ & $\begin{array}{l}\text { Percentage } \\
\text { and absolute } \\
\text { count of B-cells; } \\
\text { Immunoglobulins IgG, } \\
\text { IgA, IgM }\end{array}$ & $\begin{array}{l}\text { During ENL a significant increase in the percentage and } \\
\text { absolute count of B-lymphocytes Significantly elevated serum } \\
\text { immunoglobulin values after subsidence of ENL }\end{array}$ \\
\hline $\begin{array}{l}\text { Levis et al. (187); } \\
\text { USA }\end{array}$ & $\begin{array}{l}40 \text { ENL, } 63 \text { leprosy } \\
\text { without ENL, HC }\end{array}$ & ND & ND & ND & Serum & $\begin{array}{l}\text { IgM antibody to } \\
\text { PGL-I; IgM and IgG } \\
\text { Abs to M.tb and } M \text {. } \\
\text { leprae LAM }\end{array}$ & No correlation between $\lg M$ or $\lg G A b$ to LAM and bacillary index \\
\hline
\end{tabular}


TABLE 5 | Continued

\begin{tabular}{|c|c|c|c|c|c|c|c|}
\hline $\begin{array}{l}\text { Reference; } \\
\text { study site(s) }\end{array}$ & Study population & $\begin{array}{l}\text { Timing of } \\
\text { sampling }\end{array}$ & MDT status & $\begin{array}{l}\text { ENL treatment } \\
\text { status }\end{array}$ & Type of samples & Measures & Findings \\
\hline $\begin{array}{l}\text { Rao and Rao } \\
\text { (85); India }\end{array}$ & $\begin{array}{l}44 \text { ENL, } 39 \\
\text { lepromatous, } 22 \\
\text { post-ENL }\end{array}$ & $\begin{array}{l}\text { ENL blood before } \\
\text { starting ENL } \\
\text { treatment, post- } \\
\text { ENL after patient } \\
\text { does not take any } \\
\text { anti-inflammatory } \\
\text { drugs or steroids } \\
\text { for the last } 3 \text { or } \\
7 \text { days }\end{array}$ & $\begin{array}{l}20 \text { patients no } \\
\text { previous MDT } \\
\text { and } 19 \text { treated } \\
\text { with dapsone }\end{array}$ & $\begin{array}{l}\text { Before starting } \\
\text { treatment with anti- } \\
\text { inflammatory drugs } \\
\text { or steroids }\end{array}$ & Blood & $\begin{array}{l}\text { Leukocyte migration } \\
\text { inhibition test }\end{array}$ & Lower migratory indices to whole $M$. leprae during ENL \\
\hline $\begin{array}{l}\text { Rao and Rao } \\
\text { (78); India } \beta\end{array}$ & $\begin{array}{l}44 \text { ENL, } 39 \mathrm{BL} / \mathrm{LL}, 22 \\
\text { post-ENL }\end{array}$ & $\begin{array}{l}\text { ENL before } \\
\text { starting anti-ENL } \\
\text { treatment, post- } \\
\text { ENL ensuring that } \\
\text { the patient had } \\
\text { not taken anti- } \\
\text { inflammatory drugs } \\
\text { or steroids for at } \\
\text { least } 3 \text { or } 7 \text { days }\end{array}$ & $\begin{array}{l}20 \mathrm{BL} / \mathrm{LL} \\
\text { untreated and } \\
19 \mathrm{BL} / \mathrm{LL} \text { treated } \\
\text { with dapsone }\end{array}$ & $\begin{array}{l}\text { Before starting } \\
\text { treatment with } \\
\text { steroids or anti- } \\
\text { inflammatory drugs }\end{array}$ & Serum & $\lg G, \lg A, \lg M$ & $\begin{array}{l}\text { IgG and IgM decreased in ENL than lepromatous and post-ENL } \\
\text { Serum IgA elevated in ENL than lepromatous group and further } \\
\text { increase post-ENL }\end{array}$ \\
\hline $\begin{array}{l}\text { Filley et al. (168); } \\
\text { India } \delta\end{array}$ & $7 \mathrm{ENL}$ & $\begin{array}{l}\text { Before, during and } \\
\text { after the episode }\end{array}$ & $\begin{array}{l}\text { All patients on } \\
\text { MDT }\end{array}$ & $\begin{array}{l}\text { ENL was treated } \\
\text { with steroids and/ } \\
\text { or thalidomide }\end{array}$ & Serum & $\% G O$ & $\begin{array}{l}\text { During ENL\%GO transiently raised, and this rise parallels an } \\
\text { increase in circulating IL2R }\end{array}$ \\
\hline $\begin{array}{l}\text { Bhoopat et al. } \\
\text { (127); Thailand } \gamma\end{array}$ & $\begin{array}{l}57 \text { ENL (19 acute/38 } \\
\text { chronic), } 61 \text { active LL, } \\
33 \text { control patients } \\
\text { whose leprosy had } \\
\text { been cured }\end{array}$ & $\begin{array}{l}26 \mathrm{BL} \text { and } 35 \mathrm{LL} \\
\text { newly diagnosed } \\
\text { and untreated }\end{array}$ & ND & $\begin{array}{l}\text { When treatment } \\
\text { with corticosteroids } \\
\text { and/or thalidomide } \\
\text { was initiated } \\
\text { precise timing } \\
\text { was recorded with } \\
\text { respect to the time } \\
\text { of collection of } \\
\text { specimens }\end{array}$ & $\begin{array}{l}\text { Blisters } \\
\text { induced over a } \\
\text { representative } \\
\text { skin lesion }\end{array}$ & $\begin{array}{l}\text { IgM antibody to PGL-I } \\
\text { and Tac peptide }\end{array}$ & $\begin{array}{l}\text { IgM antibody to PGL-I and Tac peptide levels were elevated in } \\
\text { chronic ENL lesions } \\
\text { Corticosteroids reduced IgM antibody to PGL-I but did not } \\
\text { change the levels of Tac peptide }\end{array}$ \\
\hline $\begin{array}{l}\text { Ramanathan } \\
\text { et al. (49); India } \beta\end{array}$ & $\begin{array}{l}26 \mathrm{BL} / \mathrm{LL} \text { of which } 11 \\
\text { ENL, } 24 \mathrm{HC}\end{array}$ & $\begin{array}{l}\text { Blood was taken } \\
\text { before initiation } \\
\text { of treatment and } \\
\text { then to } 2 \text {-month } \\
\text { intervals up to } \\
20 \text { months }\end{array}$ & $\begin{array}{l}\text { Untreated and } \\
\text { then on MDT } \\
\text { samples every } \\
2 \text { months }\end{array}$ & $\begin{array}{l}\text { Treated but after } \\
\text { blood sampling }\end{array}$ & Serum & $\lg G, \lg A$ and $\lg M$ & ENL no significant relation with immunoglobulin levels \\
\hline $\begin{array}{l}\text { Sullivan et al. } \\
\text { (173); USA } \delta\end{array}$ & ND & ND & ND & ND & Skin & $\begin{array}{l}\text { ICAM-1, ICAM-1 } \\
\text { ligand LFA-1 }\end{array}$ & Prominent keratinocyte ICAM-1 expression \\
\hline
\end{tabular}




\begin{tabular}{|c|c|c|c|c|c|c|c|}
\hline $\begin{array}{l}\text { Reference; } \\
\text { study site(s) }\end{array}$ & Study population & $\begin{array}{l}\text { Timing of } \\
\text { sampling }\end{array}$ & MDT status & $\begin{array}{l}\text { ENL treatment } \\
\text { status }\end{array}$ & Type of samples & Measures & Findings \\
\hline $\begin{array}{l}\text { Scollard et al. } \\
\text { (82); Thailand } \beta\end{array}$ & $\begin{array}{l}4 \text { cured leprosy, } 10 \\
\text { leprosy (5BT, 3BL, } \\
2 \mathrm{LL}), 8 \mathrm{ENL} \text { patients } \\
\text { (5LL and 3BL), 3 T1R, } \\
4 \mathrm{HC}\end{array}$ & ND & ND & ND & $\begin{array}{l}\text { Blisters } \\
\text { induced over } \\
\text { representative } \\
\text { skin lesion } \\
\text { Sera }\end{array}$ & $\begin{array}{l}\text { Immunoglobulins (lgG, } \\
\text { IgA, IgM) to whole } M \text {. } \\
\text { leprae and to PGL-I }\end{array}$ & No statistically significant difference regarding immunoglobulins \\
\hline $\begin{array}{l}\text { Sehgal et al. } \\
\text { (188); India }\end{array}$ & $\begin{array}{l}25 \text { leprosy with } \\
\text { reactions (of which } \\
11 \text { ENL), } 20 \text { leprosy } \\
\text { without reactions, } 10 \\
\text { HC }\end{array}$ & ND & On MDT & $\begin{array}{l}\text { Reactional patients } \\
\text { on prednisolone }\end{array}$ & Lymphocytes & $\begin{array}{l}\text { Lymphocyte } \\
\text { adenosine deaminase } \\
\text { activity (L-ADA) }\end{array}$ & $\begin{array}{l}\text { The patients with leprosy reactions (both ENL and T1Rs) had } \\
\text { higher enzyme L-ADA than controls (the enzyme has a role in } \\
\text { activation, differentiation and proliferation of lymphocytes) }\end{array}$ \\
\hline $\begin{array}{l}\text { Sampaio et al. } \\
\text { (139); Brazil } \delta\end{array}$ & $\begin{array}{l}49 \mathrm{BL} / \mathrm{LL} \text { of which } 24 \\
\text { ENL }\end{array}$ & $\begin{array}{l}\text { ENL at the time of } \\
\text { developing ENL, } \\
\text { during thalidomide } \\
\text { treatment, or } \\
\text { after thalidomide } \\
\text { treatment }\end{array}$ & $\begin{array}{l}\text { MDT was } \\
\text { continued } \\
\text { through the } \\
\text { study }\end{array}$ & $\begin{array}{l}\text { Certain ENL } \\
\text { during thalidomide } \\
\text { treatment }\end{array}$ & Skin biopsies & $\begin{array}{l}\text { MCH II and ICAM-1 in } \\
\text { histology }\end{array}$ & $\begin{array}{l}\text { MHC II and ICAM-1 on epidermal keratinocytes in ENL } \\
\text { downregulated with thalidomide }\end{array}$ \\
\hline $\begin{array}{l}\text { Santos et al. } \\
\text { (129); Brazil } \gamma\end{array}$ & $\begin{array}{l}10 \mathrm{ENL}, 59 \mathrm{LL} / \mathrm{BL}, 4 \\
\mathrm{~T} 1 \mathrm{R}, 4 \text { post-reactional }\end{array}$ & ND & On MDT & $\begin{array}{l}\text { No antireactional } \\
\text { treatment before } \\
\text { blood collection }\end{array}$ & $\begin{array}{l}\text { PBMC, } \\
\text { Monocytes }\end{array}$ & $\begin{array}{l}\text { Monocyte activation } \\
\text { by procoagulant } \\
\text { activity, HLA-DR }\end{array}$ & $\begin{array}{l}\text { No significant difference in monocyte activation between the } \\
\text { different groups No significant differences in HLA-DR between } \\
\text { groups }\end{array}$ \\
\hline $\begin{array}{l}\text { Singh et al. (189); } \\
\text { India }\end{array}$ & $\begin{array}{l}44 \text { active ENL, } 48 \text { prior } \\
\text { history of ENL, } 125 \\
\text { stable lepromatous, } 40 \\
\text { HC not endemic }\end{array}$ & $\mathrm{ND}$ & ND & Untreated samples & Serum & $\begin{array}{l}\text { Antibodies against } \\
B \text { cell epitopes of } M \text {. } \\
\text { leprae recombinant } \\
\text { protein LSR }\end{array}$ & $\begin{array}{l}\text { Antibodies against a specific distinct peptide region only in } \\
\text { patients undergoing ENL }\end{array}$ \\
\hline $\begin{array}{l}\text { Kifayet and } \\
\text { Hussain (190); } \\
\text { Pakistan }\end{array}$ & $\begin{array}{l}67 \mathrm{BL} / \mathrm{LL} \text { acute } \mathrm{ENL} \text {, } \\
83 \text { non-reactional } \mathrm{BL} / \\
\mathrm{LL}, 77 \text { endemic } \mathrm{HC}\end{array}$ & ND & $\begin{array}{l}\text { Most on MDT } \\
\text { but } 83 \text { non- } \\
\text { reactional less } \\
\text { than } 2 \text { weeks of } \\
\text { MDT }\end{array}$ & ND & Plasma & $\begin{array}{l}\text { M. leprae-specific } \lg G \\
\text { subclasses }\end{array}$ & $\begin{array}{l}\text { Lower concentrations of all IgG subclasses during ENL but lower } \\
\text { IgG1 and IgG3 during ENL before treatment }\end{array}$ \\
\hline $\begin{array}{l}\text { Kifayet et al. } \\
\text { (191); Pakistan }\end{array}$ & $\begin{array}{l}13 \text { ENL acute and } \\
\text { post-remission of } \\
\text { reaction, } 16 \text { non- } \\
\text { reactional stable LL, } 32 \\
\text { endemic HC }\end{array}$ & $\begin{array}{l}\text { During acute ENL } \\
(n=13) \text { and after } \\
\text { the reaction has } \\
\text { subsided }\end{array}$ & ND & ND & $\begin{array}{l}\text { Plasma } \\
\text { B-cells }\end{array}$ & $\begin{array}{l}\text { IgG subclasses } \\
\text { M. leprae-specific } \\
\text { antibodies; } \\
\text { Detection and } \\
\text { enumeration of } \\
\text { antibody-secreting } \\
\text { B cells by ELISPOT }\end{array}$ & $\begin{array}{l}\text { Polyclonal lgG1 elevated in acute ENL compared LL controls and } \\
\text { decreased when ENL subsided } \\
\text { IgG2 antibodies lower during acute ENL and increased after } \\
\text { reaction has subsided } \\
\text { Discrepancy in serum concentrations and B cell frequency }\end{array}$ \\
\hline $\begin{array}{l}\text { Vieira et al. (131); } \\
\text { Brazil } \gamma, \delta\end{array}$ & $\begin{array}{l}95 \mathrm{MB} \text { leprosy ( } 30 \mathrm{LL} \\
\text { and } 65 \mathrm{BL} \text { ) of which } \\
51 \mathrm{ENL}\end{array}$ & $\begin{array}{l}\text { At leprosy } \\
\text { diagnosis and at } \\
\text { onset of reactional } \\
\text { episode }\end{array}$ & $\begin{array}{l}\text { Time of MDT } \\
\text { for each ENL } \\
\text { patients in study }\end{array}$ & $\begin{array}{l}\text { Sample before } \\
\text { thalidomide and } \\
\text { steroids? }\end{array}$ & Serum & $\begin{array}{l}\text { Circulating anti-neural } \\
\text { and antimycobacterial } \\
\text { antibodies }\end{array}$ & $\begin{array}{l}\text { Detection of anti-neural (anti-ceramide and anti- } \\
\text { galactocerebroside) antibodies in ENL sera } \\
\text { No difference between reactional and non-reactional } \\
\text { lepromatous patients regarding IgM antibodies } \\
\text { Higher levels of anti-ceramide IgM and diminished levels of } \\
\text { anti-galactocerebroside antibodies in reactional compared to } \\
\text { non-reactional patients }\end{array}$ \\
\hline
\end{tabular}


TABLE 5 | Continued

\begin{tabular}{|c|c|c|c|c|c|c|c|}
\hline $\begin{array}{l}\text { Reference; } \\
\text { study site(s) }\end{array}$ & Study population & $\begin{array}{l}\text { Timing of } \\
\text { sampling }\end{array}$ & MDT status & $\begin{array}{l}\text { ENL treatment } \\
\text { status }\end{array}$ & Type of samples & Measures & Findings \\
\hline $\begin{array}{l}\text { Rojas et al. (50); } \\
\text { Brazil } \beta\end{array}$ & $\begin{array}{l}19 \text { ENL, } 10 \text { BL/LL non- } \\
\text { ENL patients, } 13 \text { family } \\
\text { contacts; } 15 \text { healthy } \\
\text { non-contacts }\end{array}$ & ND & $\begin{array}{l}\text { Both untreated } \\
\text { patients and } \\
\text { patients on MDT } \\
\text { for } 1-72 \text { months }\end{array}$ & ND & Serum & $\begin{array}{l}\text { Anti-PGL-I lgM, } \\
\text { IgG responses to } \\
\text { recombinant } 10-\mathrm{kDa} \\
\text { heat shock protein }\end{array}$ & $\begin{array}{l}\text { IgM anti-PGL-I and IgG anti-10-kDa heat shock protein } \\
\text { antibodies were constituents of the immune complexes in } \\
\text { patients with ENL while free antibody levels did not differentiate } \\
\text { between ENL and non-ENL patients }\end{array}$ \\
\hline $\begin{array}{l}\text { Beuria et al. } \\
\text { (192); India }\end{array}$ & $\begin{array}{l}18 \mathrm{ENL}, 44 \mathrm{BL} / \mathrm{LL}, 62 \\
\mathrm{BT} / \mathrm{TT}, 17 \mathrm{HC}\end{array}$ & ND & $\begin{array}{l}\text { Most patients } \\
\text { on MDT }\end{array}$ & ND & Serum & $\begin{array}{l}\text { IgG subclass levels to } \\
\text { M. leprae sonicated } \\
\text { antigens (MLSA) and } \\
\text { PGL-I }\end{array}$ & $\begin{array}{l}\text { ENL patients showed a significant fall in lgG3 antibody to MLSA } \\
\text { and PGL-I compared to BL/LL leprosy controls }\end{array}$ \\
\hline $\begin{array}{l}\text { Freire et al. (193); } \\
\text { Brazil }\end{array}$ & $\begin{array}{l}59 \text { leprosy (including } 12 \\
\text { ENL), } 60 \mathrm{HC}\end{array}$ & ND & $\begin{array}{l}11 / 12 \text { ENL } \\
\text { were on MDT } \\
\text { and } 1 / 12 \text { with } \\
\text { dapsone }\end{array}$ & ND & Serum & $\begin{array}{l}\text { Anti-neutrophil } \\
\text { cytoplasmic } \\
\text { antibodies (ANCA) }\end{array}$ & $\begin{array}{l}\text { ANCA are present in } 28.8 \% \text { of leprosy patients but are not } \\
\text { related to vasculitis in the ENL reaction and are not a marker of a } \\
\text { specific clinical from }\end{array}$ \\
\hline $\begin{array}{l}\text { Partida-Sanchez } \\
\text { et al. (142); } \\
\text { Mexico } \delta\end{array}$ & $\begin{array}{l}9 \mathrm{ENL}, 10 \text { non-ENL } \\
\text { leprosy, } 10 \mathrm{HC}\end{array}$ & $\begin{array}{l}\text { Beginning of } \\
\text { reaction and after } \\
1 \text { and } 2 \text { months of } \\
\text { thalidomide }\end{array}$ & $\begin{array}{l}\text { All patients on } \\
\text { MDT }\end{array}$ & $\begin{array}{l}\text { Before thalidomide, } \\
\text { second sample } \\
\text { after } 1 \text { month } \\
\text { of thalidomide } \\
\text { and third after } \\
2 \text { months }\end{array}$ & Plasma & $\begin{array}{l}\text { IgM and IgG antibody } \\
\text { subclasses to } M \text {. } \\
\text { leprae sonicated } \\
\text { extract }\end{array}$ & $\begin{array}{l}\text { ENL at the onset of reaction had slightly higher anti-M. leprae } \\
\text { IgG1 and IgG2 antibodies compared to non-ENL but not } \\
\text { statistically significant }\end{array}$ \\
\hline $\begin{array}{l}\text { Stefani et al. } \\
\text { (194); Brazil }\end{array}$ & $\begin{array}{l}600 \text { leprosy: } 31 \mathrm{ENL} \\
45 \mathrm{~T} 1 \mathrm{R}, \mathrm{HC}\end{array}$ & Untreated & $\begin{array}{l}\text { Before MDT } \\
\text { treatment }\end{array}$ & Untreated & Serum & $\begin{array}{l}\lg M \text { and } \lg G \\
\text { anti-PGL-I }\end{array}$ & $\begin{array}{l}\text { Patients presenting with T1R or ENL at leprosy diagnosis have } \\
\text { same level of IgM anti-PGL-I antibody response as leprosy } \\
\text { patients without reactions at diagnosis }\end{array}$ \\
\hline $\begin{array}{l}\text { Beuria et al. } \\
\text { (195); India }\end{array}$ & $\begin{array}{l}44 \mathrm{BL} / \mathrm{LL}, 62 \mathrm{TT} / \mathrm{BT}, 18 \\
\text { ENL, } 15 \mathrm{~T} 1 \mathrm{R}, 17 \mathrm{HC}\end{array}$ & ND & $\begin{array}{l}\text { BL/LL: } 90 \% \text { on } \\
\text { MDT } \\
\text { TT/BT: mostly } \\
\text { untreated }\end{array}$ & $\begin{array}{l}\text { Steroids after } \\
\text { collection of } \\
\text { samples }\end{array}$ & Serum & $\begin{array}{l}\lg G 1, \lg G 2, \lg G 3 \text { and } \\
\operatorname{lgG} 4 \text { to LAM }\end{array}$ & $\begin{array}{l}\text { Reduction in IgG3 in ENL compared to active BL/LL } \\
\text { Higher IgG1 in ENL than T1R }\end{array}$ \\
\hline $\begin{array}{l}\text { Hamerlinck et al. } \\
\text { (196); Philippines, } \\
\text { Netherlands }\end{array}$ & $\begin{array}{l}13 \mathrm{ENL}, 22 \mathrm{~T} 1 \mathrm{R}, 26 \\
\text { leprosy unreactional, } \\
10 \mathrm{HC}\end{array}$ & $\begin{array}{l}\text { Serial samples } \\
\text { during MDT: } 2 \\
\text { ENL follow-up } \\
\text { and received } \\
\text { corticosteroids, } \\
14 \text { leprosy free of } \\
\text { reactions, } 4 \text { T1R } 6 \text {, } \\
\text { 12, } 18,30 \text { months } \\
\text { during follow-up }\end{array}$ & $\begin{array}{l}13 \text { ENL before } \\
\text { MDT, } 2 \text { ENL } \\
\text { during MDT }\end{array}$ & $\begin{array}{l}\text { During ENL before } \\
\text { treatment }\end{array}$ & Serum & Neopterin & $\begin{array}{l}\text { T1R and ENL higher neopterin levels compared to non-reactional } \\
\text { individuals } \\
\text { Corticosteroid treatment reduces levels of neopterin }\end{array}$ \\
\hline $\begin{array}{l}\text { Mahaisavariya } \\
\text { et al. (197); } \\
\text { Thailand }\end{array}$ & $\begin{array}{l}95 \text { leprosy patients: } 63 \\
\text { non-reactional, } 19 \text { T1R, } \\
13 \text { ENL }\end{array}$ & $\begin{array}{l}\text { A biopsy at time of } \\
\text { diagnosis and an } \\
\text { additional biopsy } \\
\text { later, in some } \\
\text { cases at the time } \\
\text { of reaction }\end{array}$ & ND & $\begin{array}{l}\text { Before } \\
\text { antireactional } \\
\text { treatment? }\end{array}$ & Skin & Mast cells & $\begin{array}{l}\text { Reduction of mast cell counts in both T1R and ENL compared to } \\
\text { non-reactional patients }\end{array}$ \\
\hline
\end{tabular}


TABLE 5 | Continued

\begin{tabular}{|c|c|c|c|c|c|c|c|}
\hline $\begin{array}{l}\text { Reference; } \\
\text { study site(s) }\end{array}$ & Study population & $\begin{array}{l}\text { Timing of } \\
\text { sampling }\end{array}$ & MDT status & $\begin{array}{l}\text { ENL treatment } \\
\text { status }\end{array}$ & Type of samples & Measures & Findings \\
\hline $\begin{array}{l}\text { Schon et al. } \\
\text { (198); Ethiopia }\end{array}$ & $4 \mathrm{ENL}, 5 \mathrm{~T} 1 \mathrm{R}$ & ND & $\begin{array}{l}\text { ENL cases: } \\
2 \text { MDT } \\
\text { untreated and } 2 \\
\text { MDT-treated }\end{array}$ & Steroids & Urine & $\begin{array}{l}\text { Urinary levels of } \\
\text { metabolites of NO }\end{array}$ & $\begin{array}{l}\text { Urinary nitric oxide metabolites decreased significantly after } \\
\text { steroid treatment }\end{array}$ \\
\hline $\begin{array}{l}\text { Antunes et al. } \\
\text { (199); Brazil }\end{array}$ & 3 ENL, 3 T1R & $\begin{array}{l}\text { First biopsy during } \\
\text { reactional episode } \\
\text { and second during } \\
\text { remission }\end{array}$ & On MDT & $\begin{array}{l}\text { Thalidomide for } \\
\text { ENL }\end{array}$ & Skin & $\begin{array}{l}\text { Neuropeptides; } \\
\text { quantification of mast } \\
\text { cells and their subsets }\end{array}$ & $\begin{array}{l}\text { Increase mast cells in the inflammatory infiltrate of the reactional } \\
\text { (both T1R and ENL) biopsies compared to non-reactional }\end{array}$ \\
\hline $\begin{array}{l}\text { Rada et al. (200); } \\
\text { Venezuela }\end{array}$ & $\begin{array}{l}29 \mathrm{ENL}, 19 \mathrm{MB} \text { not } \\
\text { reactional, } 11 \mathrm{~PB} \text {, } \\
28 \mathrm{HC}\end{array}$ & Before treatment & $\begin{array}{l}\text { Untreated } \\
\text { samples }\end{array}$ & Untreated samples & $\begin{array}{l}\text { Serum } \\
\text { PBMC }\end{array}$ & Nitrite/Nitrate levels & $\begin{array}{l}\text { Supernatants of PBMC from ENL patients significantly elevated } \\
\text { levels of nitrite/nitrates compared to LL or tuberculoid leprosy }\end{array}$ \\
\hline $\begin{array}{l}\text { Sunderkotter } \\
\text { et al. (201); Brazil }\end{array}$ & $\begin{array}{l}\text { Skin Biopsies: } 41 \\
\text { non-reactional leprosy, } \\
8 \text { ENL, } 10 \text { T1R; Serum } \\
\text { samples: 16ENL, 5RR, } \\
7 T, 13 B T / B B / L L, \\
19 \text { HC }\end{array}$ & Untreated samples & $\begin{array}{l}\text { Skin biopsies: } \\
42 \text { untreated } \\
\text { non-reactional } \\
\text { leprosy } \\
8 \text { ENL of which } \\
5 \text { MDT }\end{array}$ & $\begin{array}{l}\text { Before treatment } \\
\text { with steroids or } \\
\text { thalidomide }\end{array}$ & $\begin{array}{l}\text { Serum } \\
\text { Skin }\end{array}$ & MRP8, MRP14 & $\begin{array}{l}\text { Increase of serum levels of MRP8 and MRP14 in ENL } \\
\text { Higher percentage of MRP8 }{ }^{+} \text {and MRP14+ cells in ENL skin } \\
\text { lesions than non-reactional }\end{array}$ \\
\hline $\begin{array}{l}\text { Nigam et al. } \\
\text { (202); India }\end{array}$ & $\begin{array}{l}80 \text { leprosy: } 10 \text { ENL and } \\
10 \mathrm{~T} 1 \mathrm{R} ; 20 \mathrm{HC}\end{array}$ & ND & ND & ND & Serum & Deaminase & Deaminase levels were higher in patients with reaction \\
\hline $\begin{array}{l}\text { Villahermosa } \\
\text { et al. (134); } \\
\text { Philippines } \gamma, \delta\end{array}$ & $22 \mathrm{ENL}$ & $\begin{array}{l}\text { Before thalidomide } \\
\text { administration } \\
\text { and at study } \\
\text { weeks } 3 \text { and } 7 \\
\text { during thalidomide } \\
\text { treatment }\end{array}$ & $\begin{array}{l}\text { MDT was } \\
\text { continued } \\
\text { during the study }\end{array}$ & $\begin{array}{l}\text { Samples untreated } \\
\text { for antireactional } \\
\text { drugs and during } \\
\text { thalidomide } \\
\text { treatment }\end{array}$ & Urine & Neopterin & ENL higher neopterin values in urine than $\mathrm{HC}$ \\
\hline $\begin{array}{l}\text { Iyer et al. (143); } \\
\text { Indonesia } \delta\end{array}$ & $\begin{array}{l}131 \text { leprosy patients } \\
\text { (44 ENL), } 112 \mathrm{HC}\end{array}$ & ND & $\begin{array}{l}\text { Patients were } \\
\text { classified } \\
\text { irrespective of } \\
\text { MDT status }\end{array}$ & $\begin{array}{l}\text { Prednisolone to } \\
\text { treat reactions }\end{array}$ & Plasma & Neopterin & Neopterin no significant difference between ENL and non-ENL \\
\hline $\begin{array}{l}\text { Mohanty et al. } \\
\text { (203); India }\end{array}$ & $\begin{array}{l}14 \mathrm{ENL} \text { before and } \\
\text { after resolution of ENL, } \\
5 \mathrm{LL}\end{array}$ & $\begin{array}{l}\text { Before } \\
\text { commencing } \\
\text { antireactional } \\
\text { therapy and after } \\
\text { resolution of ENL }\end{array}$ & $\begin{array}{l}\text { All patients on } \\
\text { MDT }\end{array}$ & $\begin{array}{l}\text { Before } \\
\text { commencing } \\
\text { antireactional } \\
\text { treatment }\end{array}$ & Urine & $\begin{array}{l}\text { Urinary nitric oxide } \\
\text { metabolites }\end{array}$ & $\begin{array}{l}\text { Urinary nitric oxide metabolite higher in ENL compared to non- } \\
\text { reactional } L L \\
\text { These levels were reduced with resolution of reaction following } \\
\text { antireactional therapy }\end{array}$ \\
\hline $\begin{array}{l}\text { Santos et al. } \\
\text { (204); Brazil }\end{array}$ & 8 leprosy: 3 ENL & ND & $\begin{array}{l}\text { MDT during the } \\
\text { study: length of } \\
\text { MDT described }\end{array}$ & $\begin{array}{l}\text { Thalidomide during } \\
\text { the study }\end{array}$ & $\begin{array}{l}\text { PBMC } \\
\text { Skin }\end{array}$ & $\begin{array}{l}\text { B7-1 expression (flow } \\
\text { cytometry and } \mathrm{IHC} \text { ) }\end{array}$ & $\begin{array}{l}\text { Higher B7 expression in ENL and T1R patients than non- } \\
\text { reactional in both PBMC and cutaneous lesions }\end{array}$ \\
\hline
\end{tabular}


TABLE 5 | Continued

\begin{tabular}{|c|c|c|c|c|c|c|c|}
\hline $\begin{array}{l}\text { Reference; } \\
\text { study site(s) }\end{array}$ & Study population & $\begin{array}{l}\text { Timing of } \\
\text { sampling }\end{array}$ & MDT status & $\begin{array}{l}\text { ENL treatment } \\
\text { status }\end{array}$ & Type of samples & Measures & Findings \\
\hline $\begin{array}{l}\text { Silva et al. (205); } \\
\text { Brazil }\end{array}$ & $\begin{array}{l}25 \text { leprosy: } 5 \text { ENL and } \\
8 \text { T1R }\end{array}$ & $\begin{array}{l}0,2,4,6 \text {, and } \\
12 \text { months of MDT }\end{array}$ & $\begin{array}{l}\text { All patients on } \\
\text { MDT }\end{array}$ & Untreated & Plasma & $\begin{array}{l}\text { PGL-I levels } \\
\text { Neopterin }\end{array}$ & $\begin{array}{l}\text { Serum PGL-I levels did not differ significantly between ENL and } \\
\text { non-ENL } \\
\text { No significant correlation of neopterin between ENL and } \\
\text { non-ENL }\end{array}$ \\
\hline $\begin{array}{l}\text { Brito Mde et al. } \\
\text { (206); Brazil }\end{array}$ & $\begin{array}{l}104 \text { reactions after } \\
\text { completion of MDT ( } 44 \\
\text { ENL), } 104 \text { with no post- } \\
\text { treatment reactions } \\
\text { (8 ENL) }\end{array}$ & ND & $\begin{array}{l}\text { All patients were } \\
\text { treated with } \\
\text { MDT; half had } \\
\text { finished MDT }\end{array}$ & ND & Plasma & $\begin{array}{l}\text { ML flow (IgM } \\
\text { anti-PGL-I positive } \\
\text { serology) }\end{array}$ & $\begin{array}{l}\text { The patients with positive serology after MDT presented a } 10.4 \\
\text { fold greater chance of developing post-treatment reactions (ENL } \\
\text { or T1R) }\end{array}$ \\
\hline $\begin{array}{l}\text { Iyer et al. (207); } \\
\text { Indonesia }\end{array}$ & $\begin{array}{l}78 \text { leprosy ( } 36 \mathrm{ENL} \text { and } \\
3 \mathrm{~T} 1 \mathrm{R}), 36 \mathrm{HC}\end{array}$ & ND & $\begin{array}{l}30 \text { untreated } \\
\text { and } 48 \text { treated } \\
\text { patients }\end{array}$ & $\begin{array}{l}\text { Reactions were } \\
\text { treated using } \\
\text { prednisolone }\end{array}$ & $\begin{array}{l}\text { Serum } \\
\text { Skin }\end{array}$ & Chitotriocidase & $\begin{array}{l}\text { Serum chitotriosidase activity elevated in ENL compared with } \mathrm{HC} \\
\text { but not with non-ENL leprosy } \\
\text { Significant decline of serum chitotriosidase following } \\
\text { corticosteroid treatment in ENL }\end{array}$ \\
\hline $\begin{array}{l}\text { Lee et al. (24); } \\
\text { USA } \alpha\end{array}$ & $6 \mathrm{ENL}, 7 \mathrm{LL}$ & ND & ND & ND & Skin & $\begin{array}{l}\text { Microarrays and gene } \\
\text { expression; IHC for } \\
\text { E-selectin }\end{array}$ & $\begin{array}{l}\text { Upregulation of gene expression: in ENL lesions of the selectin } \\
\text { family of adhesion molecules } \\
\text { IHC: higher levels of E-selectin in ENL lesions }\end{array}$ \\
\hline $\begin{array}{l}\text { Massone et al. } \\
\text { (116); Brazil } \gamma\end{array}$ & $\begin{array}{l}20 \text { leprosy biopsies } \\
\text { (3 ENL) }\end{array}$ & $\begin{array}{l}\text { Biopsies at the } \\
\text { time of diagnosis }\end{array}$ & $\begin{array}{l}10,12 \text { and } \\
13 \text { months after } \\
\text { beginning of } \\
\text { MDT for LL }\end{array}$ & Untreated & Skin & $\begin{array}{l}\text { Presence, frequency } \\
\text { and distribution } \\
\text { of plasmacytoid } \\
\text { dendritic cells }\end{array}$ & CD123 expression was observed in 2/3 ENL biopsies \\
\hline $\begin{array}{l}\text { Rada et al. (135); } \\
\text { Venezuela } \gamma\end{array}$ & $\begin{array}{l}81 \mathrm{LL}, 41 \mathrm{BL}, 41 \mathrm{BB} \text {, } \\
3 \% \mathrm{BT}\end{array}$ & ND & ND & ND & Blood & $\begin{array}{l}\text { Serological } \\
\text { immunological tests to } \\
\text { various mycobacterial } \\
\text { proteins }\end{array}$ & $\begin{array}{l}\text { Mean antibody values against complete mycobacterial proteins } \\
\text { higher in non-reactional individuals }\end{array}$ \\
\hline $\begin{array}{l}\text { Teles et al. (176); } \\
\text { Brazil } \delta\end{array}$ & $\begin{array}{l}32 \text { leprosy: } 10 \text { ENL, } \\
8 \mathrm{~T} 1 \mathrm{R}\end{array}$ & $\begin{array}{l}4 \text { ENL patients } \\
\text { before and during } \\
\text { reaction biopsy } \\
\text { samples }\end{array}$ & $\begin{array}{l}\text { All patients were } \\
\text { receiving MDT }\end{array}$ & ND & $\begin{array}{l}\text { Skin } \\
\text { Serum }\end{array}$ & $\begin{array}{l}\text { MMP-2, MMP-9, } \\
\text { TIMP-1 }\end{array}$ & $\begin{array}{l}\text { RT-PCR for MMP-2 and MMP-9 versus TIMP-1 in ENL } \\
\text { sequential samples in } 4 \text { ENL patients: TNF- } \alpha \text {, MMP- } 2 \text { and MMP- } \\
9 \text { mRNA enhanced IHC and confocal microscopy: absence of } \\
\text { MMP positivity in ENL epidermis ELISA in sera of ENL: elevated } \\
\text { MMP-9 but not TIMP-1 compared to non-reactional patients }\end{array}$ \\
\hline $\begin{array}{l}\text { Jadhav et al. } \\
\text { (149); India } \delta\end{array}$ & $\begin{array}{l}303 \mathrm{MB} \text { followed up for } \\
2 \text { years: } 5 \mathrm{ENL}\end{array}$ & $\begin{array}{l}\text { Serum samples } \\
\text { at the time of } \\
\text { recruitment }\end{array}$ & $\begin{array}{l}\text { Newly registered } \\
\text { MB patients: no } \\
\text { MDT }\end{array}$ & Untreated & Serum & $\begin{array}{l}\text { Antibodies to PGL-I, } \\
\text { LAM, ceramide, S100 }\end{array}$ & No statistically significant outcome for ENL \\
\hline $\begin{array}{l}\text { Lockwood et al. } \\
\text { (178); India } \delta\end{array}$ & $\begin{array}{l}303 \text { new MB leprosy } \\
\text { (13 ENL) }\end{array}$ & $\begin{array}{l}\text { Skin biopsies at } \\
\text { enrollment }\end{array}$ & $\begin{array}{l}\text { Before MDT } \\
\text { treatment } \\
\text { started }\end{array}$ & $\begin{array}{l}\text { Before } \\
\text { antireactional } \\
\text { treatment }\end{array}$ & Nerve & $\begin{array}{l}\text { Immunostaining for } \\
\text { CD68 and iNOS }\end{array}$ & $\begin{array}{l}\text { Reactional biopsies had significantly fewer } \mathrm{CD}^{+} 8^{+} \text {cells than } \\
\text { non-reactional } \\
\text { Nearly all biopsies in the LL group had } \mathrm{CD} 68^{+} \text {cells present and } \\
\text { these were not altered in ENL } \\
\text { ENL showed some iNOS staining but not significant differences } \\
\text { with non-ENL }\end{array}$ \\
\hline
\end{tabular}


TABLE 5 | Continued

\begin{tabular}{|c|c|c|c|c|c|c|c|}
\hline $\begin{array}{l}\text { Reference; } \\
\text { study site(s) }\end{array}$ & Study population & $\begin{array}{l}\text { Timing of } \\
\text { sampling }\end{array}$ & MDT status & $\begin{array}{l}\text { ENL treatment } \\
\text { status }\end{array}$ & Type of samples & Measures & Findings \\
\hline $\begin{array}{l}\text { Martiniuk et al. } \\
\text { (179); Nepal and } \\
\text { USA } \delta\end{array}$ & $7 \mathrm{ENL}$ & $\begin{array}{l}\text { Pre- and post- } \\
\text { treatment with } \\
\text { thalidomide }\end{array}$ & ND & $\begin{array}{l}\text { Pre- and post- } \\
\text { treatment with } \\
\text { thalidomide }\end{array}$ & Skin & $\begin{array}{l}\text { RT-PCR for hROR } \mathrm{T} \text {, } \\
\text { hCD70, hCD27, } \\
\text { hPLZF-1, hCTLA4, } \\
\text { hAHR, hiNOS2, } \\
\text { hARNT, hIDO, hGARP, } \\
\text { hCD46 }\end{array}$ & $\begin{array}{l}\text { Reduction in CD70, GARP, IDO and increase of RORyT, ARNT } \\
\text { following thalidomide treatment }\end{array}$ \\
\hline $\begin{array}{l}\text { Singh et al. (208); } \\
\text { India }\end{array}$ & $\begin{array}{l}240 \text { leprosy: } 19 \mathrm{ENL} \\
69 \mathrm{BL} / \mathrm{LL}\end{array}$ & ND & ND & ND & Serum & $\begin{array}{l}\text { IgG antibodies against } \\
\text { keratin }\end{array}$ & No significant difference in ENL \\
\hline $\begin{array}{l}\text { Dupnik et al. (58); } \\
\text { Brazil } \beta, \delta\end{array}$ & $\begin{array}{l}11 \mathrm{ENL}, 11 \mathrm{~T} 1 \mathrm{R}, \\
19 \text { leprosy controls } \\
\text { without reactions for } \\
\text { microarray; additional } \\
28 \text { leprosy ( } 6 \text { ENL, } 11 \\
\text { T1R, } 11 \text { non-reactional) } \\
\text { for qPCR validation; } 3 \\
\text { ENL for IHC }\end{array}$ & ND & $\begin{array}{l}\text { 3/11 ENL } \\
\text { pre-treatment, } \\
2 / 11 \mathrm{ENL} \text { on } \\
\text { treatment and } \\
6 / 11 \text { post- } \\
\text { treatment; } \\
\text { leprosy controls } \\
\text { matched } \\
\text { for stage of } \\
\text { treatment }\end{array}$ & $\begin{array}{l}\text { Excluded patients } \\
\text { on steroids } \\
\text { within } 7 \text { days } \\
\text { and thalidomide } \\
\text { within } 28 \text { days of } \\
\text { enrollment }\end{array}$ & PBMC & $\begin{array}{l}\text { Microarray and qPCR } \\
\text { for transcriptional } \\
\text { profile of PBMC; } \\
\text { Flow cytometry for } \\
\text { monocyte populations }\end{array}$ & $\begin{array}{l}\text { Top } 3 \text { KEGG pathways in ENL were S. aureus infection, SLE, } \\
\text { cytokine-cytokine receptor interaction } \\
\text { No significant difference in the proportion of circulating } \\
\text { monocytes between reactional and non-reactional PBMC }\end{array}$ \\
\hline $\begin{array}{l}\text { Mandal et al. } \\
\text { (209); India }\end{array}$ & $\begin{array}{l}15 \text { reactional (both ENL } \\
\text { and } T 1 \mathrm{R}), 15 \mathrm{HC}\end{array}$ & ND & ND & ND & PBMC & $\begin{array}{l}\text { Vitamin D receptor } \\
\text { (VDR) mRNA }\end{array}$ & All the individuals with low VDR expression manifested ENL \\
\hline $\begin{array}{l}\text { Dias et al. (80); } \\
\text { Brazil } \delta\end{array}$ & $\begin{array}{l}30 \mathrm{ENL}, 24 \mathrm{BL} / L \mathrm{~L}, \\
31 \mathrm{HC}\end{array}$ & $\begin{array}{l}\text { Upon diagnosis of } \\
\text { reaction }\end{array}$ & $\begin{array}{l}\text { BL/LL before } \\
\text { MDT but most } \\
\text { ENL on MDT }\end{array}$ & $\begin{array}{l}\text { Before treatment } \\
\text { with thalidomide or } \\
\text { steroids }\end{array}$ & $\begin{array}{l}\text { PBMC } \\
\text { (monocytes, } \\
\text { B-cells, pDCs) } \\
\text { Skin }\end{array}$ & Expression of TLR9 & Skin lesions and PBMC of ENL express higher levels of TLR-9 \\
\hline $\begin{array}{l}\text { Schmitz et al. } \\
\text { (25); Brazil } \alpha\end{array}$ & $\begin{array}{l}62 \text { leprosy: } 22 \mathrm{ENL} \\
16 \mathrm{HC}\end{array}$ & $\begin{array}{l}\text { ENL: before } \\
\text { and } 7 \text { days after } \\
\text { thalidomide }\end{array}$ & $\begin{array}{l}\text { Patients before } \\
\text { and after MDT }\end{array}$ & $\begin{array}{l}\text { Before and after } \\
\text { thalidomide }\end{array}$ & Skin & $\begin{array}{l}\text { CD64 expression by } \\
\text { qPCR and IHC }\end{array}$ & $\begin{array}{l}\text { CD64 mRNA and protein expressed in ENL lesions } \\
\text { Thalidomide reduced CD64 expression }\end{array}$ \\
\hline
\end{tabular}

$\alpha$, also in Table 1; $\beta$, also in Table 2; $\gamma$, also in Table 3; $\delta$, also in Table 4.

BB, mid-borderline leprosy; BL, borderline lepromatous leprosy; BT, borderline tuberculoid leprosy: ENL, erythema nodosum leprosum; HC, healthy controls; ICAM-1, keratinocyte intracellular adhesion molecule 1; ICS, immune

complexes; LAM, lipoarabinomannan; LL, lepromatous leprosy polar; MLSA, M. leprae sonicated antigens; ND, not described; PGL I, phenolic glycolipid I; SLE, systemic lupus erythematosus; TB, tuberculosis; TT, tuberculoid leprosy; polar,\%GO, proportion of oligosaccharide chains on the Fc fragment of Ig G which terminate with N-acetylg/ucosamine and not galactose. 


\section{New Suggested Pathogenetic Mechanisms}

Two recent studies of gene expression provide evidence of activation of novel molecular pathways in ENL.

Lee et al performed bioinformatic pathways analysis of gene expression profiles in leprosy skin lesions and found "cell movement" as the top biological pathway characterizing ENL (24). The study further described a neutrophil recruitment pathway including genes of key molecules that mediate neutrophil binding to endothelial cells (24). This neutrophil recruitment pathway characterizing ENL was inhibited by thalidomide (24). Consistent with these findings is a study of transcriptional profiles in PBMC of leprosy patients by Dupnik et al which identified "granulocyte adhesion and diapedesis" as one of the top canonical pathways characterizing ENL (58). Dupnik et al. identified 517 differentially expressed genes in patients with ENL (58). The pathway analysis revealed that the top three Kyoto Encyclopedia of Genes and Genomes (KEGG) pathways that changed in ENL were Staphylococcus aureus infection, systemic lupus erythematosus (SLE), and cytokine-cytokine receptor interaction, while the complement and coagulation pathway was also associated with ENL (58). CCL5 was the most significant upstream regulator in the array followed by IFN- $\gamma$ (58). Transcripts uniquely increased in ENL included the complement receptors C3AR1 and C5AR1 while uniquely decreased transcripts in ENL included IL-10 and cytotoxic T-lymphocyte associates protein 4 (CTLA-4), modulators of T-cell responses (58). Hepcidin, catholicidin, antimicrobial peptides, C1q, and defencins had also an increased expression in ENL, while CCL2, CCL3, and SOD2 could be potential biomarkers for ENL (58). Transcripts increased in PBMC from ENL patients also included FcyR1 (CD64), FPR1, and FPR2, which recognize formylated peptides produced by bacteria triggering receptor on myeloid cells 1 (TREM1) and the related molecule triggering receptor expressed on myeloid cells-like 1 (TREML-1) (58).

The microarray studies performed in skin lesions and PBMC have generated a long list of candidate genes that regulate immune function to be associated with ENL. These merit further research.

\section{LIMITATIONS OF THE SYSTEMATIC REVIEW}

PubMed was the only database used to identify eligible studies. This will have resulted in studies published in journals not listed in PubMed being omitted from our review. A search of gray literature may also have contributed data which may have influenced our conclusions. The high heterogeneity of included studies in terms of study questions and outcomes and the different methodologies used meant that a meta-analysis was not possible.

\section{METHODOLOGICAL CONSIDERATIONS OF THE STUDIES INCLUDED IN THE SYSTEMATIC REVIEW}

Many of the studies of immunological features of ENL contain significant limitations in both design and reporting. Most seriously $66 \%$ of the studies did not have a case definition of ENL.
More than $70 \%$ of studies sampled individuals at a single time point. Sampling at two time points was seen in $21.2 \%$ of studies, 3 time points in $2.7 \%$ of studies, whereas 4 or more time points was described in only $5.5 \%$ of studies. Some studies did not have appropriate controls- patients with uncomplicated BL and LL. Although $93.2 \%$ of studies used BL/LL patients as controls, the remaining $6.8 \%$ of studies used other control groups such as healthy volunteers or leprosy contacts or tuberculoid leprosy patients or patients with Type 1 reaction. Often the controls were not matched for age, sex or treatment status. Controls should be matched for age and sex since these factors may influence $\mathrm{T}$ cell and neutrophil numbers and functions (214-216) as well as TNF$\alpha$ and other cytokine levels (217).

ENL is a condition that can be acute, recurrent, or chronic, and therefore, the timing of sample collection is crucial. No information on the timing of the sampling is described in $54.8 \%$ of all studies. The importance of timing for sample collection during ENL could explain the discrepancies observed in multiple studies as has been suggested in the studies addressing the role of neutrophils in ENL. Studies using serial sampling yield more meaningful data compared to cross-sectional studies. The interval between time points is important and needs to be kept as consistent as possible for all study subjects.

Only one study matched BL/LL controls and ENL cases for length of MDT. Patients may develop ENL prior to the diagnosis of leprosy, during MDT or after successful completion of MDT. MDT may affect the immune status of leprosy patients and thus the matching of cases and controls for this variable is important. Two of the components of MDT, dapsone and clofazimine, have been associated with alterations in neutrophil and lymhocyte function (218-220). Dapsone stimulates neutrophil migration (218) and inhibits production of Prostaglandin $E_{2}$ by neutrophils (220). In addition, dapsone inhibits lymphocyte transformation (218). On the other hand, clofazimine enhances production of Prostaglandin $\mathrm{E}_{2}$ by neutrophils (220). Dapsone and anti-dapsone antibodies have been identified in circulating ICs of leprosy patients (221). Circulating cytokine and chemokine levels also change with MDT $(165,222,223)$. In addition, gene expression studies could be affected by MDT since the MDT component rifampicin may modify the expression of certain housekeeping genes (224). A total of $30.8 \%$ of studies did not report the MDT status of their cases or controls, $12.3 \%$ collected untreated patient samples, whereas $56.2 \%$ collected patient samples at various stages of MDT.

The effect of immunosuppressive drugs used to treat ENL on the findings of studies is an important factor which should be considered. In $37.7 \%$ of studies, there was no reporting of whether participants were on ENL treatment when samples were collected. Treatment with corticosteroids affects T-cells and neutrophil function $(225,226)$ and also gene expression studies by influencing housekeeping genes (224). Treatment with thalidomide may increase the neutrophil numbers, at least partially through differentially modulating the surface expression of markers CD18 and CD44 by the neutrophils in the bone marrow and the spleen (227). Thalidomide treatment may also affect T-cell functions by suppressing $\mathrm{CD}^{+}{ }^{+} \mathrm{T}$-cell proliferation while increasing their conversion to $\mathrm{CD} 4^{+} \mathrm{FoxP}^{+}$Tregs (228). 
Moreover, thalidomide treatment may reduce cytokine levels (229). Less than half (34.2\%) of studies indicate that samples were obtained prior to the start of ENL treatment.

Only $17.8 \%$ of all studies collected samples from more than one system, while samples from both blood and skin were described in only $12.3 \%$ of all studies.

\section{FUTURE STUDY DESIGN}

Studies of ENL may be difficult to design and conduct. In addition, no animal model of ENL is available. Obtaining sufficient numbers of patients so that studies are adequately powered is difficult unless multicenter studies are performed which increase the logistical complexity and cost of the research. Patients are often on treatment (both MDT and immunosuppression) which may influence the study outcomes.

A large cohort study of newly diagnosed patients with BL and LL would be optimal in allowing matching of cases and controls. Some BL/LL patients who have not developed ENL at enrollment in the study should be recruited and followed until they develop the disorder. Detailed clinical information which includes demographic data, ENL severity using a robust measure, treatment status, in conjunction with well-timed and documented specimen collection (preferably of blood and skin), effective specimen storage, and transportation. ENL is a systemic disease and ideally samples from more than one system, i.e., both blood and skin should be obtained where appropriate. Well-designed laboratory experiments using a wide range of techniques should be used to interrogate such important specimens.

\section{CONCLUSION}

Figure 2 gives an overview of the immunology of ENL.

Our understanding of the causes of ENL is limited. The factors that initiate and/or sustain it might help to identify strategies to prevent or control the associated inflammation.

There is some evidence to support a role for neutrophils and ICs/complement in the inflammation associated with ENL; however, their role in the initiation of ENL remains unclear. The increase of TNF- $\alpha$ and other pro-inflammatory cytokines during ENL has been shown in multiple investigations, while suppression of TNF- $\alpha$ leads to clinical improvement. T-cell subsets appear to be important in ENL since multiple reports describe an increased $\mathrm{CD} 4^{+} / \mathrm{CD}^{+}$ratio in ENL patients compared to BL/LL controls.

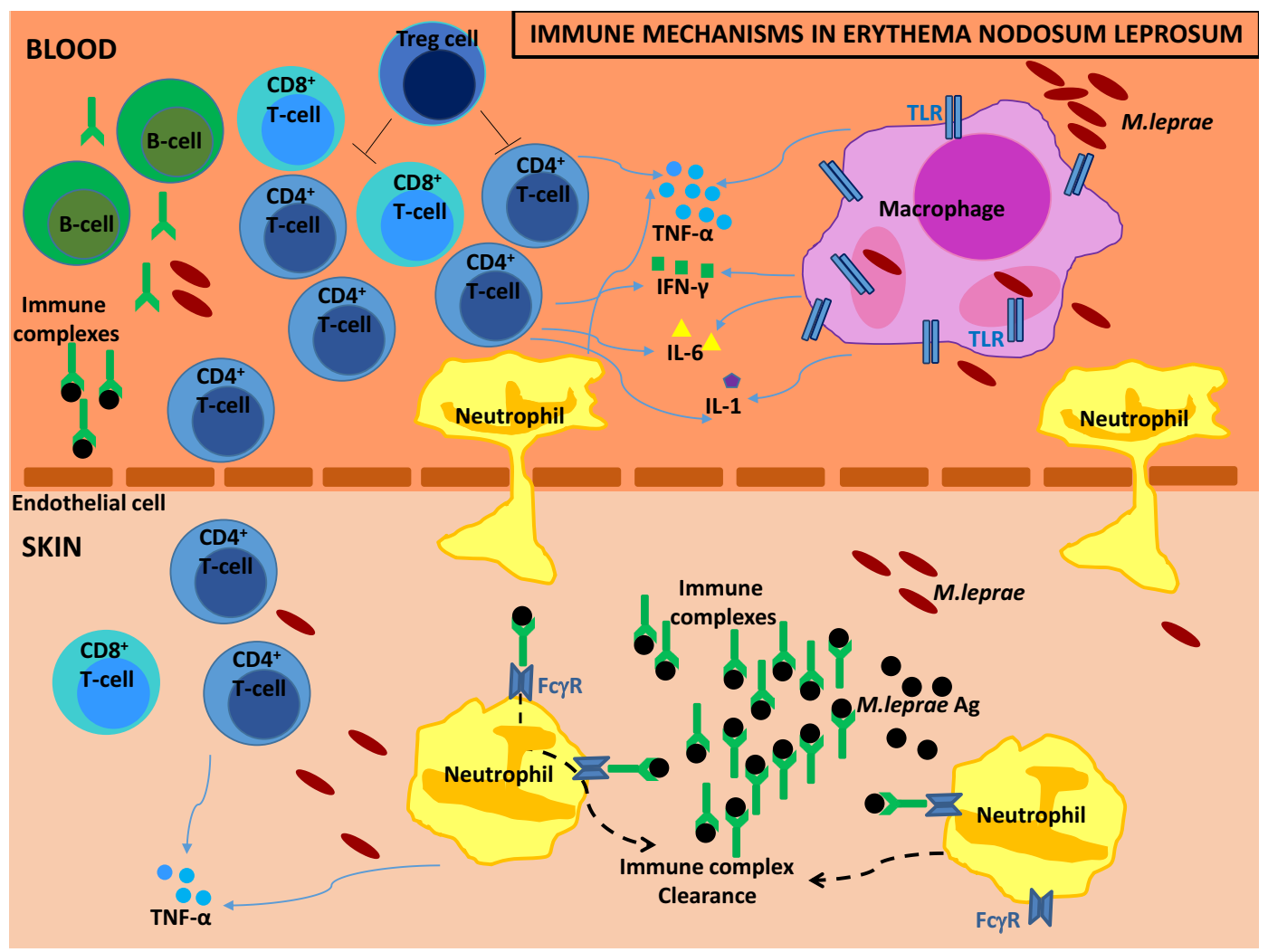

FIGURE 2 | Immune mechanisms in erythema nodosum leprosum (ENL). The diagram illustrates the different immune mechanisms which have been described in the literature of ENL. High volume of immune complexes (ICs) are formulated due to the increased antibody formation by the B cells and the increased mycobacterial antigens by fragmentation of the M. leprae bacilli. ICs are deposited in the skin. Neutrophils are drawn to the skin where they help in the IC clearance using their surface Fcy receptors. An increase of $\mathrm{CD}^{+} / \mathrm{CD} 8^{+} \mathrm{T}$ cell subset ratio in both peripheral blood and skin characterizes the disorder. Macrophages form the M. leprae intracellular niche and in concert with neutrophils and T-cells secret high levels of tumor necrosis factor (TNF)- $\alpha$ and other pro-inflammatory cytokines to further complicate the phenotype of ENL. 
New technologies such as microarray studies pave the way and may lead to novel immunological pathways associated with ENL. Further research of the association of ENL with pathophysiological pathways such as the SLE pathway or the S. aureus infection pathway may improve our understanding of the disorder and potentially lead to novel therapeutic strategies. There are still large gaps in our understanding of this severe complication of leprosy despite the large number of studies examining the immunology of ENL. A systems biology approach may provide new insights.

This systematic review has highlighted the complex interactions at play in ENL and the difficulty in elucidating the various inflammatory pathways. We should rise to the challenge of understanding how these mechanisms operate and interact so that we can improve the treatment of patients with ENL.

\section{REFERENCES}

1. Britton WJ, Lockwood DN. Leprosy. Lancet (2004) 363(9416):1209-19. doi:10.1016/S0140-6736(04)15952-7

2. Ridley DS, Jopling WH. Classification of leprosy according to immunity. A five-group system. Int J Lepr Other Mycobact Dis (1966) 34(3):255-73.

3. Turk JL, Waters MF. Cell-mediated immunity in patients with leprosy. Lancet (1969) 2(7614):243-6. doi:10.1016/S0140-6736(69)90009-9

4. Moran CJ, Ryder G, Turk JL, Waters MF. Evidence for circulating immune complexes in lepromatous leprosy. Lancet (1972) 2(7777):572-3. doi:10.1016/ S0140-6736(72)91962-9

5. Scollard DM, Smith T, Bhoopat L, Theetranont C, Rangdaeng S, Morens DM. Epidemiologic characteristics of leprosy reactions. Int J Lepr Other Mycobact Dis (1994) 62(4):559-67.

6. Walker SL, Balagon M, Darlong J, Doni SN, Hagge DA, Halwai V, et al. ENLIST 1: an international multi-centre cross-sectional study of the clinical features of erythema nodosum leprosum. PLoS Negl Trop Dis (2015) 9(9):e0004065. doi:10.1371/journal.pntd.0004065

7. Mabalay MC, Helwig EB, Tolentino JG, Binford CH. The histopathology and histochemistry of erythema nodosum leprosum. Int J Lepr (1965) 33:28-49.

8. Anthony J, Vaidya MC, Dasgupta A. Ultrastructure of skin in erythema nodosum leprosum. Cytobios (1983) 36(141):17-23.

9. Murphy GF, Sanchez NP, Flynn TC, Sanchez JL, Mihm MC Jr, Soter NA. Erythema nodosum leprosum: nature and extent of the cutaneous microvascular alterations. J Am Acad Dermatol (1986) 14(1):59-69. doi:10.1016/ S0190-9622(86)70008-X

10. Sehgal VN, Gautam RK, Koranne RV, Beohar PC. The histopathology of type I (lepra) and type II (ENL) reactions in leprosy. Indian J Lepr (1986) 58(2):240-3.

11. Adhe V, Dongre A, Khopkar U. A retrospective analysis of histopathology of 64 cases of lepra reactions. Indian J Dermatol (2012) 57(2):114-7. doi:10.4103/0019-5154.94278

12. Sarita S, Muhammed K, Najeeba R, Rajan GN, Anza K, Binitha MP, et al. A study on histological features of lepra reactions in patients attending the Dermatology Department of the Government Medical College, Calicut, Kerala, India. Lepr Rev (2013) 84(1):51-64.

13. Job CK, Gude S, Macaden VP. Erythema nodosum leprosum. A clinicopathologic study. Int J Lepr (1964) 32:177-84.

14. Pocaterra L, Jain S, Reddy R, Muzaffarullah S, Torres O, Suneetha S, et al. Clinical course of erythema nodosum leprosum: an 11-year cohort study in Hyderabad, India. Am J Trop Med Hyg (2006) 74(5):868-79.

15. Chandler DJ, Hansen KS, Mahato B, Darlong J, John A, Lockwood DN. Household costs of leprosy reactions (ENL) in rural India. PLoS Negl Trop Dis (2015) 9(1):e0003431. doi:10.1371/journal.pntd. 0003431

16. Walker SL, Lebas E, Doni SN, Lockwood DN, Lambert SM. The mortality associated with erythema nodosum leprosum in ethiopia: a retrospective

\section{AUTHOR CONTRIBUTIONS}

AP and SW were responsible for the study concept and design; made critical revision of the manuscript for important intellectual content. AP was responsible for acquisition, analysis, and interpretation of data and for drafting the manuscript. AP, SW, and DL edited the manuscript.

\section{ACKNOWLEDGMENTS}

We would like to thank Anna and Andreas Goulielmos for proof reading and grammatical error corrections.

\section{FUNDING}

This work was supported by Hospital and Homes of St. Giles.

hospital-based study. PLoS Negl Trop Dis (2014) 8(3):e2690. doi:10.1371/ journal.pntd.0002690

17. Shamseer L, Moher D, Clarke M, Ghersi D, Liberati A, Petticrew M, et al Preferred reporting items for systematic review and meta-analysis protocols (PRISMA-P) 2015: elaboration and explanation. BMJ (2015) 349:g7647. doi:10.1136/bmj.g7647

18. Kruger P, Saffarzadeh M, Weber AN, Rieber N, Radsak M, von Bernuth $\mathrm{H}$, et al. Neutrophils: between host defence, immune modulation, and tissue injury. PLoS Pathog (2015) 11(3):e1004651. doi:10.1371/journal. ppat.1004651

19. Leliefeld PH, Koenderman L, Pillay J. How neutrophils shape adaptive immune responses. Front Immunol (2015) 6:471. doi:10.3389/fimmu.2015 00471

20. Abalos RM, Tolentino JG, Bustillo CC. Histochemical study of erythema nodosum leprosum (ENL) lesions. Int J Lepr Other Mycobact Dis (1974) 42(4):385-91.

21. Hussain R, Lucas SB, Kifayet A, Jamil S, Raynes J, Uqaili Z, et al. Clinical and histological discrepancies in diagnosis of ENL reactions classified by assessment of acute phase proteins SAA and CRP. Int J Lepr Other Mycobact Dis (1995) 63(2):222-30.

22. Waters MF, Turk JL, Wemambu SN. Mechanisms of reactions in leprosy. Int J Lepr Other Mycobact Dis (1971) 39(2):417-28.

23. Pepler WJ, Kooij R, Marshall J. The histopathology of acute panniculitis nodosa leprosa (erythema nodosum leprosum). Int J Lepr (1955) 23(1): 53-60.

24. Lee DJ, Li H, Ochoa MT, Tanaka M, Carbone RJ, Damoiseaux R, et al. Integrated pathways for neutrophil recruitment and inflammation in leprosy. J Infect Dis (2010) 201(4):558-69. doi:10.1086/650318

25. Schmitz V, Prata RB, Barbosa MG, Mendes MA, Brandao SS, Amadeu TP, et al. Expression of CD64 on circulating neutrophils favoring systemic inflammatory status in erythema nodosum leprosum. PLoS Negl Trop Dis (2016) 10(8):e0004955. doi:10.1371/journal.pntd.0004955

26. Hogg N. The structure and function of Fc receptors. Immunol Today (1988) 9(7-8):185-7. doi:10.1016/0167-5699(88)91206-6

27. Herra CM, Keane CT, Whelan A. Increased expression of Fc gamma receptors on neutrophils and monocytes may reflect ongoing bacterial infection. J Med Microbiol (1996) 44(2):135-40. doi:10.1099/00222615-442-135

28. Song SH, Kim HK, Park MH, Cho HI. Neutrophil CD64 expression is associated with severity and prognosis of disseminated intravascular coagulation. Thromb Res (2008) 121(4):499-507. doi:10.1016/j.thromres.2007. 05.013

29. Buckle AM, Hogg N. The effect of IFN-gamma and colony-stimulating factors on the expression of neutrophil cell membrane receptors. J Immunol (1989) 143(7):2295-301.

30. Voorend CG, Post EB. A systematic review on the epidemiological data of erythema nodosum leprosum, a type 2 leprosy reaction. PLoS Negl Trop Dis (2013) 7(10):e2440. doi:10.1371/journal.pntd.0002440 
31. Goihman-Yahr M, Rodriguez-Ochoa G, Aranzazu N, Convit J. Polymorphonuclear activation in leprosy. I. Spontaneous and endotoxin-stimulated reduction of nitroblue tetrazolium: effects of serum and plasma on endotoxin-induced activation. Clin Exp Immunol (1975) 20(2): 257-64.

32. Sher R, Anderson R, Glover A, Wadee AA. Polymorphonuclear cell function in the various polar types of leprosy and erythema nodosum leprosum. Infect Immun (1978) 21(3):959-65.

33. Oliveira RB, Moraes MO, Oliveira EB, Sarno EN, Nery JA, Sampaio EP. Neutrophils isolated from leprosy patients release TNF-alpha and exhibit accelerated apoptosis in vitro. J Leukoc Biol (1999) 65(3):364-71.

34. Wiggins RC, Cochrane CG. Immune-complex-mediated biologic effects. N Engl J Med (1981) 304(9):518-20. doi:10.1056/NEJM198102263040904

35. Hoiby N, Doring G, Schiotz PO. The role of immune complexes in the pathogenesis of bacterial infections. Annu Rev Microbiol (1986) 40:29-53. doi:10.1146/annurev.mi.40.100186.000333

36. Schifferli JA, Ng YC, Peters DK. The role of complement and its receptor in the elimination of immune complexes. N Engl J Med (1986) 315(8):488-95. doi:10.1056/NEJM198608213150805

37. Wemambu SN, Turk JL, Waters MF, Rees RJ. Erythema nodosum leprosum: a clinical manifestation of the arthus phenomenon. Lancet (1969) 2(7627):933-5. doi:10.1016/S0140-6736(69)90592-3

38. Anthony J, Vaidya MC, Dasgupta A. Immunological methods employed in an attempt to induce erythema nodosum leprosum (ENL) in mice. Lepr India (1978) 50(3):356-62.

39. Ridley MJ, Ridley DS. The immunopathology of erythema nodosum leprosum: the role of extravascular complexes. Lepr Rev (1983) 54(2): 95-107.

40. Andreoli A, Brett SJ, Draper P, Payne SN, Rook GA. Changes in circulating antibody levels to the major phenolic glycolipid during erythema nodosum leprosum in leprosy patients. Int J Lepr Other Mycobact Dis (1985) 53(2):211-7.

41. Chakrabarty AK, Maire M, Saha K, Lambert PH. Identification of components of IC purified from human sera. II. Demonstration of mycobacterial antigens in immune complexes isolated from sera of lepromatous patients. Clin Exp Immunol (1983) 51(2):225-31.

42. Furukawa F, Ozaki M, Imamura S, Yoshida H, Pinrat A, Hamashima Y. Associations of circulating immune complexes, clinical activity, and bacterial index in Japanese patients with leprosy. Arch Dermatol Res (1982) 274(1-2):185-8. doi:10.1007/BF00510372

43. Rojas-Espinosa O, Mendez-Navarrete I, Estrada-Parra S. Presence of C1qreactive immune complexes in patients with leprosy. Clin Exp Immunol (1972) 12(2):215-23.

44. Wager O, Penttinen K, Almeida JD, Opromolla DV, Godal T, Kronvall G. Circulating complexes in leprosy studied by the platelet aggregation test. The platelet aggregation test and its relation to the Rubino test and other sero-immunological parameters in 135 patients with leprosy. Clin Exp Immunol (1978) 34(3):326-37.

45. Geniteau M, Adam C, Verroust P, Pasticier A, Saimot G, Coulaud JP, et al. [Immune complexes and complement in leprosy (author's transl)]. Nouv Presse Med (1981) 10(45):3697-700.

46. Bjorvatn B, Barnetson RS, Kronvall G, Zubler RH, Lambert PH. Immune complexes and complement hypercatabolism in patients with leprosy. Clin Exp Immunol (1976) 26(3):388-96.

47. Jayapal N, Shanmugasundaram N, Thomas PA, Valli PR, Thyagarajan SP, Subramanian S. A simple method to quantitate circulating immune complexes in different diseases. Indian J Pathol Microbiol (1989) 32(1):33-9.

48. Ramanathan VD, Sharma P, Ramu G, Sengupta U. Reduced complementmediated immune complex solubilization in leprosy patients. Clin Exp Immunol (1985) 60(3):553-8.

49. Ramanathan VD, Tyagi P, Ramanathan U, Katoch K, Sengupta U, Ramu G. Persistent reduced solubilization of immune complexes in lepromatous leprosy patients with reactions. Int J Lepr Other Mycobact Dis (1991) 59(1):5-11.

50. Rojas RE, Demichelis SO, Sarno EN, Segal-Eiras A. IgM anti-phenolic glycolipid I and IgG anti-10-kDa heat shock protein antibodies in sera and immune complexes isolated from leprosy patients with or without erythema nodosum leprosum and contacts. FEMS Immunol Med Microbiol (1997) 19(1):65-74. doi:10.1111/j.1574-695X.1997.tb01073.x
51. Tung KS, Kim B, Bjorvatn B, Kronvall G, McLaren LC, Williams RC Jr. Discrepancy between Clq deviation and Raji cell tests in detection of circulating immune complexes in patients with leprosy. J Infect Dis (1977) 136(2):216-21. doi:10.1093/infdis/136.2.216

52. Tyagi P, Ramanathan VD, Girdhar BK, Katoch K, Bhatia AS, Sengupta U. Activation of complement by circulating immune complexes isolated from leprosy patients. Int J Lepr Other Mycobact Dis (1990) 58(1):31-8.

53. Tyagi P, Patil SA, Girdhar BK, Katoch K, Sengupta U. Suppressive effect of circulating immune complexes from leprosy patients on the lymphocyte proliferation induced by M. leprae antigens in healthy responders. Int J Lepr Other Mycobact Dis (1992) 60(4):562-9.

54. Valentijn RM, Faber WR, Lai AFRF, Chan Pin Jie JC, Daha MR, van Es LA. Immune complexes in leprosy patients from an endemic and a nonendemic area and a longitudinal study of the relationship between complement breakdown products and the clinical activity of erythema nodosum leprosum. Clin Immunol Immunopathol (1982) 22(2):194-202. doi:10.1016/0090-1229(82)90037-X

55. Penttinen K, Myllyla G, Vaheri A, Vesikari T, Kaariainen L. The platelet aggregation test (PA) as an immunological method in virology. Prog Immunobiol Stand (1970) 4:672-5.

56. Yanase K, Imamura S. Detection of circulating immune complexes in some skin diseases by platelet aggregation test. Br J Dermatol (1979) 100(2):227-8. doi:10.1111/j.1365-2133.1979.tb05567.x

57. Rojas RE, Segal-Eiras A. Characterization of circulating immune complexes in leprosy patients and their correlation with specific antibodies against Mycobacterium leprae. Clin Exp Dermatol (1997) 22(5):223-9. doi:10.1046/j.1365-2230.1997.2620675.x

58. Dupnik KM, Bair TB, Maia AO, Amorim FM, Costa MR, Keesen TS, et al. Transcriptional changes that characterize the immune reactions of leprosy. J Infect Dis (2015) 211(10):1658-76. doi:10.1093/infdis/jiu612

59. de Azevedo MP, de Melo PH. A comparative study of the complementary activity of serum in the polar forms of leprosy and in the leprosy reaction. Int J Lepr Other Mycobact Dis (1966) 34(1):34-8.

60. Anthony J, Vaidya MC, Dasgupta A. Immunoglobulin deposits in erythema nodosum leprosum (ENL). Hansen Int (1978) 3(1):12-7.

61. Lange K, Wasserman E, Slobody LB. The significance of serum complement levels for the diagnosis and prognosis of acute and subacute glomerulonephritis and lupus erythematosus disseminatus. Ann Intern Med (1960) 53:636-46. doi:10.7326/0003-4819-53-4-636

62. Lewis EJ, Carpenter CB, Schur PH. Serum complement component levels in human glomerulonephritis. Ann Intern Med (1971) 75(4):555-60. doi:10.7326/0003-4819-75-4-555

63. Ohi H, Tamano M. Decreased apolipoprotein levels are associated with decreased complement levels in acute glomerulonephritis. Nephron (2001) 88(4):389-90. doi:10.1159/000046028

64. Baatrup G, Petersen I, Kappelgaard E, Jepsen HH, Svehag SE. Complementmediated solubilization of immune complexes. Solubilization inhibition and complement factor levels in SLE patients. Clin Exp Immunol (1984) 55(2):313-8.

65. Grevink ME, Horst G, Limburg PC, Kallenberg CG, Bijl M. Levels of complement in sera from inactive SLE patients, although decreased, do not influence in vitro uptake of apoptotic cells. J Autoimmun (2005) 24(4):329-36. doi:10.1016/j.jaut.2005.03.004

66. Schifferli JA, Morris SM, Dash A, Peters DK. Complement-mediated solubilization in patients with systemic lupus erythematosus, nephritis or vasculitis. Clin Exp Immunol (1981) 46(3):557-64.

67. de Messias IJ, Santamaria J, Brenden M, Reis A, Mauff G. Association of $\mathrm{C} 4 \mathrm{~B}$ deficiency $\left(\mathrm{C}^{*} \mathrm{~B}^{*} \mathrm{Q} 0\right)$ with erythema nodosum in leprosy. Clin Exp Immunol (1993) 92(2):284-7. doi:10.1111/j.1365-2249.1993. tb03393.x

68. Hauptmann G, Tappeiner G, Schifferli JA. Inherited deficiency of the fourth component of human complement. Immunodefic Rev (1988) $1(1): 3-22$

69. Gelber RH, Drutz DJ, Epstein WV, Fasal P. Clinical correlates of C1Qprecipitating substances in the sera of patients with leprosy. Am J Trop Med Hyg (1974) 23(3):471-5.

70. Izumi S, Sugiyama K, Matsumoto Y, Nagai T. Numerical changes in T cell subsets (T gamma and T mu) in leprosy patients. Microbiol Immunol (1980) 24(8):733-40. doi:10.1111/j.1348-0421.1980.tb02874.x 
71. Harikrishan S, Balakrishnan S, Bhatia VN. Serum immunoglobulin profile and C3 level in lepromatous leprosy patients. Lepr India (1982) 54(3):454-60.

72. Saha K, Chakraborty AK, Sharma V, Sehgal VN. An appraisal of third complement component (C3) and breakdown product (C3d) in erythema nodosum leprosum (ENL). Lepr Rev (1982) 53(4):253-60.

73. Mshana RN, Humber DP, Belehu A, Harboe M. Immunohistological studies of skin biopsies from patients with lepromatous leprosy. J Clin Immunol (1983) 3(1):22-9. doi:10.1007/BF00919135

74. Ramanathan VD, Parkash O, Ramu G, Parker D, Curtis J, Sengupta U, et al. Isolationandanalysisofcirculatingimmunecomplexesinleprosy.ClinImmunol Immunopathol (1984) 32(3):261-8. doi:10.1016/0090-1229(84)90270-8

75. Saha K, Chakrabarty AK, Sharma VK, Sehgal VN. Polyethylene glycol precipitates in serum during and after erythema nodosum leprosum - study of their composition and anticomplementary activity. Int J Lepr Other Mycobact Dis (1984) 52(1):44-8.

76. Sehgal VN, Gautam RK, Sharma VK. Immunoprofile of reactions in leprosy. Int J Dermatol (1986) 25(4):240-4. doi:10.1111/j.1365-4362.1986.tb02233.x

77. Chakrabarty AK, Kashyap A, Sehgal VN, Saha K. Solubilization of preformed immune complexes in sera of patients with type 1 and type 2 lepra reactions. Int J Lepr Other Mycobact Dis (1988) 56(4):559-65.

78. Rao TD, Rao PR. Serum immune complexes in erythema nodosum leprosum reactions of leprosy. Indian J Lepr (1988) 60(2):189-95.

79. Sehgal VN, Sharma V, Sharma VK. The effect of anti-reactional drugs on complement components in the type II, erythema nodosum leprosum, reaction. Br J Dermatol (1988) 119(2):255-8. doi:10.1111/j.1365-2133.1988. tb03209.x

80. Dias AA, Silva CO, Santos JP, Batista-Silva LR, Acosta CC, Fontes AN, et al. DNA sensing via TLR-9 constitutes a major innate immunity pathway activated during erythema nodosum leprosum. JImmunol (2016) 197(5):1905-13. doi:10.4049/jimmunol.1600042

81. Sehgal VN, Sharma V, Sharma VK. Comprehensive evaluation of complement components in the course of type I (Lepra) and type II (ENL) reactions. Int J Dermatol (1989) 28(1):32-5. doi:10.1111/j.1365-4362.1989. tb01306.x

82. Scollard DM, Bhoopat L, Kestens L, Vanham G, Douglas JT, Moad J. Immune complexes and antibody levels in blisters over human leprosy skin lesions with or without erythema nodosum leprosum. Clin Immunol Immunopathol (1992) 63(3):230-6. doi:10.1016/0090-1229(92)90227-F

83. Kim HJ, Cantor H. CD4 T-cell subsets and tumor immunity: the helpful and the not-so-helpful. Cancer Immunol Res (2014) 2(2):91-8. doi:10.1158/23266066.CIR-13-0216

84. Lim SD, Kiszkiss DF, Jacobson RR, Choi YS, Good RA. Thymus-dependent lymphocytes of peripheral blood in leprosy patients. Infect Immun (1974) 9(2):394-9.

85. Rao TD, Rao PR. Enhanced cell-mediated immune responses in erythema nodosum leprosum reactions of leprosy. Int J Lepr Other Mycobact Dis (1987) 55(1):36-41.

86. Bach MA, Chatenoud L, Wallach D, Phan Dinh Tuy F, Cottenot F. Studies on T cell subsets and functions in leprosy. Clin Exp Immunol (1981) 44(3):491-500.

87. Wallach D, Cottenot F, Bach MA. Imbalances in T cell subpopulations in lepromatous leprosy. Int J Lepr Other Mycobact Dis (1982) 50(3):282-90.

88. Mshana RN, Haregewoin A, Harboe M, Belehu A. Thymus dependent lymphocytes in leprosy. I. T lymphocyte subpopulations defined by monoclonal antibodies. Int J Lepr Other Mycobact Dis (1982) 50(3):291-6.

89. Narayanan RB, Laal S, Sharma AK, Bhutani LK, Nath I. Differences in predominant $\mathrm{T}$ cell phenotypes and distribution pattern in reactional lesions of tuberculoid and lepromatous leprosy. Clin Exp Immunol (1984) 55(3):623-8.

90. Mshana RN, Haregewoin A, Belehu A. Thymus-dependent lymphocytes in leprosy. II. Effect of chemotherapy on T-lymphocyte subpopulations. J Clin Immunol (1982) 2(2):69-74. doi:10.1007/BF00916889

91. Wallach D, Flageul B, Cottenot F, Bach MA. Patients with erythema nodosum leprosum lack T-suppressor cells. Arch Dermatol (1985) 121(11):1379. doi:10.1001/archderm.1985.01660110027002

92. Hussain T, Kulshreshtha KK, Yadav VS, Katoch K. CD4+, CD8+, CD3+ cell counts and CD4+/CD8+ ratio among patients with mycobacterial diseases (leprosy, tuberculosis), HIV infections, and normal healthy adults: a comparative analysis of studies in different regions of India. J Immunoassay Immunochem (2015) 36(4):420-43. doi:10.1080/15321819.2014.978082

93. Sakane T, Steinberg AD, Green I. Studies of immune functions of patients with systemic lupus erythematosus. I. Dysfunction of suppressor T-cell activity related to impaired generation of, rather than response to, suppressor cells. Arthritis Rheum (1978) 21(6):657-64. doi:10.1002/art. 1780210608

94. Laal S, Bhutani LK, Nath I. Natural emergence of antigen-reactive T cells in lepromatous leprosy patients during erythema nodosum leprosum. Infect Immun (1985) 50(3):887-92.

95. Bullock WE. Leprosy: a model of immunological perturbation in chronic infection. J Infect Dis (1978) 137(3):341-54. doi:10.1093/infdis/137.3.341

96. Rea TH, Bakke AC, Parker JW, Modlin RL, Horwitz DA. Peripheral blood T lymphocyte subsets in leprosy. Int J Lepr Other Mycobact Dis (1984) 52(3):311-7.

97. Modlin RL, Gebhard JF, Taylor CR, Rea TH. In situ characterization of T lymphocyte subsets in the reactional states of leprosy. Clin Exp Immunol (1983) 53(1):17-24.

98. Modlin RL, Hofman FM, Taylor CR, Rea TH. T lymphocyte subsets in the skin lesions of patients with leprosy. J Am Acad Dermatol (1983) 8(2):182-9. doi:10.1016/S0190-9622(83)70021-6

99. Modlin RL, Bakke AC, Vaccaro SA, Horwitz DA, Taylor CR, Rea TH. Tissue and blood T-lymphocyte subpopulations in erythema nodosum leprosum. Arch Dermatol (1985) 121(2):216-9. doi:10.1001/archderm. 121.2.216

100. Modlin RL, Mehra V, Jordan R, Bloom BR, Rea TH. In situ and in vitro characterization of the cellular immune response in erythema nodosum leprosum. J Immunol (1986) 136(3):883-6.

101. Shen JY, Hofman FM, Gunter JR, Modlin RL, Rea TH. In situ identification of activated Ta1+ T lymphocytes in human leprosy skin lesions. Int $J$ Lepr Other Mycobact Dis (1987) 55(3):494-8.

102. Rea TH, Modlin RL. Immunopathology of leprosy skin lesions. Semin Dermatol (1991) 10(3):188-93.

103. Mahaisavariya P, Kulthanan K, Khemngern S, Pinkaew S. Lesional T-cell subset in leprosy and leprosy reaction. Int J Dermatol (1999) 38(5):345-7. doi:10.1046/j.1365-4362.1999.00621.x

104. Fehervari Z, Sakaguchi S. CD4+ Tregs and immune control. J Clin Invest (2004) 114(9):1209-17. doi:10.1172/JCI23395

105. Saini C, Prasad HK, Rani R, Murtaza A, Misra N, Narayan NP, et al. Lsr 2 of Mycobacterium leprae and its synthetic peptides elicit restitution of in vitro $\mathrm{T}$ cell responses in erythema nodosum leprosum and reversal reactions in lepromatous leprosy patients. Clin Vaccine Immunol (2013) 20(5):673-82. doi:10.1128/CVI.00762-12

106. Saini C, Ramesh V, Nath I. CD4+ Th17 cells discriminate clinical types and constitute a third subset of non Th1, Non Th2 $\mathrm{T}$ cells in human leprosy. PLoS Negl Trop Dis (2013) 7(7):e2338. doi:10.1371/journal.pntd. 0002338

107. Attia EA, Abdallah M, Saad AA, Afifi A, El Tabbakh A, El-Shennawy $\mathrm{D}$, et al. Circulating CD4+ CD25 high FoxP3+ T cells vary in different clinical forms of leprosy. Int J Dermatol (2010) 49(10):1152-8. doi:10.1111/j.1365-4632.2010.04535.x

108. Boer MC, Joosten SA, Ottenhoff TH. Regulatory T-cells at the interface between human host and pathogens in infectious diseases and vaccination. Front Immunol (2015) 6:217. doi:10.3389/fimmu.2015.00217

109. Abdallah M, Attia EA, Saad AA, El-Khateeb EA, Lotfi RA, Abdallah M, et al. Serum Th1/Th2 and macrophage lineage cytokines in leprosy; correlation with circulating CD4(+) CD25(high) FoxP3(+) T-regs cells. Exp Dermatol (2014) 23(10):742-7. doi:10.1111/exd.12529

110. Attia EA, Abdallah M, El-Khateeb E, Saad AA, Lotfi RA, Abdallah M, et al. Serum Th17 cytokines in leprosy: correlation with circulating CD4(+) CD25 (high)FoxP3 (+) T-regs cells, as well as down regulatory cytokines. Arch Dermatol Res (2014) 306(9):793-801. doi:10.1007/s00403014-1486-2

111. Santegoets SJ, Dijkgraaf EM, Battaglia A, Beckhove P, Britten CM, Gallimore $\mathrm{A}$, et al. Monitoring regulatory $\mathrm{T}$ cells in clinical samples: consensus on an essential marker set and gating strategy for regulatory $\mathrm{T}$ cell analysis by flow cytometry. Cancer Immunol Immunother (2015) 64(10):1271-86. doi:10.1007/s00262-015-1729-x 
112. Brusko T, Wasserfall C, McGrail K, Schatz R, Viener HL, Schatz D, et al. No alterations in the frequency of FOXP3+ regulatory T-cells in type 1 diabetes. Diabetes (2007) 56(3):604-12. doi:10.2337/db06-1248

113. Saini C, Siddiqui A, Ramesh V, Nath I. Leprosy reactions show increased Th17 cell activity and reduced FOXP3 + Tregs with concomitant decrease in TGF-beta and increase in IL-6. PLoS Negl Trop Dis (2016) 10(4):e0004592. doi:10.1371/journal.pntd.0004592

114. Ye ZJ, Zhou Q, Du RH, Li X, Huang B, Shi HZ. Imbalance of Th17 cells and regulatory $\mathrm{T}$ cells in tuberculous pleural effusion. Clin Vaccine Immunol (2011) 18(10):1608-15. doi:10.1128/CVI.05214-11

115. Haslett PA, Roche P, Butlin CR, Macdonald M, Shrestha N, Manandhar R, et al. Effective treatment of erythema nodosum leprosum with thalidomide is associated with immune stimulation. J Infect Dis (2005) 192(12):2045-53. doi:10.1086/498216

116. Massone C, Nunzi E, Ribeiro-Rodrigues R, Talhari C, Talhari S, Schettini AP, et al. T regulatory cells and plasmocytoid dentritic cells in hansen disease: a new insight into pathogenesis? Am J Dermatopathol (2010) 32(3):251-6. doi:10.1097/DAD.0b013e3181b7fc56

117. Miyao T, Floess S, Setoguchi R, Luche H, Fehling HJ, Waldmann H, et al. Plasticity of Foxp3(+) T cells reflects promiscuous Foxp3 expression in conventional $\mathrm{T}$ cells but not reprogramming of regulatory $\mathrm{T}$ cells. Immunity (2012) 36(2):262-75. doi:10.1016/j.immuni.2011.12.012

118. Rea TH, Levan NE. Variations in dinitrochlorobenzene responsivity in untreated leprosy: evidence of a beneficial role for anergy. Int J Lepr Other Mycobact Dis (1980) 48(2):120-5.

119. Anders EM, McAdam KP, Anders RF. Cell-mediated immunity in amyloidosis secondary to lepromatous leprosy. Clin Exp Immunol (1977) 27(1):111-7.

120. Dubey GK, Joglekar VK, Hardas UD, Chaubey BS. A study of cell mediated immunity in leprosy. Lepr India (1981) 53(2):197-203.

121. Bach MA, Hoffenbach A, Lagrange PH, Wallach D, Cottenot F. Mechanisms of T-cell unresponsiveness in leprosy. Ann Immunol (1983) 134D(1):75-84.

122. Sasiain MC, Ruibal Ares B, Balina LM, Valdez R, Bachmann AE. ConAinduced suppressor cells in lepromatous leprosy patients during and after erythema nodosum leprosum. Int J Lepr Other Mycobact Dis (1983) 51(3):321-7.

123. Rao TD, Rao PR. Tr, T mu and B lymphocytes in erythema nodosum leprosum reactions of leprosy. Indian J Lepr (1986) 58(4):601-8.

124. Bottasso O, Puig N, Amerio N, Morini JC. [Study of T lymphocyte subpopulations in patients with leprosy, using incubation with theophylline]. Med Cutan Ibero Lat Am (1988) 16(5):397-401.

125. Rasheed FN, Locniskar M, McCloskey DJ, Hasan RS, Chiang TJ, Rose P, et al. Serum lymphocytotoxic activity in leprosy. Clin Exp Immunol (1989) 76(3):391-7.

126. Sasiain MD, de la Barrera S, Valdez R, Balina LM. Reduced suppressor cell response to Mycobacterium leprae in lepromatous leprosy. Infect Immun (1989) 57(3):951-6.

127. Bhoopat L, Scollard DM, Theetranont C, Chiewchanvit S, Nelson DL, Utaipat U. Studies of human leprosy lesions in situ using suction-induced blisters: cell changes with IgM antibody to PGL-1 and interleukin-2 receptor in clinical subgroups of erythema nodosum leprosum. Asian Pac J Allergy Immunol (1991) 9(2):107-19.

128. Foss NT, de Oliveira EB, Silva CL. Correlation between TNF production, increase of plasma C-reactive protein level and suppression of T lymphocyte response to concanavalin A during erythema nodosum leprosum. Int J Lepr Other Mycobact Dis (1993) 61(2):218-26.

129. Santos DO, Suffys PN, Moreira AL, Bonifacio K, Salgado JL, Esquenazi D, et al. Evaluation of chemiluminescence, procoagulant activity and antigen presentation by monocytes from lepromatous leprosy patients with or without reactional episodes. Lepr Rev (1994) 65(2):88-99.

130. de la Barrera S, Fink S, Finiasz M, Minnucci F, Valdez R, Balina LM, et al. Lack of cytotoxic activity against Mycobacterium leprae 65-kD heat shock protein (hsp) in multibacillary leprosy patients. Clin Exp Immunol (1995) 99(1):90-7. doi:10.1111/j.1365-2249.1995.tb03477.x

131. Vieira LM, Sampaio EP, Nery JA, Duppre NC, Albuquerque EC, Scheinberg $\mathrm{MA}$, et al. Immunological status of ENL (erythema nodosum leprosum) patients: its relationship to bacterial load and levels of circulating IL-2R. Rev Inst Med Trop Sao Paulo (1996) 38(2):103-11. doi:10.1590/ S0036-46651996000200004
132. Tadesse A, Taye E, Sandoval F, Shannon EJ. Thalidomide does not modify the ability of cells in leprosy patients to incorporate $[3 \mathrm{H}]$-thymidine when incubated with M. leprae antigens. Lepr Rev (2003) 74(3):206-14.

133. Mohanty KK, Joshi B, Katoch K, Sengupta U. Leprosy reactions: humoral and cellular immune responses to $M$. leprae, $65 \mathrm{kDa}, 28 \mathrm{kDa}$, and $18 \mathrm{kDa}$ antigens. Int J Lepr Other Mycobact Dis (2004) 72(2):149-58. doi:10.1489/ 1544-581X(2004)072<0149:LRHACI >2.0.CO;2

134. Villahermosa LG, Fajardo TT Jr, Abalos RM, Balagon MV, Tan EV, Cellona $\mathrm{RV}$, et al. A randomized, double-blind, double-dummy, controlled dose comparison of thalidomide for treatment of erythema nodosum leprosum. Am J Trop Med Hyg (2005) 72(5):518-26.

135. Rada E, Aranzazu N, Rodriguez V, Borges R, Convit J. [Serological and cellular reactivity to mycobacterial proteins in Hansen's disease]. Invest Clin (2010) 51(3):325-40.

136. Saini C, Prasad HK, Rani R, Murtaza A, Misra N, Shanker Narayan NP, et al. Lsr2 of Mycobacterium leprae and its synthetic peptides elicit restitution of $\mathrm{T}$ cell responses in erythema nodosum leprosum and reversal reactions in patients with lepromatous leprosy. Clin Vaccine Immunol (2013) 20(5):67382. doi:10.1128/CVI.00762-12

137. Parente JN, Talhari C, Schettini AP, Massone C. T regulatory cells (TREG) (TCD4+CD25+FOXP3+) distribution in the different clinical forms of leprosy and reactional states. An Bras Dermatol (2015) 90(1):41-7. doi:10.1590/ abd1806-4841.20153311

138. Sarno EN, Grau GE, Vieira LM, Nery JA. Serum levels of tumour necrosis factor-alpha and interleukin-1 beta during leprosy reactional states. Clin Exp Immunol (1991) 84(1):103-8.

139. Sampaio EP, Kaplan G, Miranda A, Nery JA, Miguel CP, Viana SM, et al. The influence of thalidomide on the clinical and immunologic manifestation of erythema nodosum leprosum. J Infect Dis (1993) 168(2):408-14. doi:10.1093/ infdis/168.2.408

140. Parida SK, Grau GE, Zaheer SA, Mukherjee R. Serum tumor necrosis factor and interleukin 1 in leprosy and during lepra reactions. Clin Immunol Immunopathol (1992) 63(1):23-7. doi:10.1016/0090-1229(92)90088-6

141. Memon RA, Kifayet A, Shahid F, Lateef A, Chiang J, Hussain R. Low serum HDL-cholesterol is associated with raised tumor necrosis factor-alpha during ENL reactions. Int J Lepr Other Mycobact Dis (1997) 65(1):1-11.

142. Partida-Sanchez S, Favila-Castillo L, Pedraza-Sanchez S, Gomez-Melgar M, Saul A, Estrada-Parra S, et al. IgG antibody subclasses, tumor necrosis factor and IFN-gamma levels in patients with type II lepra reaction on thalidomide treatment. Int Arch Allergy Immunol (1998) 116(1):60-6. doi: $10.1159 / 000023926$

143. Iyer A, Hatta M, Usman R, Luiten S, Oskam L, Faber W, et al. Serum levels of interferon-gamma, tumour necrosis factor-alpha, soluble interleukin-6R and soluble cell activation markers for monitoring response to treatment of leprosy reactions. Clin Exp Immunol (2007) 150(2):210-6. doi:10.1111/j.1365-2249.2007.03485.x

144. Madan NK, Agarwal K, Chander R. Serum cytokine profile in leprosy and its correlation with clinico-histopathological profile. Lepr Rev (2011) 82(4):371-82.

145. Rodrigues LS, Hacker MA, Illarramendi X, Pinheiro MF, Nery JA, Sarno EN, et al. Circulating levels of insulin-like growth factor-I (IGF-I) correlate with disease status in leprosy. BMC Infect Dis (2011) 11:339. doi:10.1186/1471-2334-11-339

146. Bhattacharya SN, Chattopadhaya D, Saha K. Tumor necrosis factor: status in reactions in leprosy before and after treatment. Int J Dermatol (1993) 32(6):436-9. doi:10.1111/j.1365-4362.1993.tb02816.x

147. Sampaio EP, Moraes MO, Nery JA, Santos AR, Matos HC, Sarno EN. Pentoxifylline decreases in vivo and in vitro tumour necrosis factor-alpha (TNF-alpha) production in lepromatous leprosy patients with erythema nodosum leprosum (ENL). Clin Exp Immunol (1998) 111(2):300-8. doi:10.1046/j.1365-2249.1998.00510.x

148. Moubasher AD, Kamel NA, Zedan H, Raheem DD. Cytokines in leprosy, I. Serum cytokine profile in leprosy. Int J Dermatol (1998) 37(10):733-40. doi:10.1046/j.1365-4362.1998.00381.x

149. Jadhav R, Suneetha L, Kamble R, Shinde V, Devi K, Chaduvula MV, et al. Analysis of antibody and cytokine markers for leprosy nerve damage and reactions in the INFIR cohort in India. PLoS Negl Trop Dis (2011) 5(3):e977. doi:10.1371/journal.pntd.0000977 
150. Sampaio EP, Moreira AL, Sarno EN, Malta AM, Kaplan G. Prolonged treatment with recombinant interferon gamma induces erythema nodosum leprosum in lepromatous leprosy patients. J Exp Med (1992) 175(6):1729-37. doi:10.1084/jem.175.6.1729

151. Stefani MM, Guerra JG, Sousa AL, Costa MB, Oliveira ML, Martelli CT, et al. Potential plasma markers of Type 1 and Type 2 leprosy reactions: a preliminary report. BMC Infect Dis (2009) 9:75. doi:10.1186/14712334-9-75

152. Wolkenstein P, Latarjet J, Roujeau JC, Duguet C, Boudeau S, Vaillant L, et al. Randomised comparison of thalidomide versus placebo in toxic epidermal necrolysis. Lancet (1998) 352(9140):1586-9. doi:10.1016/ S0140-6736(98)02197-7

153. Jacobson JM, Greenspan JS, Spritzler J, Ketter N, Fahey JL, Jackson JB, et al. Thalidomide for the treatment of oral aphthous ulcers in patients with human immunodeficiency virus infection. National Institute of Allergy and Infectious Diseases AIDS Clinical Trials Group. N Engl J Med (1997) 336(21):1487-93. doi:10.1056/NEJM199705223362103

154. Haslett PA, Hanekom WA, Muller G, Kaplan G. Thalidomide and a thalidomide analogue drug costimulate virus-specific CD8+ T cells in vitro. J Infect Dis (2003) 187(6):946-55. doi:10.1086/368126

155. Barnes PF, Chatterjee D, Brennan PJ, Rea TH, Modlin RL. Tumor necrosis factor production in patients with leprosy. Infect Immun (1992) 60(4): $1441-6$.

156. Santos DO, Suffys PN, Bonifacio K, Marques MA, Sarno EN. In vitro tumor necrosis factor production by mononuclear cells from lepromatous leprosy patients and from patients with erythema nodosum leprosum. Clin Immunol Immunopathol (1993) 67(3 Pt 1):199-203. doi:10.1006/clin. 1993.1065

157. Sampaio EP, Oliveira RB, Warwick-Davies J, Neto RB, Griffin GE, Shattock RJ. T cell-monocyte contact enhances tumor necrosis factor-alpha production in response to Mycobacterium leprae. J Infect Dis (2000) 182(5):1463-72. doi: $10.1086 / 315902$

158. Faber WR, Jensema AJ, Goldschmidt WF. Treatment of recurrent erythema nodosum leprosum with infliximab. N Engl J Med (2006) 355(7):739. doi:10.1056/NEJMc052955

159. Ramien ML, Wong A, Keystone JS. Severe refractory erythema nodosum leprosum successfully treated with the tumor necrosis factor inhibitor etanercept. Clin Infect Dis (2011) 52(5):e133-5. doi:10.1093/cid/ciq213

160. Chowdhry S, Shukla A, D'Souza P, Dhali T, Jaiswal P. Treatment of severe refractory erythema nodosum leprosum with tumor necrosis factor inhibitor etanercept. Int J Mycobacteriol (2016) 5(2):223-5. doi:10.1016/ j.ijmyco.2016.02.002

161. Moraes MO, Sarno EN, Almeida AS, Saraiva BC, Nery JA, Martins RC, et al. Cytokine mRNA expression in leprosy: a possible role for interferon-gamma and interleukin-12 in reactions (RR and ENL). Scand J Immunol (1999) 50(5):541-9. doi:10.1046/j.1365-3083.1999.00622.x

162. Nath I, Vemuri N, Reddi AL, Bharadwaj M, Brooks P, Colston MJ, et al. Dysregulation of IL-4 expression in lepromatous leprosy patients with and without erythema nodosum leprosum. Lepr Rev (2000) 71(Suppl): S130-7.

163. Nath I, Vemuri N, Reddi AL, Jain S, Brooks P, Colston MJ, et al. The effect of antigen presenting cells on the cytokine profiles of stable and reactional lepromatous leprosy patients. Immunol Lett (2000) 75(1):69-76. doi:10.1016/ S0165-2478(00)00271-6

164. Moraes MO, Sarno EN, Teles RM, Almeida AS, Saraiva BC, Nery JA, et al. Anti-inflammatory drugs block cytokine mRNA accumulation in the skin and improve the clinical condition of reactional leprosy patients. J Invest Dermatol (2000) 115(6):935-41. doi:10.1046/j.1523-1747.2000.00158.x

165. Moubasher AD, Kamel NA, Zedan H, Raheem DD. Cytokines in leprosy, II. Effect of treatment on serum cytokines in leprosy. Int J Dermatol (1998) 37(10):741-6. doi:10.1046/j.1365-4362.1998.00381.x

166. Sallam MA, Attia EA, Soliman MS. Assessment of serum level of interleukin-1b and interleukin-12 in leprosy: impact of previous bacillus calmitte guerin vaccination. Arch Dermatol Res (2014) 306(2):189-95. doi:10.1007/ s00403-013-1411-0

167. Berrington WR, Kunwar CB, Neupane K, van den Eeden SJ, Vary JC Jr, Peterson GJ, et al. Differential dermal expression of CCL17 and CCL18 in tuberculoid and lepromatous leprosy. PLoS Negl Trop Dis (2014) 8(11):e3263. doi:10.1371/journal.pntd.0003263
168. Filley E, Andreoli A, Steele J, Waters M, Wagner D, Nelson D, et al. A transient rise in agalactosyl IgG correlating with free interleukin 2 receptors, during episodes of erythema nodosum leprosum. Clin Exp Immunol (1989) 76(3):343-7.

169. Belgaumkar VA, Gokhale NR, Mahajan PM, Bharadwaj R, Pandit DP, Deshpande S. Circulating cytokine profiles in leprosy patients. Lepr Rev (2007) 78(3):223-30.

170. Sousa AL, Fava VM, Sampaio LH, Martelli CM, Costa MB, Mira MT, et al. Genetic and immunological evidence implicates interleukin 6 as a susceptibility gene for leprosy type 2 reaction. J Infect Dis (2012) 205(9):1417-24. doi:10.1093/infdis/jis208

171. Abdallah M, Emam H, Attia E, Hussein J, Mohamed N. Estimation of serum level of interleukin-17 and interleukin-4 in leprosy, towards more understanding of leprosy immunopathogenesis. Indian J Dermatol Venereol Leprol (2013) 79(6):772-6. doi:10.4103/0378-6323.120723

172. Sehgal VN, Bhattacharya SN, Shah Y, Sharma VK, Gupta CK. Soluble interleukin-2 receptors: levels in leprosy, and during and after type 1 (lepra) and type 2 (ENL) reactions. Lepr Rev (1991) 62(3):262-8.

173. Sullivan L, Sano S, Pirmez C, Salgame P, Mueller C, Hofman F, et al. Expression of adhesion molecules in leprosy lesions. Infect Immun (1991) 59(11):4154-60.

174. Goulart IM, Mineo JR, Foss NT. Production of transforming growth factor-beta 1 (TGF-betal) by blood monocytes from patients with different clinical forms of leprosy. Clin Exp Immunol (2000) 122(3):330-4. doi:10.1046/j.1365-2249.2000.01376.x

175. Motta AC, Furini RB, Simao JC, Ferreira MA, Komesu MC, Foss NT. The recurrence of leprosy reactional episodes could be associated with oral chronic infections and expression of serum IL-1, TNF-alpha, IL-6, IFN-gamma and IL-10. Braz Dent J (2010) 21(2):158-64. doi:10.1590/ S0103-64402010000200012

176. Teles RM, Teles RB, Amadeu TP, Moura DF, Mendonca-Lima L, Ferreira H, et al. High matrix metalloproteinase production correlates with immune activation and leukocyte migration in leprosy reactional lesions. Infect Immun (2010) 78(3):1012-21. doi:10.1128/IAI.00896-09

177. Chaitanya S, Lavania M, Turankar RP, Karri SR, Sengupta U. Increased serum circulatory levels of interleukin $17 \mathrm{~F}$ in type 1 reactions of leprosy. JClin Immunol (2012) 32(6):1415-20. doi:10.1007/s10875-012-9747-3

178. Lockwood DN, Nicholls P, Smith WC, Das L, Barkataki P, van Brakel W, et al. Comparing the clinical and histological diagnosis of leprosy and leprosy reactions in the INFIR cohort of Indian patients with multibacillary leprosy. PLoS Negl Trop Dis (2012) 6(6):e1702. doi:10.1371/journal.pntd. 0001702

179. Martiniuk F, Giovinazzo J, Tan AU, Shahidullah R, Haslett P, Kaplan G, et al. Lessons of leprosy: the emergence of TH17 cytokines during type II reactions (ENL) is teaching us about T-cell plasticity. J Drugs Dermatol (2012) 11(5):626-30.

180. Reichlin M, Pranis RA, Gelber RH, Rees RJ, Taverne J, Turk JL. Correlation of euglobulin immunoglobulin $\mathrm{G}$ levels with erythema nodosum leprosum in lepromatous leprosy. Clin Immunol Immunopathol (1977) 8(2):335-44. doi:10.1016/0090-1229(77)90123-4

181. Humphres RC, Gelber RH, Krahenbuhl JL. Suppressed natural killer cell activity during episodes of erythema nodosum leprosum in lepromatous leprosy. Clin Exp Immunol (1982) 49(3):500-8.

182. Rea TH, Yoshida T. Serum macrophage migration inhibition activity in patients with leprosy. J Invest Dermatol (1982) 79(5):336-9. doi:10.1111/15231747.ep12500088

183. Miller RA, Harnisch JP, Buchanan TM. Antibodies to mycobacterial arabinomannan in leprosy: correlation with reactional states and variation during treatment. Int J Lepr Other Mycobact Dis (1984) 52(2):133-9.

184. Schwerer B, Meeker HC, Sersen G, Levis WR. IgM antibodies against phenolic glycolipid I from Mycobacterium leprae in leprosy sera: relationship to bacterial index and erythema nodosum leprosum. Acta Leprol (1984) 2(2-4):394-402.

185. Blavy G, Thiam D, Ndoye B, Diakhate L, Millan J. [HLA and leprosy in Dakar: distribution of histocompatibility antigens in leprous patients and their relationship to ENL reactions]. Acta Leprol (1986) 4(1):93-9.

186. Levis WR, Meeker HC, Schuller-Levis G, Sersen E, Schwerer B. IgM and IgG antibodies to phenolic glycolipid I from Mycobacterium leprae in leprosy: insight into patient monitoring, erythema nodosum leprosum, and bacillary 
persistence. J Invest Dermatol (1986) 86(5):529-34. doi:10.1111/1523-1747. ep12354963

187. Levis WR, Meeker HC, Schuller-Levis G, Sersen E, Brennan PJ, Fried P. Mycobacterial carbohydrate antigens for serological testing of patients with leprosy. J Infect Dis (1987) 156(5):763-9. doi:10.1093/infdis/156.5.763

188. Sehgal VN, Bhattacharya SN, Shah Y, Rao YN, Gupta CK. Lymphocyte adenosine deaminase activity (L-ADA) in leprosy, during and after treatment of reactions. Clin Exp Dermatol (1992) 17(1):20-3. doi:10.1111/ j.1365-2230.1992.tb02526.x

189. Singh S, Jenner PJ, Narayan NP, Ramu G, Colston MJ, Prasad HK, et al. Critical residues of the Mycobacterium leprae LSR recombinant protein discriminate clinical activity in erythema nodosum leprosum reactions. Infect Immun (1994) 62(12):5702-5.

190. Kifayet A, Hussain R. Selective decrease of M. leprae-specific IgG1 and IgG3 antibodies in leprosy patients associated with ENL. Int J Lepr Other Mycobact Dis (1996) 64(2):105-14.

191. Kifayet A, Shahid F, Lucas S, Hussain R. Erythema nodosum leprosum is associated with up-regulation of polyclonal IgG1 antibody synthesis. Clin Exp Immunol (1996) 106(3):447-53. doi:10.1046/j.1365-2249.1996.d01-860.x

192. Beuria MK, Parkash O, Joshi B, Mohanty KK, Katoch K, Sengupta U. Levels of IgG subclasses in active and inactive cases in the disease spectrum of leprosy. Int Arch Allergy Immunol (1998) 115(1):61-6. doi:10.1159/ 000023831

193. Freire BF, Ferraz AA, Nakayama E, Ura S, Queluz TT. Anti-neutrophil cytoplasmic antibodies (ANCA) in the clinical forms of leprosy. Int J Lepr Other Mycobact Dis (1998) 66(4):475-82.

194. Stefani MM, Martelli CM, Morais-Neto OL, Martelli P, Costa MB, de Andrade AL. Assessment of anti-PGL-I as a prognostic marker of leprosy reaction. Int J Lepr Other Mycobact Dis (1998) 66(3):356-64.

195. Beuria MK, Mohanty KK, Katoch K, Sengupta U. Determination of circulating IgG subclasses against lipoarabinomannan in the leprosy spectrum and reactions. Int J Lepr Other Mycobact Dis (1999) 67(4):422-8.

196. Hamerlinck FF, Klatser PR, Walsh DS, Bos JD, Walsh GP, Faber WR. Serum neopterin as a marker for reactional states in leprosy. FEMS Immunol Med Microbiol (1999) 24(4):405-9. doi:10.1111/j.1574-695X.1999. tb01312.x

197. Mahaisavariya P, Jiamton S, Manonukul J, Khemngern S. Mast cells in leprosy and leprosy reaction. Int JDermatol (2000) 39(4):274-7. doi:10.1046/j.1365-4362.2000.00908.x

198. Schon T, Leekassa R, Gebre N, Sundqvist T, Bizuneh E, Britton S. High dose prednisolone treatment of leprosy patients undergoing reactions is associated with a rapid decrease in urinary nitric oxide metabolites and clinical improvement. Lepr Rev (2000) 71(3):355-62.

199. Antunes SL, Liang Y, Neri JA, Sarno EN, Haak-Frendscho M, Johansson O. Mast cell subsets and neuropeptides in leprosy reactions. Arq Neuropsiquiatr (2003) 61(2A):208-19. doi:10.1590/S0004-282X2003000200010

200. Rada E, Marzal M, Aranzazu N, Convit J. [Increase in nitric oxide concentrations in serum and mononuclear cell cultures from patients with Type II reaction state of Hansen's disease]. Invest Clin (2003) 44(2):129-36.

201. Sunderkotter CH, Tomimori-Yamashita J, Nix V, Maeda SM, Sindrilaru A, Mariano $M$, et al. High expression of myeloid-related proteins 8 and 14 characterizes an inflammatorily active but ineffective response of macrophages during leprosy. Immunology (2004) 111(4):472-80. doi:10.1111/j.0019-2805.2004.01836.x

202. Nigam PK, Srivastava P, Patra PK. Serum adenosine deaminase levels in reactional and non-reactional leprosy. Indian J Dermatol Venereol Leprol (2005) 71(1):20-2. doi:10.4103/0378-6323.13780

203. Mohanty KK, Gupta M, Girdhar BK, Girdhar A, Chakma JK, Sengupta U. Increased level of urinary nitric oxide metabolites in leprosy patients during type 2 reactions and decreased after antireactional therapy. Lepr Rev (2007) 78(4):386-90.

204. Santos DO, Castro HC, Bourguignon SC, Bastos OM, Rodrigues CR, Van Heuverswyn $\mathrm{H}$, et al. Expression of B7-1 costimulatory molecules in patients with multibacillary leprosy and reactional states. Clin Exp Dermatol (2007) 32(1):75-80. doi:10.1111/j.1365-2230.2006.02291.x

205. Silva EA, Iyer A, Ura S, Lauris JR, Naafs B, Das PK, et al. Utility of measuring serum levels of anti-PGL-I antibody, neopterin and C-reactive protein in monitoring leprosy patients during multi-drug treatment and reactions.
Trop Med Int Health (2007) 12(12):1450-8. doi:10.1111/j.1365-3156.2007. 01951.x

206. Brito Mde F, Ximenes RA, Gallo ME, Buhrer-Sekula S. Association between leprosy reactions after treatment and bacterial load evaluated using anti PGL-I serology and bacilloscopy. Rev Soc Bras Med Trop (2008) 41 (Suppl 2):67-72.

207. Iyer A, van Eijk M, Silva E, Hatta M, Faber W, Aerts JM, et al. Increased chitotriosidase activity in serum of leprosy patients: association with bacillary leprosy. Clin Immunol (2009) 131(3):501-9. doi:10.1016/j.clim.2009. 02.003

208. Singh I, Yadav AR, Mohanty KK, Katoch K, Bisht D, Sharma P, et al. Molecular mimicry between HSP 65 of Mycobacterium leprae and cytokeratin 10 of the host keratin; role in pathogenesis of leprosy. Cell Immunol (2012) 278(1-2):63-75. doi:10.1016/j.cellimm.2012.06.011

209. Mandal D, Reja AH, Biswas N, Bhattacharyya P, Patra PK, Bhattacharya B. Vitamin D receptor expression levels determine the severity and complexity of disease progression among leprosy reaction patients. New Microbes New Infect (2015) 6:35-9. doi:10.1016/j.nmni.2015.04.001

210. Berrington WR, Macdonald M, Khadge S, Sapkota BR, Janer M, Hagge DA, et al. Common polymorphisms in the NOD2 gene region are associated with leprosy and its reactive states. J Infect Dis (2010) 201(9):1422-35. doi:10.1086/651559

211. Teixeira MA, Silva NL, Ramos Ade L, Hatagima A, Magalhaes V. [NRAMP1 gene polymorphisms in individuals with leprosy reactions attended at two reference centers in Recife, northeastern Brazil]. Rev Soc Bras Med Trop (2010) 43(3):281-6. doi:10.1590/S0037-86822010000300014

212. de Sales Marques C, Brito-de-Souza VN, Albuquerque Guerreiro LT, Martins JH, Amaral EP, Cardoso CC, et al. Toll-like receptor 1 (TLR1) N248S single nucleotide polymorphism is associated with leprosy risk and regulates immune activation during mycobacterial infection. J Infect Dis (2013) 208(1):120-9. doi:10.1093/infdis/jit133

213. Schuring RP, Hamann L, Faber WR, Pahan D, Richardus JH, Schumann RR, et al. Polymorphism N248S in the human toll-like receptor 1 gene is related to leprosy and leprosy reactions. J Infect Dis (2009) 199(12):1816-9. doi:10.1086/599121

214. Scotland RS, Stables MJ, Madalli S, Watson P, Gilroy DW. Sex differences in resident immune cell phenotype underlie more efficient acute inflammatory responses in female mice. Blood (2011) 118(22):5918-27. doi:10.1182/ blood-2011-03-340281

215. Tan Trao V, Huong PL, Thuan AT, Long HT, Trach DD, Wright EP. Responses to Mycobacterium leprae by lymphocytes from new and old leprosy patients: role of exogenous lymphokines. Ann Inst Pasteur Immunol (1988) 139(2):121-33. doi:10.1016/0769-2625(88)90034-7

216. Beyrau M, Bodkin JV, Nourshargh S. Neutrophil heterogeneity in health and disease: a revitalized avenue in inflammation and immunity. Open Biol (2012) 2(11):120134. doi:10.1098/rsob.120134

217. Fatima N, Faisal SM, Zubair S, Ajmal M, Siddiqui SS, Moin S, et al. Role of pro-inflammatory cytokines and biochemical markers in the pathogenesis of type 1 diabetes: correlation with age and glycemic condition in diabetic human subjects. PLoS One (2016) 11(8):e0161548. doi:10.1371/journal. pone. 0161548

218. Anderson R, Gatner EM, van Rensburg CE, Grabow G, Imkamp FM, Kok SK, et al. In vitro and in vivo effects of dapsone on neutrophil and lymphocyte functions in normal individuals and patients with lepromatous leprosy. Antimicrob Agents Chemother (1981) 19(4):495-503. doi:10.1128/ AAC.19.4.495

219. Anderson R, Gatner EM. Changes in neutrophil motility accompanying dapsone and rifampicin therapy. Lepr Rev (1981) 52(1):19-22.

220. Anderson R. Enhancement by clofazimine and inhibition by dapsone of production of prostaglandin E2 by human polymorphonuclear leukocytes in vitro. Antimicrob Agents Chemother (1985) 27(2):257-62. doi:10.1128/ AAC.27.2.257

221. Das PK, Klatser PR, Pondman KW, Huikeshoven H, Landheer JE, Leiker DL, et al. Dapsone and anti-dapsone antibody in circulating immune complexes in leprosy patients. Lancet (1980) 1(8181):1309-11. doi:10.1016/ S0140-6736(80)91772-9

222. Trao VT, Huong PL, Thuan AT, Anh DD, Trach DD, Rook GA, et al. Changes in cellular response to mycobacterial antigens and cytokine production 
patterns in leprosy patients during multiple drug therapy. Immunology (1998) 94(2):197-206. doi:10.1046/j.1365-2567.1998.00485.x

223. Mendonca VA, Costa RD, Lyon S, Penido RA, Borges VO, Bretas TL, et al. Plasma levels of chemokines during leprosy specific treatment. Acta Trop (2010) 113(2):151-4. doi:10.1016/j.actatropica.2009.10.010

224. Nishimura M, Koeda A, Suzuki E, Shimizu T, Kawano Y, Nakayama $\mathrm{M}$, et al. Effects of prototypical drug-metabolizing enzyme inducers on mRNA expression of housekeeping genes in primary cultures of human and rat hepatocytes. Biochem Biophys Res Commun (2006) 346(3):1033-9. doi:10.1016/j.bbrc.2006.06.012

225. Libert C, Dejager L. How steroids steer T cells. Cell Rep (2014) 7(4):938-9. doi:10.1016/j.celrep.2014.04.041

226. Langereis JD, Oudijk EJ, Schweizer RC, Lammers JW, Koenderman L, Ulfman LH. Steroids induce a disequilibrium of secreted interleukin-1 receptor antagonist and interleukin-1beta synthesis by human neutrophils. Eur Respir J (2011) 37(2):406-15. doi:10.1183/09031936. 00170409

227. Auttachoat W, Zheng JF, Chi RP, Meng A, Guo TL. Differential surface expression of CD18 and CD44 by neutrophils in bone marrow and spleen contributed to the neutrophilia in thalidomide-treated female $\mathrm{B} 6 \mathrm{C} 3 \mathrm{~F} 1$ mice. Toxicol Appl Pharmacol (2007) 218(3):227-37. doi:10.1016/j.taap. 2006.11.019

228. Kim BS, Kim JY, Lee JG, Cho Y, Huh KH, Kim MS, et al. Immune modulatory effect of thalidomide on T cells. Transplant Proc (2015) 47(3):787-90. doi:10.1016/j.transproceed.2014.12.038

229. Hernandez Mde O, Fulco Tde O, Pinheiro RO, Pereira Rde M, Redner P, Sarno EN, et al. Thalidomide modulates Mycobacterium leprae-induced NF-kappaB pathway and lower cytokine response. Eur J Pharmacol (2011) 670(1):272-9. doi:10.1016/j.ejphar.2011.08.046

Conflict of Interest Statement: The authors declare that the research was conducted in the absence of any commercial or financial relationships that could be construed as a potential conflict of interest.

Copyright (C) 2017 Polycarpou, Walker and Lockwood. This is an open-access article distributed under the terms of the Creative Commons Attribution License (CC BY). The use, distribution or reproduction in other forums is permitted, provided the original author(s) or licensor are credited and that the original publication in this journal is cited, in accordance with accepted academic practice. No use, distribution or reproduction is permitted which does not comply with these terms. 